\title{
PROPRIEDADES FÍSICAS E MECÂNICAS DE PAINÉIS MDF DE DIFERENTES DENSIDADES E TEORES DE RESINA
}

\author{
JACKSON ROBERTO ELEOTÉRIO
}

Dissertação apresentada à Escola Superior de Agricultura "Luiz de Queiroz", Universidade de São Paulo, para obtenção do título de Mestre em Ciências, Área de Concentração: Ciência e Tecnologia de Madeiras.

\author{
PIRACICABA \\ Estado de São Paulo - Brasil
}

Fevereiro de 2000 


\title{
PROPRIEDADES FÍSICAS E MECÂNICAS DE PAINÉIS MDF DE DIFERENTES DENSIDADES E TEORES DE RESINA
}

\author{
JACKSON ROBERTO ELEOTÉRIO \\ Engenheiro Florestal
}

Orientador: Prof. Dr. Mario Tomazello Filho

Dissertação apresentada à Escola Superior de Agricultura "Luiz de Queiroz", Universidade de São Paulo, para obtenção do título de Mestre em Ciências, Área de Concentração: Ciência e Tecnologia de Madeiras.

\author{
PIRACICABA \\ Estado de São Paulo - Brasil
}

Fevereiro de 2000 
Dados Internacionais de Catalogação na Publicação (CIP) DIVISÃo DE BIBLIOTECA E DOCUMENTAÇÃO - Campus “Luiz de Queiroz"/USP

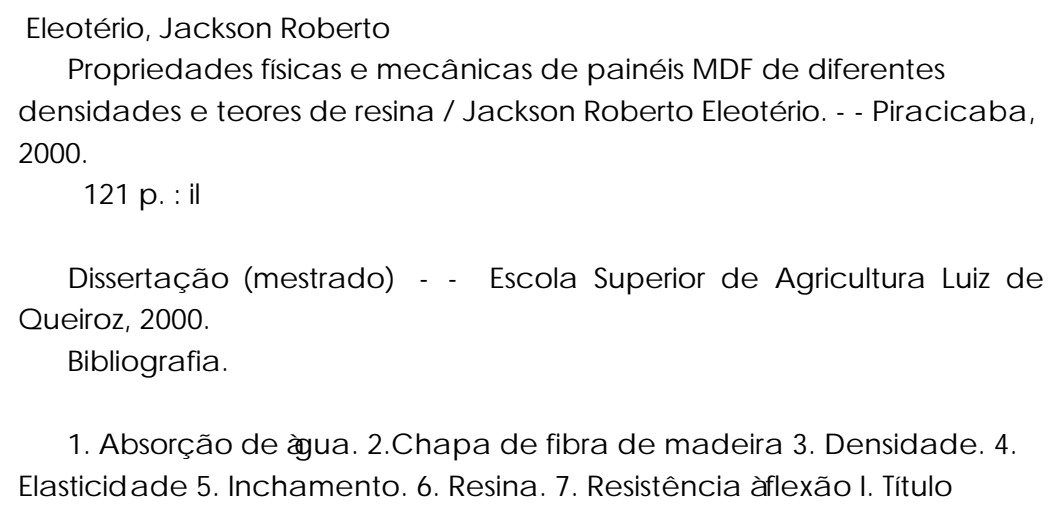

1. Absorção de àgua. 2.Chapa de fibra de madeira 3. Densidade. 4. Ela sticid ade 5. Inchamento. 6. Resina. 7. Resistênc ia àflexão I. Título

CDD 674.835 


\section{AGRADECIMENTOS}

À Duratex S.A., pelo apoio financeiro, metodológico e logístico dispensado a este trabalho, em especial ao sr. Mário Colombelli Filho -Diretor Industrial, sr. Carlos Nogueira Gama Neto - Gerente Industrial, Engenheiros Químicos José Antônio Bernardo e José Reinaldo Sartori Astolphi, Química Industrial Catia Benaduce e suas respectivas equipes.

Aos professores Clóvis Roberto Haselein (UFSM), Geraldo Bortoletto Júnior (ESALQ), Hernando Lara Palma (UNESP-Botucatu), Hilton Tadeu Zarate de Couto (ESALQ), Ivaldo Pontes Jankowsky (ESALQ) e Mario Tomazello Filho (ESALQ) pelas orientações e sugestões em todas as fases deste trabalho.

À minha esposa Eliane Santos da Rocha Eleotério, pelo apoio e pelos momentos de alegria.

A minha família pelo apoio e incentivo e principalmente pela educação pautada em valores sólidos.

Aos amigos de Blumenau (SC) e Santa Maria (RS) pelo apoio e incentivo.

À Fernanda Pozzera pelo auxílio e dedicação a este projeto durante a realização do seu estágio de conclusão do curso.

Ao Núcleo de Apoio à Pesquisa em Microscopia Eletrônica Aplicada a Agricultura (NAP/MEPA), em especial ao Prof. Dr. Elliot Watanabe Kitajima, pela boa vontade em divulgar a microscopia eletrônica e disponibilizar o equipamento aos alunos.

Aos funcionários do Departamento de Ciências Florestais, da Biblioteca Central, do IPEF e da Gráfica que exercem suas atividades com presteza e boa vontade.

Ao Conselho Nacional de Desenvolvimento Científico e Tecnológico, na pessoa do Sr. Felizardo Penalva da Silva, pela concessão da bolsa de estudos. 


\title{
PROPRIEDADES FÍSICAS E MECÂNICAS DE PAINÉIS MDF DE DIFERENTES DENSIDADES E TEORES DE RESINA
}

\author{
Autor: Jackson Roberto Eleotério
}

Orientador: Prof. MARIO TOMAZELLO FILHO

\section{RESUMO}

Painéis MDF (Medium Density Fiberboard) foram produzidos em laboratório, com diferentes densidades $\left(550\right.$ a $750 \mathrm{~kg} / \mathrm{m}^{3}$ ) e diferentes teores de resina $(6 ; 8 ; 10 ; 12$ e 14\%), com o objetivo de avaliar o efeito destes dois fatores, bem como sua interação, sobre o módulo de elasticidade e de ruptura, adesão interna, inchamento em espessura e absorção de água. Análises auxiliares foram realizadas, em especial do perfil de densidade e das dimensões das fibras. Todas as variáveis apresentaram correlação significativa com os fatores teor de resina e densidade, a interação só foi significativa a $1 \%$ com o inchamento em espessura. Modelos foram propostos para determinação das variáveis analisadas em função da densidade média e do teor de resina, tanto em percentagem como em valor absoluto. 


\title{
MECHANICAL AND PHYSICAL PROPERTIES OF MDF PANELS OF DIFFERENT DENSITIES AND RESIN CONTEN
}

\author{
Author: Jackson Roberto Eleotério \\ Adviser: Prof. MARIO TOMAZELLO FILHO
}

\section{SUMMARY}

MDF Panelboards of Pinus spp fibers were prepared in laboratorial scale, with a range of densities (550 - $750 \mathrm{~kg} / \mathrm{m3}$ ) and urea-formaldehyde resin content (6; 8; 10; 12 and 14 wt. \%), with the purpose of evaluating their mechanical and physical properties. The effect of density and resin content and their interactions were analyzed based on panel mechanical and physical properties. Mechanical properties evaluated were modulus of rupture, modulus of elasticity and internal bond, while physical properties studied were thickness swelling and water absorption. Also the alterations on wood fiber length and the MDF panel density profile were determined. All the physical and mechanical properties of the MDF panel were significantly related to the resin content and density. The interaction were significant only, at a degree of $1 \%$, with the thickness swelling. Models have been proposed to evaluate the physical and mechanical variables of the MDF panel as a function of the average density and resin content, as percentages as well as in absolute values. 


\section{SUMÁRIO}

Página

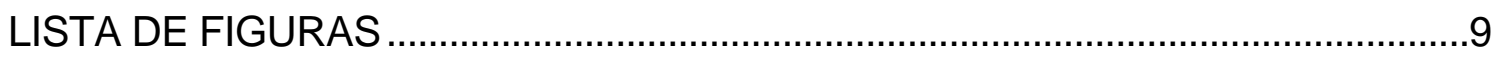

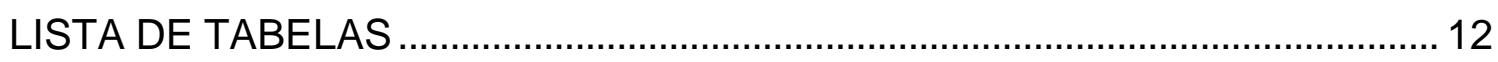

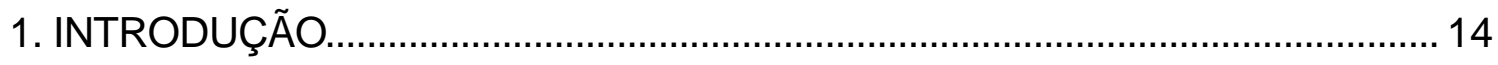

2. REVISÃO DE LITERATURA ...................................................................... 18

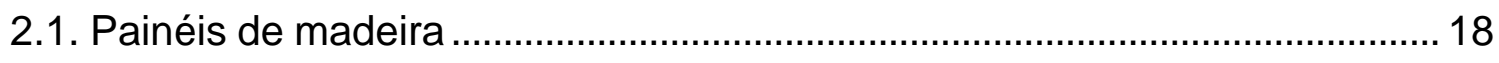

2.1.1. Vantagens da utilização de painéis de madeira ......................................... 18

2.1.2. Classificação dos painéis de madeira ......................................................... 19

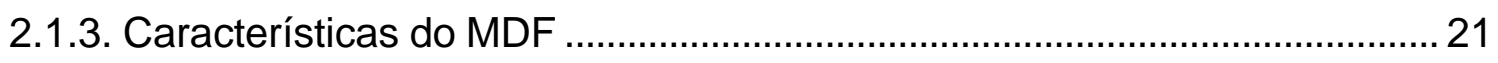

2.1.4. Tendências de mercado e custos na produção de painéis MDF.................. 22

2.2. Fatores que afetam as características dos painéis MDF............................... 22

2.2.1. Influência dos cavacos e das fibras............................................................ 23

2.2.1.1. Influência do teor de umidade dos cavacos............................................... 26

2.2.1.2. Influência do $\mathrm{pH}$ das fibras e do teor de extrativos..................................... 27

2.2.2. Influência das variáveis do desfibramento ..................................................... 27

2.2.3. Influência das resinas ou adesivos........................................................... 29

2.2.4. Influência do teor de umidade do colchão ....................................................... 33

2.2.5. Influência da prensagem.............................................................................. 35

2.2.6. Influência do alinhamento das fibras .......................................................... 36

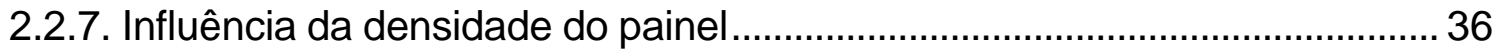

2.2.8. Influência do perfil de densidade do painel................................................... 38

2.2.9. Influência do teor de umidade do painel..................................................... 41 
2.2.10. Influência de tratamento preservativo e outros aditivos 41

2.3. Metodologias utilizadas em análises de fibras ............................................... 42

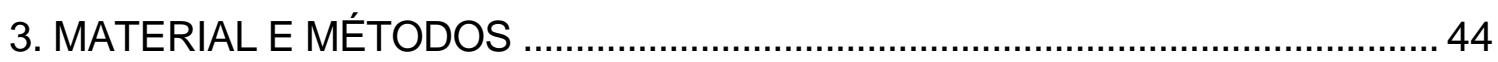

3.1. Delineamento experimental......................................................................... 44

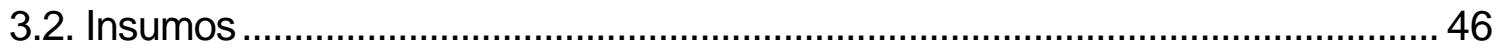

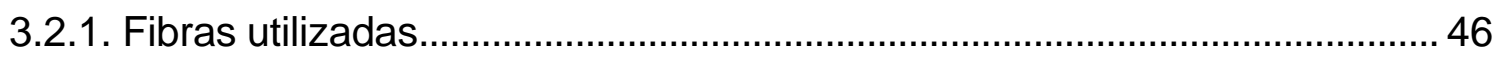

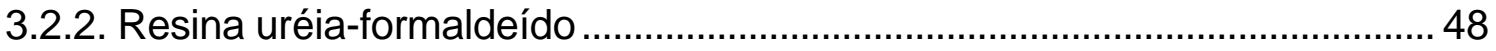

3.2.3. Emulsão de parafina ............................................................................. 49

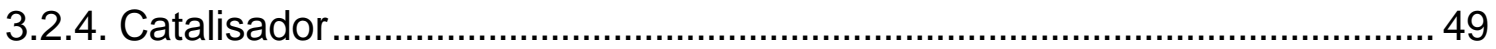

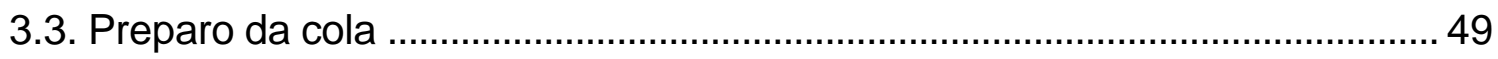

3.3.1. Dosagem da resina............................................................................... 49

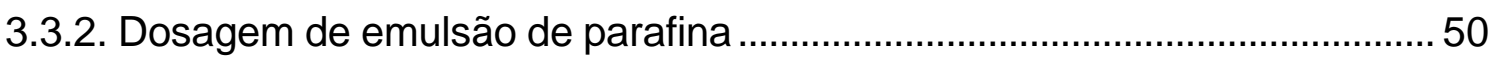

3.3.3. Dosagem de catalisador .............................................................................. 50

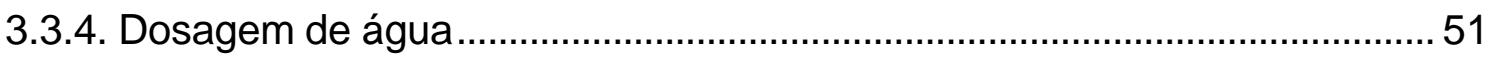

3.3.5. Solução a ser pulverizada sobre as fibras …………................................ 52

3.4. Preparação dos painéis experimentais ......................................................... 52

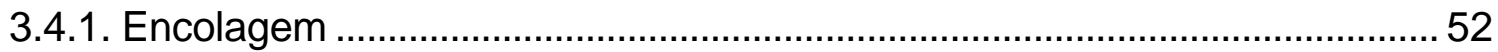

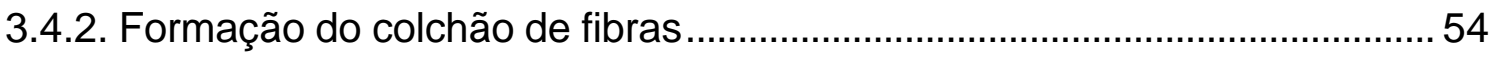

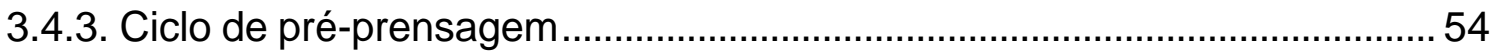

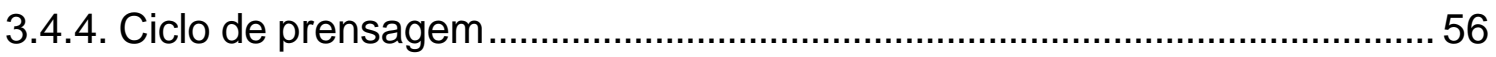

3.4.5. Retirada e condicionamento dos corpos-de-prova ....................................... 58

3.4.6. Ensaio de inchamento em espessura e absorção de água........................... 58

3.4.7. Ensaio para determinação da densidade ................................................... 60

3.4.8. Ensaios para determinação do módulo de ruptura e de elasticidade .......... 61

3.4.9. Ensaio para determinação da adesão interna ............................................... 63

3.4.10. Determinação do perfil de densidade ........................................................ 64

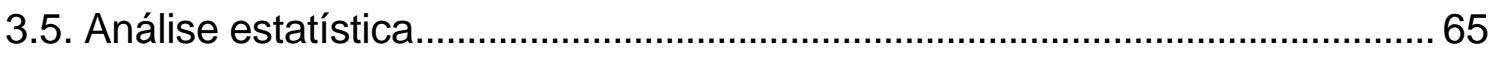

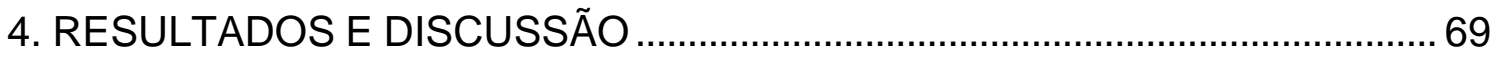




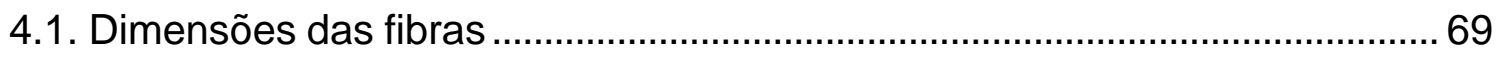

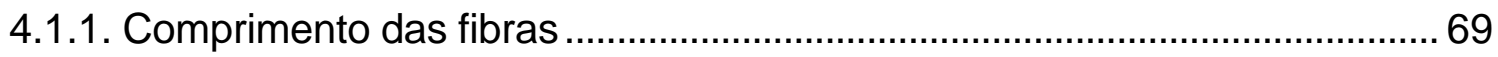

4.1.2. Largura e espessura da parede das fibras .............................................. 71

4.1.2.1. Resultados dos ensaios físicos e mecânicos........................................... 74

4.1.2.2. Resultados da análise do perfil de densidade ......................................... 81

4.2. Modelos em função da densidade média e do teor de resina em

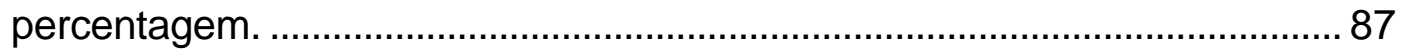

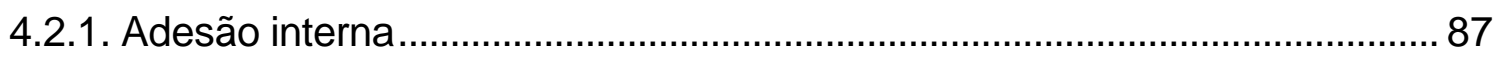

4.2.2. Módulo de ruptura ................................................................................... 90

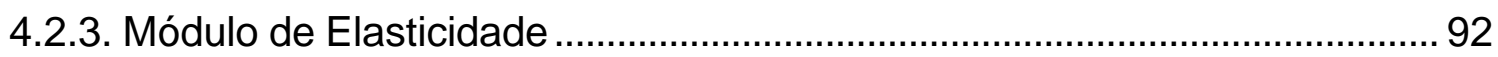

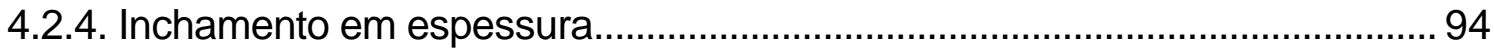

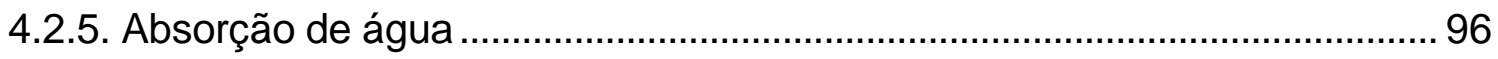

4.3. Análise em função da densidade e do teor de resina em massa ................... 98

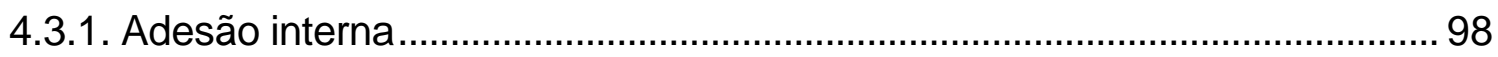

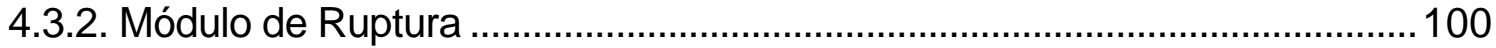

4.3.3. Módulo de Elasticidade ......................................................................... 101

4.3.4. Inchamento em espessura....................................................................... 103

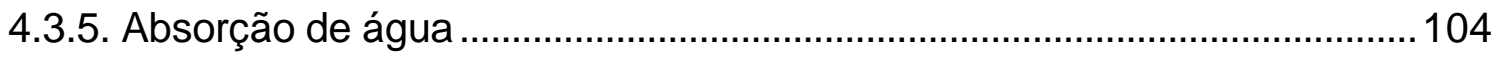

4.4. Considerações a respeito do método experimental...................................... 106

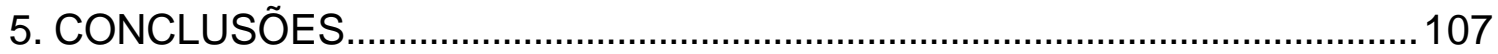

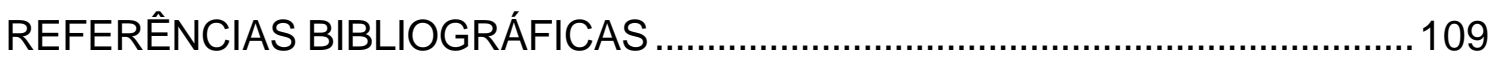




\section{LISTA DE FIGURAS}

\section{Página}

1. Classificação dos painéis a base de madeira, segundo o grau de transformação da matéria-prima, processo e densidade. Modificado de Suchsland \& Woodson (1987).

2. Estufa utilizada para secagem artificial das fibras dispostas em bandejas de tela metálica (a).

3. Encoladeira de laboratório aberta, mostrando o compartimento para encolagem (a) e o compartimento para desagregação de grumos (b). Ambos os compartimentos, dotados de pás para movimentação do material (c).

4. Formadora laboratorial do colchão de fibras (a), sobre chapa metálica (b), preenchida com fibras encoladas (c)

5. Ciclo de pré-prensagem utilizado no colchão de fibras.

6. Aspecto da pré-prensagem: colchão de fibras (a), chapas metálicas (b), pratos da prensa (d) e chapas de aglomerado (c).

7. Ciclo de prensagem utilizado na confecção dos painéis MDF

8. Estrutura utilizada para prensagem dos painéis MDF: bitoladores (a), painel prensado (d), chapas metálicas (b) e pratos da prensa (c).

9. Forma de retirada dos corpos-de-prova: 1. flexão estática, 2. adesão interna, 3. inchamento em espessura e absorção de água, 4. densidade e 5. perfil de densidade. 
10. Dimensões do corpo-de-prova para os ensaios de inchamento em espessura e absorção de água..

11. Dimensões do corpo-de-prova para o ensaio de densidade.

12. Representação gráfica do ensaio de flexão estática, sendo t espessura do corpo-de-prova, $\mathbf{I}_{2}=$ comprimento do corpo-de-prova, $\mathbf{I}_{1}=$ distância entre os apoios, $\mathbf{D}=$ diâmetro do cutelo, $\mathbf{d}=$ diâmetro do suporte, $\mathbf{F}=$ força aplicada.

13. Ensaio de adesão interna: corpo-de-prova (a) e suportes de metal (b).

14. Exemplo de uma superfície de resposta obtida e sua projeção no plano, na forma de isolinhas.

15. Distribuição da freqüência relativa (\%) do comprimento das fibras inteiras e desfibradas termomecanicamente.

16. Distribuição da freqüência da largura das fibras obtidas termomecânicamente.

17. Distribuição de freqüência para espessura de parede das fibras. 73

18. Aspecto das fibras obtidas termomecânicamente.

19. Disposição das fibras na camada interna de um painel MDF

20. Relação entre densidades de referência ao longo do perfil e densidade média. 82

21. Exemplo de perfil de densidade do painel: camada externa (a), camada interna (b) e densidade média (c).

22. Camada externa de um painel MDF experimental, demonstrando a compactação das fibras, que gera uma maior densidade.

23. Camada interna de um painel MDF experimental, demonstrando a presença de espaços vazios, que gera uma menor densidade

24. Isolinhas de adesão interna (MPa) em função da densidade média e do teor de resina relativo. 
25. Isolinhas de módulo de ruptura (MPa) em função da densidade média e do teor de resina relativo.

26. Isolinhas de módulo de elasticidade (GPa) em função da densidade média e do teor de resina (\%).

27. Isolinhas de inchamento em espessura (\%) em função da densidade média e do teor relativo de resina.

28. Isolinhas de absorção de água (\%) em função da densidade média e do teor relativo de resina.

29. Isolinhas de adesão interna (MPa) em função da densidade média e do teor absoluto de resina.

30. Isolinhas de módulo de ruptura (MPa) em função da densidade média e do teor de resina absoluto.

31. Isolinhas de módulo de elasticidade (GPa) em função da densidade média e do teor absoluto de resina.

32. Isolinhas de inchamento em espessura (\%) em função da densidade média e do teor absoluto de resina.

33. Isolinhas de absorção de água (\%) em função da densidade média e do teor absoluto de resina. 


\section{LISTA DE TABELAS}

\section{Página}

1. Classificação de chapas de fibra, segundo FAO (1958).................................. 20

2. Tratamentos para fabricação de painéis MDF. ................................................. 45

3. Características da resina UF utilizada............................................................... 48

4. Exemplo de solução a ser pulverizada nas fibras............................................... 52

5. Distribuição das freqüências absoluta e relativa do comprimento das fibras inteiras e desfibradas termomecanicamente.

6. Estatísticas básicas do comprimento das fibras obtidas termomecânicamente e inteiras.

7. Distribuição de freqüência absoluta e relativa da largura das fibras desfibradas termomecanicamente.

8. Distribuição da freqüência absoluta e relativa da espessura da parede das fibras desfibradas termomecânicamente.

9. Estatística da espessura da parede e largura das fibras.

10. Resultados médios por painel para os ensaios de adesão interna (Al), módulo de elasticidade (MOE), módulo de ruptura (MOR), inchamento em espessura e absorção de água.

10. Resultados médios por painel para os ensaios de adesão interna (Al), módulo de elasticidade (MOE), módulo de ruptura (MOR), inchamento em espessura e absorção de água (continuação).

11. Coeficientes de correlação de Pearson (\%) entre as variáveis analisadas e teor relativo e absoluto de resina e densidade média. 
12. Interação entre os fatores densidade e teor de resina, expressa através do valor do teste $\mathrm{F}$.

13. Coeficientes de correlação de Pearson (\%) entre variáveis dependentes. .... 80

14. Densidade $\left(\mathrm{kg} / \mathrm{m}^{3}\right)$ média (MÉDIA), da camada externa (CE), da camada interna (Cl), máxima (MÁX) e mínima (MíN) por painel.

14. Densidade $\left(\mathrm{kg} / \mathrm{m}^{3}\right)$ média (MÉDIA), da camada externa (CE), da camada interna $(\mathrm{Cl})$, máxima (MÁX) e mínima (MÍN) por painel (continuação).

15. Coeficientes de correlação de Pearson (\%) entre as variáveis analisadas e a densidade ao longo do perfil.

16. Coeficientes de correlação de Pearson (\%) entre as ao longo do perfil: sendo DMED densidade média, DCE densidade da camada externa, DCI densidade da camada interna, DMX densidade máxima e DMIN densidade mínima

17. Adesão interna (MPa), valores obtidos a partir da eq. (11) em função da densidade média e do teor relativo de resina.

18. Módulos de ruptura (MPa), para diferentes densidades médias e teores de resina, a partir da eq. (12)

19. Módulos de elasticidade (MPa), para diferentes densidades médias e teores de resina, a partir da eq. (13).

20. Inchamento em espessura (\%), para diferentes densidades médias e teores de resina, a partir da eq. (14).

21. Absorção de água (\%), para diferentes densidades médias e teores de resina, a partir da eq. (15) 


\section{INTRODUÇÃO}

A utilização de produtos de madeira ou seus derivados apresenta uma série de vantagens em relação à outros materiais de construção. A madeira é um material renovável; disponível abundantemente, biodegradável ou durável dependendo do tratamento, reciclável e imobiliza carbono proveniente da atmosfera em sua estrutura.

Para produzir produtos madeireiros consome-se menor quantidade de energia em comparação à produção de aço, plásticos e materiais a base de cimento. Outras vantagens da madeira são a alta resistência em relação àmassa específica e a boa trabalhabilidade.

Por sua vez, a utilização de painéis a base de madeira permite manter muitas das vantagens da madeira sólida, adicionando outras como dimensões dos painéis não estritamente relacionadas às dimensões das árvores; pode-se agregar valor a materiais de baixa aceitação como resíduos de serrarias e desbastes; possibilidade de eliminar muitos defeitos provenientes da anatomia da árvore como nós, medulas, desvios da grã, conferindo ao produto final homogeneidade muito maior que a encontrada na madeira serrada. Pode-se ainda, pela especificação da densidade, controlar a maioria das propriedades e adicionando produtos específicos, aumentar a resistência dos painéis ao fogo e à biodeterioração. 
Observa-se mundialmente, com a substituição de florestas nativas por florestas plantadas, um aumento expressivo na produção e consumo de painéis a base de madeira. Entre estes, destaca-se o MDF (Medium Density Fiberboard), um dos painéis a base de madeira mais avançados tecnologicamente. Os painéis MDF são formados por processo de prensagem àseco e utilizam como matériaprima madeira desfibrada termomecânicamente com a adição de resina sintética, geralmente uréia-formaldeído, além de outros aditivos em menor quantidade. Estes painéis são prensados a quente e sua densidade final varia de 500 a $800 \mathrm{~kg} / \mathrm{m}^{3}$.

Algumas características favoráveis dos painéis MDF são a homogeneidade, capacidade de receber acabamentos como tintas e vernizes, boa trabalhabilidade e resistência ao arrancamento de parafusos.

No Brasil é um produto recente, pois tornou-se disponível no mercado a partir do final dos anos 80. Inicialmente era importado da Argentina e do Chile e a partir de setembro de 1997 passou a ser fabricado no país.

A produção brasileira ainda não tem participação representativa no mercado mundial de MDF. Porém, apresenta grande potencial, principalmente considerando-se a disponibilidade de florestas plantadas passíveis de serem utilizadas como matéria-prima e a característica do processo de fabricação que permitem agregar valor à madeira de baixa qualidade e aos resíduos gerados pela indústria de base florestal.

Um forte limitante ao crescimento da produção brasileira é o investimento inicial necessário para aquisição das instalações industriais, possível apenas para grandes grupos empresariais. 
As propriedades dos painéis MDF, muito próximas da madeira sólida e em alguns aspectos superiores, permitem 0 uso em diferentes setores, principalmente na indústria moveleira e na construção civil.

Sabe-se pela literatura que diversos estudos ocuparam-se em analisar, isoladamente, os efeitos de alguns fatores da matéria-prima e do processo que afetam as propriedades finais dos painéis. Entre estes fatores destaca-se a densidade da matéria-prima, o comprimento das fibras, a densidade do painel e seu perfil vertical, tipo e teor de resina, teor de umidade do colchão e outras variáveis relacionadas ao desfibramento e prensagem.

Por outro lado, um número relativamente menor de trabalhos tem abordado os efeitos das interações entre os fatores envolvidos. Isto evidencia que pesquisas sobre interações entre dois ou mais fatores envolvidos na produção de painéis MDF e os possíveis ganhos na melhoria das propriedades e/ou redução do custo total de produção dos painéis podem trazer contribuições relevantes neste campo.

A densidade média e o teor de resina são alguns dos fatores que mais influenciam as propriedades finais dos painéis MDF. A identificação da forma como estes fatores interagem é muito útil para a melhoria das propriedades e economia de insumos, determinando para cada combinação de densidade um teor ideal de resina em função das propriedades desejadas.

Espera-se que aumentando a densidade dos painéis, reduzindo assim os espaços vazios e aumentando a área de contato entre fibras, obtenha-se, pela interação, um aumento na eficiência da resina.

A otimização do uso da resina justifica-se pelo seu alto custo, que algumas vezes representa o maior custo envolvido na produção de painéis MDF. 


\subsection{Objetivos}

\subsubsection{Objetivo geral}

O objetivo deste estudo foi analisar o efeito da densidade média e do teor de resina, bem como da interação entre estes fatores sobre algumas propriedades físicas e mecânicas.

\subsubsection{Objetivos específicos}

Avaliar o efeito do teor de resina, densidade e sua interação sobre o módulo de ruptura e de elasticidade e adesão interna como propriedades mecânicas.

Avaliar o efeito do teor de resina, densidade e sua interação sobre 0 inchamento em espessura e absorção de água como propriedades físicas.

Caracterizar as fibras utilizadas neste trabalho antes e depois do desfibramento.

Correlacionar as propriedades físicas e mecânicas analisadas com o perfil de densidade.

Propor modelos para as variáveis dependentes estudadas em função da densidade e do teor de resina, este último tanto em percentagem como em valor absoluto. 


\section{REVISÃO DE LITERATURA}

\subsection{Painéis de madeira}

\subsubsection{Vantagens da utilização de painéis de madeira}

Os painéis a base de madeira apresentam uma série de vantagens inerentes a esta matéria-prima, como renovabilidade, boa resistência em relação à massa específica, elevada disponibilidade, reciclabilidade, capacidade de imobilizar em sua massa grande quantidade de gás carbônico proveniente da atmosfera e demandam menor quantidade de energia para produção, transporte e instalação (Society of Wood Science and Technology, 1997).

Tratando-se de um material de origem biológica, a madeira pode apresentar alguns defeitos inerentes a anatomia das árvores como nós, presença de medula, grã desalinhada, tensões de crescimento e dimensões atreladas à forma das árvores.

Muitos desses defeitos podem ser eliminados durante os processos de fabricação de painéis, sendo possível obter um produto final com dimensões relacionadas apenas ao equipamento disponível e demanda de consumo. Destes processos resultam produtos livres de defeitos isolados, com maior homogeneidade tanto dentro do painel como entre painéis, além da possibilidade de adicionar características desejáveis como resistência ao fogo e à 
biodeterioração, aumentando a durabilidade e a diversificação da utilização (Maloney, 1989).

A tecnologia desenvolvida para a fabricação de painéis reconstituídos permite utilizar, como matéria-prima, sub-produtos da indústria madeireira, por exemplo costaneiras ou madeira de diâmetro reduzido proveniente de desbastes, agregando valor a este material e diminuindo a demanda de madeira industrial e a pressão sobre os recursos naturais (Maloney, 1989).

A grande vantagem da utilização de painéis a base de madeira é elucidada quando comparamos sua utilização com materiais não-renováveis, como alvenaria, aço, plásticos e alumínio. Um consistente parâmetro de comparação é a demanda de energia para a extração, produção e transporte de cada material. A utilização de uma tonelada de MDF, no fechamento de paredes, resulta numa necessidade líquida de energia é de 8,49 milhões de BTU $\left(9^{*} 10^{9} \mathrm{~J}\right)$, a utilização de alumínio demandará 34,08 milhões de BTU $\left(36^{*} 10^{9} \mathrm{~J}\right)$ e por fim, a utilização de alvenaria para o mesmo fim, 183,28 milhões de BTU (190*10 J) (Koch, 1992).

\subsubsection{Classificação dos painéis de madeira}

São apresentadas na literatura muitas formas de classificação dos painéis a base de madeira. A grande maioria classifica estes produtos segundo a transformação da madeira em lâminas, partículas ou fibras; tipo de processo seco ou úmido e densidade final do produto.

A Figura 1, a seguir, mostra uma forma de classificação dos painéis a base de madeira, baseada em Suchsland \& Woodson (1987). 


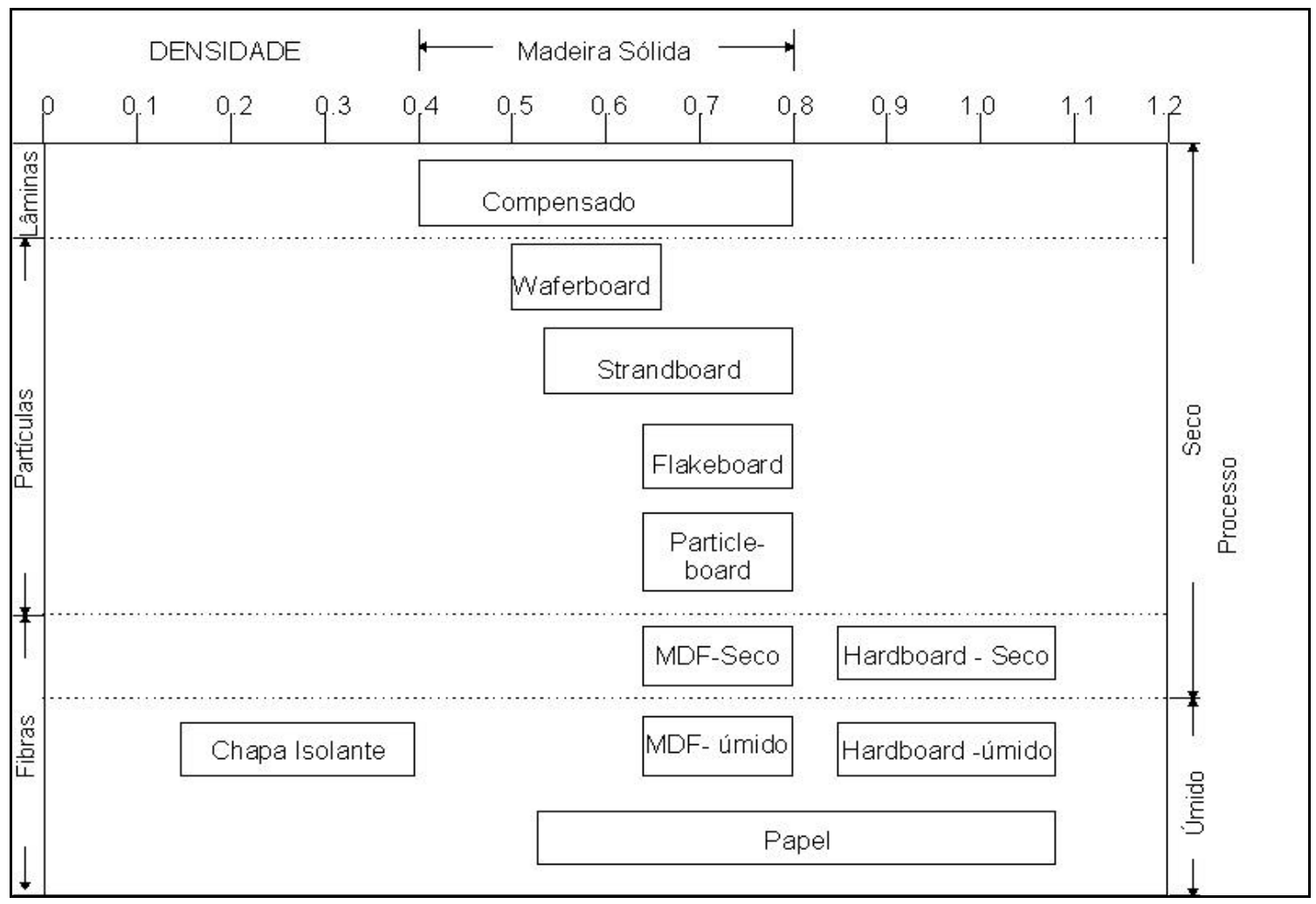

FIGURA 1. Classificação dos painéis a base de madeira, segundo o grau de transformação da matéria-prima, processo e densidade. Modificado de Suchsland \& Woodson (1987).

Segundo a FAO (1958), as chapas de fibras são classificadas de acordo com o uso de pressão ou não no processo de fabricação, bem como com a densidade das chapas prontas, o que pode ser visto na Tabela 1.

TABELA 1. Classificação de chapas de fibra.

\begin{tabular}{lll}
\hline & Chapa de Fibra & Densidade \\
\hline Não-comprimida & Chapa isolante semi-rígida & $0,02-0,15$ \\
& Chapa isolante rígida & $0,15-0,40$ \\
Comprimida & Chapa de fibra de média densidade & $0,40-0,80$ \\
& Chapa dura & $0,80-1,20$ \\
& Chapa dura especialmente densificada & $1,20-1,45$ \\
\hline
\end{tabular}

Fonte: FAO (1958). 
Entre as chapas de fibras comprimidas encontram-se as chapas de média densidade (MDF).

\subsubsection{Características do MDF}

Os painéis MDF são definidos pela ASTM-D1554 (1974) e por Maloney (1996) como "painéis fabricadas a seco, feitos com fibras lignocelulósicas combinadas com uma resina sintética ou outro agente ligante, compactados a uma densidade entre 0,50 e $0,80 \mathrm{~g} / \mathrm{cm}^{3}$ por prensagem a quente, num processo em que a totalidade da colagem entre as fibras é criada pelo adesivo adicionado".

É possível fabricá-los com características especiais como resistência a ambientes úmidos, resistência ao fogo e etc., através da escolha correta do tipo e do teor de resina e da adição de aditivos, dependendo da exigência (Bauer, 1995).

Uma característica favorável presente nos painéis MDF é a maior densidade nas faces. Esta maior densificação coincide com a região mais solicitada quando o painel trabalha sob o esforço de flexão estática. A menor quantidade de espaços vazios permite a pintura de maneira mais econômica e superfícies usinadas com menor rugosidade.

De uma forma geral os painéis MDF apresentam maior estabilidade dimensional que os painéis de partículas ou aglomerados (Grigoriou, 1983 e Suchsland et al. 1978). Este fato é explicado pelo menor teor de umidade no equilíbrio com o ambiente, pela estrutura do painel e pelo baixo potencial de sorção (Niemz \& Poblete, 1996; Jensen \& Kehr, 1995 e Xu \& Suchsland, 1991).

Segundo uma classificação apresentada por Benaduce (1998), os painéis MDF comparados com aglomerados, chapas duras e compensados; quando 
avaliados nas operações de corte, usinabilidade de borda, usinabilidade de superfície, curvagem (quando finos), torneamento, furação, pintabilidade, revestimento plano e revestimento trabalhado, apresentaram desempenho inferior apenas em relação à chapas duras e, somente, nas operações de curvagem e pintabilidade

\subsubsection{Tendências de mercado e custos na produção de painéis MDF}

Segundo Neves (1998) espera-se um grande crescimento no consumo de painéis industrializados de madeira em relação à madeira maciça. Em 1994 o consumo de painéis MDF representava $6 \%$ do volume total de painéis consumidos no mundo e esperava-se que em 2000 esse percentual chegaria a 14\% (Ernst, 1997 e FWI International, 1995).

O crescimento médio do consumo entre os anos de 1980 e 1994 foi de $15 \%$ ao ano, sendo previsto um crescimento àuma taxa em torno de $8 \%$ a.a. até 2005 (Macedo \& Roque, 1997; Neves, 1998).

Até 1997, o consumo de painéis MDF no Brasil ainda era muito baixo, devido ao desconhecimento das qualidades do produto e a recente entrada deste no mercado (Tomaselli \& Delespinasse, 1997).

Segundo simulação de INDI (1996), a resina e em seguida a madeira, são os dois maiores componentes no custo total de produção de painéis MDF, representando $23,3 \%$ e $15,9 \%$, respectivamente.

\subsection{Fatores que afetam as características dos painéis MDF}

As características finais de um painel MDF, sejam físicas, mecânicas, ambientais, etc. são influenciadas por uma série de características relacionadas à matéria-prima, ao processo e aos produtos incorporados aos painéis. Além da 
atuação de cada fator de forma isolada, pode-se esperar uma interação entre muitos destes fatores, formando o que Maloney (1989) chama de uma rede similar a uma "teia de aranha", com um fator influenciando o comportamento de outro.

É necessário registrar que devido à menor disponibilidade de literatura específica sobre todos os fatores que atuam isolados ou interagindo em painéis MDF, foram consideradas muitas informações referentes ao processo de fabricação de aglomerados e de chapas duras. Isto se justifica em parte pelo fato do processo de prensagem do aglomerado ser semelhante ao do MDF (processo seco) e pelo fato de utilizar-se, em chapas duras, fibras de madeira, assim como em MDF.

\subsubsection{Influência dos cavacos e das fibras}

A madeira, sob a forma de fibras, responde por grande parte do volume de um painel MDF e por parte das características destes painéis. No entanto, deve ser lembrando que ocorrem grandes modificações durante a transformação da madeira, fazendo com que a forma das fibras em um painel MDF seja resultante da combinação de variáveis como espécies utilizadas (folhosas ou coníferas) e sua mistura, tipo de cavaco utilizado (proveniente de toretes ou de resíduos), parâmetros de desfibramento (tempo de aquecimento, pressão do vapor aplicado, configuração dos segmentos dos discos e distância entre pratos do desfibrador), entre outras (Spaven et al. 1993).

Em geral, a utilização de madeira de baixa densidade permite a fabricação de painéis com melhores propriedades mecânicas do que quando utiliza-se madeira de alta densidade. Isso decorre da possibilidade de compactar painéis de média densidade com um suficiente contato entre fibras, o que possibilita uma melhor colagem. Espécies de baixa densidade também permitem a compactação 
com menor demanda de pressão. Usualmente utilizam-se taxas mínimas de compactação em torno de 1,3 (Maloney, 1989).

A viabilidade de utilizar-se madeira de reflorestamentos de curta rotação para produção de MDF é discutida por Dix \& Marutzky (1997). O suprimento de fibras provenientes de material jovem, como dos desbastes e de rotações curtas é desejável para a produção de chapas duras de fibras produzidas pelo processo seco, devido ao seu maior pH (Nelson, 1973). Myers \& Crist (1986), utilizando material híbrido jovem, com 6 anos, e material adulto proveniente de uma floresta nativa de Populus tremuloides, não encontraram diferenças significativas nas propriedades mecânicas e nem na estabilidade dimensional dos painéis MDF fabricados a partir destas matérias-primas.

Pugel et al. (1990a) e Pugel et al. (1990b), produziram painéis MDF e aglomerados a partir de madeira juvenil e adulta de Pinus taeda e observaram que, para a mesma densidade, painéis de madeira juvenil apresentaram propriedades mecânicas comparáveis aos painéis de madeira adulta, mas estabilidade dimensional inferior.

Shupe et al. (1999) também produziram aglomerados e painéis MDF a partir de madeira interna e externa de Pinus taeda e não encontraram diferenças significativas no módulo de elasticidade e de ruptura, adesão interna, inchamento e absorção de água.

Groom et al. (1997), a partir de testes práticos, afirmaram que as propriedades de rigidez e resistência de painéis MDF relacionam-se inversamente àresistência das fibras.

Painéis MDF fabricados a partir de fibras de seringueira (Hevea brasiliensis) de 3, 8 e 14 anos, com comprimentos de fibras de 1,24; 1,33 e 1,50 
mm, respectivamente, satisfizeram as normas JIS A5906-1993. Porém, os painéis de fibras das árvores com 3 e 8 anos apresentaram maior resistência à tração perpendicular, apesar das fibras terem menor comprimento (Mohd-Nor, 1995).

Nelson (1973) afirmou que a estabilidade linear foi positivamente relacionada com o comprimento das fibras da madeira, mas que este fator não afetou a resistência mecânica dos painéis. Menor quantidade de finos resultou em uma maior movimentação linear, em um estudo feito com material híbrido jovem e adulto de Populus (Myers \& Crist, 1986). Maior quantidade de finos resultou em maior compactação, maior densidade do painel e na elevação dos valores de módulo de ruptura e de elasticidade na flexão estática (Myers, 1983). Park et al. (1998) afirmam que fibras mais curtas tem sua superfície total aumentada o que faz com que o consumo de resina seja maior. Fibras mais longas apresentaram problemas na formação do colchão.

Spaven et al. (1993) apresentaram uma superfície de resposta com a interação comprimento das fibras e teor de resina, apresentando um decréscimo nas propriedades mecânicas com o aumento do comprimento das fibras.

Utilizando 14 espécies de folhosas, com uma ampla faixa de densidade, Woodson (1976) determinou que a densidade das toras, dos cavacos e das fibras tem influência inversa no módulo de ruptura, módulo de elasticidade e resistência àtração em MDF.

A maioria das propriedades mecânicas analisadas por Nelson (1973), foram negativamente afetadas pela densidade da madeira e densidade do colchão; esses fatores tem apenas uma pequena influência na estabilidade dimensional e de massa. Segundo Maloney (1989), a densidade da madeira tem sido utilizada para selecionar espécies para manufatura de painéis, usualmente 
na faixa de 0,3 a $0,5 \mathrm{~g} / \mathrm{cm}^{3}$. Nesta faixa é possível que, com a prensagem, obtenha-se média densidade com um bom contato entre fibras, garantindo a colagem.

Segundo Myers (1983), o inchamento em espessura dos painéis de média densidade produzidos pelo processo úmido parece ter sido influenciado pela contração volumétrica da madeira utilizada; nenhuma outra propriedade foi relacionada com a contração volumétrica da madeira ou com o comprimento médio das fibras.

Comparando painéis MDF fabricado com fibras de Pinus radiata com painéis fabricados com fibras de Hevea brasiliensis, Singh \& McDonald (1998) afirmam que o inchamento dos painéis fabricados a partir de fibras de Hevea brasiliensis é $40 \%$ menor, demonstrando que a espécie utilizada como matériaprima influencia nesta propriedade.

Procurando alternativas de matéria-prima, Dube \& Kehr (1995) utilizaram resíduos de papel para a produção de MDF e obtiveram painéis com menor resistência àflexão estática e tração perpendicular, além de descoloração.

Analisando a rugosidade final da superfície de painéis MDF, Hiziroglu (1996) afirmou que o tamanho e a forma das fibras são parâmetros que influenciam esta propriedade.

\subsubsection{Influência do teor de umidade dos cavacos}

Labosky Jr. et al. (1993) concluíram que, depois do teor de resina, o fator que mais afeta as propriedades das fibras e dos painéis é o teor de umidade dos cavacos durante o desfibramento. Segundo este autor, fibras provenientes de cavacos com baixo teor de umidade apresentaram-se inteiras e em feixes, 
dificultando a formação do colchão, sendo o rompimento não localizado na lamela média.

Segundo Maloney (1989) a alta umidade dos cavacos aumenta o custo da secagem, produz fibras crespas que dificultam a colagem e demandam mais resina.

\subsubsection{Influência do $\mathrm{pH}$ das fibras e do teor de extrativos}

Todas as propriedades mecânicas e a estabilidade linear estão correlacionadas positivamente com o pH das fibras. A absorção de água está correlacionada negativamente com este fator (Nelson, 1973).

Problemas provenientes da presença de grande quantidade de extrativos podem ser representados por um aumento no consumo de resina e alteração na sua taxa de cura, redução na resistência à umidade e problemas como a formação de bolhas durante a prensagem (Maloney, 1989).

\subsubsection{Influência das variáveis do desfibramento}

A operação de desfibramento consiste em desagregar, por atrito, as fibras da madeira. Utiliza-se um desfibrador composto de dois discos, um estacionário e outro rotatório ou os dois rotatórios, sendo os cavacos de madeira introduzidos entre eles. Alguns procedimentos auxiliam a performance desta operação, tanto no aspecto de qualidade das fibras geradas como no consumo de energia, como a imersão dos cavacos em água, a aplicação de vapor para enfraquecer a ligação de lignina entre as células da madeira e a utilização de produtos químicos, geralmente álcalis (Forest Products Laboratory, 1999).

Segundo Okamoto et al. (1994), o aumento da pressão e do tempo de aplicação de vapor resultaram em aumento da estabilidade dimensional e 
redução das propriedades mecânicas dos painéis MDF. Este fato está associado a uma redução no teor de hemiceluloses e alfa-celuloses. A condição ótima encontrada foi de 60 a 90 segundos de aplicação e $11 \mathrm{kgf} / \mathrm{cm}^{2}(1,1 \mathrm{MPa})$ ou 90 a 180 segundos de aplicação e $6 \mathrm{kgf} / \mathrm{cm}^{2}$ (0,6 MPa) de pressão de vapor.

A utilização de fibras processadas em desfibrador de discos duplos pressurizado resultou em painéis de melhores propriedades que aqueles produzidos com fibras provenientes de desfibrador não-pressurizado. O método de desfibração não afetou a adesão interna e o inchamento em espessura (Kawai \& Sasaki, 1989).

Labosky Jr. et al. (1993), também utilizando desfibrador de discos duplos pressurizado, variando a pressão de 50 a 100 psi $(0,34$ a $0,68 \mathrm{MPa})$, não encontraram diferença significativa na resistência dos painéis, tampouco aumento na estabilidade dimensional, apesar de encontrar uma redução no comprimento médio das fibras e no aumento de finos.

Chow (1976), afirma que o incremento da pressão de desfibramento resulta em decréscimo na adesão interna e atribui este fato à perda de extrativos fenólicos que contribuiriam para a adesão.

Short (1981), analisando várias superfícies de fratura entre fibras após o desfibramento, indicou que, com disco duplo e disco simples, a ruptura ocorre na lamela média ou parede primária. Isso poderia gerar fibras com superfícies compostas principalmente por lignina (substância não-polar), e assim, para uma maior eficiência, seria recomendado o uso de adesivos não-polares. Não foram observadas mudanças nas características morfológicas das fibras desfibradas em discos com aberturas de 0,025; 0,050 e 0,075 polegadas $(0,63 ; 1,27$ e 1,90 $\mathrm{mm})$. 
Butterfield et al. (1992) encontraram a mesma morfologia de fibras após o desfibramento e indicaram que longo tempo de processo pode produzir uma fibrilação, que pode interferir na cobertura e colagem das fibras.

Singh \& McDonald (1998), afirmam que a separação entre fibras durante o desfibramento de Pinus radiata ocorre na lamela média ou na transição entre esta e a parede primária, gerando uma superfície de espessura mais uniforme. Já em Hevea brasiliensis, a ruptura ocorre sempre na lamela média, mas resulta em superfície mais irregular.

Um aumento do tempo de desfibramento de fibras destinadas a produção de chapa dura, resultou em diminuição da fração grosseira de fibras e consequentemente aumento da fração mais fina, indicando que os feixes de fibras ou fibras foram reduzidas àpartículas menores; além da redução do comprimento das fibras, foram observadas alterações como deterioração das paredes das fibras, perda de pontuações e algumas quebras (Myers, 1983).

\subsubsection{Influência das resinas ou adesivos}

Existem vários mecanismos envolvidos na adesão entre dois materiais diferentes. Pode-se citar a interligação ou o enganchamento mecânico, a interdifusão de moléculas, as ligações químicas primárias e a adesão específica resultante de ligações químicas secundárias. Vários autores desenvolveram cada um desses mecanismos numa teoria particular de adesão. Na verdade, nenhuma dessas teorias isoladamente, explica totalmente o fenômeno de adesão. Cada uma delas contribui em parte para a explicação da colagem da madeira. No caso da madeira, a adesão por forças secundárias sempre aparece como sendo o componente principal (Pizzi, 1994). 
Como a maior parte dos adesivos para madeira possuem água como solvente, o fator mais importante que afeta a perda de solvente pelo adesivo é o teor de umidade da madeira.

Segundo Maloney (1989) e Pizzi (1994), juntamente com o fenol-formaldeído as formulações a base de uréia-formaldeído correspondem aos adesivos mais utilizados para colar a madeira, sendo utilizadas em $90 \%$ dos painéis a base de madeira produzidos pelo processo seco no mundo. A uréia-formaldeído (UF) é um adesivo para uso interno (sem contato com umidade), com boas propriedades de colagem, coloração clara, não é inflamável, cura tanto a frio (com catalisador ácido) como a quente e é o de mais baixo custo existente atualmente. Pode ser misturado com melamina, aumentando a resistência àumidade. As desvantagens são a baixa resistência à altas umidades e temperaturas e a emanação de formaldeído, um carcinogênico (Forest Products Laboratory, 1999).

Uma melhoria nas propriedades do adesivo é conseguida com um aumento da relação molar Formaldeído/Uréia. Valores ideais, em termos de resistência, são de $1 \mathrm{~mol}$ de uréia para 1,8 mol de formaldeído, mas com o inconveniente de altas taxas de emissão de formaldeído livre, tanto durante a fabricação como durante o uso do painel (Pizzi, 1994 e Sundin, 1995).

Segundo Hermans \& Smith (1985), resina de baixa relação molar produz MDF com boas propriedades mecânicas e taxas de emissão de formaldeído baixas o suficiente para atender aos padrões para uso interno.

Procurando atender as regulamentações sobre emissão de formaldeído, a relação molar F/U atualmente utilizada é de 1,1:1, o que faz necessário o uso de maior quantidade de adesivo para garantir a mesma qualidade de adesão, com conseqüente maior custo. Relações molares da ordem de 1:1,8 garantem 
polimerização ramificada e relações mais baixas somente polímeros lineares, de menor coesão (Pizzi, 1994 e Sundin, 1995).

Chapman \& Jenkin (1986), utilizando peróxido de hidrogênio como acelerador da cura de adesivos convencionais, afirmaram que uma melhor cura do adesivo em prensa quente, possibilitou a redução na quantidade de resina adicionada, bem como a redução de até 30\% no tempo de prensagem. Maloney (1989) cita que a adição de sais de amônia de ácidos fortes, como o sulfato de amônia, servem de catalisador por proporcionarem ácidos que são necessários para acelerar a cura da resina.

Adição de formaldeído na forma de formalina e paraformaldeído aumenta a resistência na flexão estática em $50 \%$ e reduz a absorção de água em um terço, comparando com painéis não modificados (Pawlicki, 1985).

Labosky Jr. et all.(1993), em produção experimental de MDF encontraram que o MOE, MOR e a colagem interna aumentaram com o aumento da quantidade de resina. Os valores mínimos de resistência mecânica requeridos pela norma ANSI/A208.2 foram alcançados para painéis de Acer rubrum L. com 8\% de teor de resina. Um incremento no teor de resina representou significativa redução no inchamento em espessura e absorção de água.

Maloney (1989) afirma que o teor de resina está intimamente relacionado com as propriedades dos painéis. Benaduce (1998) também encontrou relação positiva entre teor de resina e resistência mecânica, mas não encontrou interação entre teor de resina e tipo de fibra (Pinus caribaea var. hondurensis ou Eucalyptus grandis).

Suzuki \& Kato (1989) afirmam que o módulo de elasticidade e de ruptura na flexão estática aumentam com o teor de resina, especialmente em painéis com 
resina uréia-formaldeído e lignosulfonato. Segundo os mesmos autores, o inchamento em espessura decresceu com o aumento do conteúdo de resina.

Chow \& Zhao (1992) afirmam que o teor de resina afetou significativamente o módulo de ruptura, a adesão interna, a expansão linear, a absorção de água e o inchamento em espessura. Em chapas duras de Populus o aumento do conteúdo de resina resulta em diminuição no inchamento em espessura (Myers \& Crist, 1986).

Segundo Chow (1976), painéis com alto conteúdo de resina são mais rígidos e resistentes, porém a elevação do conteúdo de resina de 7,5\% para 10\% não resulta em incremento nas propriedades, semelhante ao observado com a elevação do conteúdo de resina de $5 \%$ para $7,5 \%$. Tem-se uma clara demonstração de perda da eficiência da resina, que pode ser melhor avaliada com faixas mais amplas de densidade. Wilson \& Krahmer (1976) indicam que a eficiência da resina em aglomerados depende de suas propriedades, sua distribuição nas partículas, tamanho da gota e contato entre partículas adjacentes no painel.

Uma maneira de melhorar a estabilidade dimensional dos painéis é aumentar o conteúdo de resina na superfície do colchão de fibras ou o conteúdo total de resina e/ou combinando resinas termoplásticas com fenólicas (Myers, 1983). Park et al. (1998) encontrou baixa estabilidade dimensional em painéis MDF colados com resinas UF, comparados com painéis colados com resinas FF (fenol-formaldeído).

Um painel MDF de $0,8 \mathrm{~g} / \mathrm{cm}^{3}$ otimizado, foi obtido por Lee \& Hong (1984), com 8 a $10 \%$ de resina e prensagem a $40 \mathrm{kgf} / \mathrm{cm}^{2}$. 
Para Kavvouras (1997) a quantidade de formaldeído absorvido pelas fibras aumenta proporcionalmente com a quantidade de formaldeído que é introduzida. Isto, segundo o autor, sugere que as fibras perdem a capacidade de armazenar formaldeído, depois da prensagem a quente.

Analisando o umedecimento da madeira através do ângulo de contato, uma importante propriedade quando se analisa a capacidade de tingimento do MDF, Wulf et al. (1997) afirmaram que a influência do conteúdo de resina nesta propriedade não pode ser caracterizada com precisão.

O teor de resina é um parâmetro que influencia a rugosidade final da superfície de painéis MDF (Hiziroglu, 1996).

\subsubsection{Influência do teor de umidade do colchão}

A umidade presente no colchão de fibras tem importantes funções que são transferir calor para a sua porção interna durante a prensagem e diminuir a resistência àcompressão do material, reduzindo a pressão específica necessária (Kollmann et al., 1975).

Colchões de fibras com baixos teores de umidade podem ocasionar problemas na prensagem, não permitindo que a espessura desejada seja atingida ou se mantenha estável. A umidade do colchão auxilia a reduzir a pressão específica necessária, pois vaporiza-se durante a prensagem a quente e torna plástica as fibras e ainda migra para as áreas mais frias, especialmente o centro do colchão, transportando calor. Um teor de umidade do colchão mais baixo proporciona um perfil de densidade mais homogêneo e assim uma maior resistência à tração perpendicular e ao arrancamento lateral de parafusos (Maloney, 1989). 
Kelly (1977) discutindo a influência de diferentes teores de umidade do colchão, cita também a redução da pressão específica necessária para compactação, aumento da velocidade de transferência de calor para o centro do colchão, mas, como desvantagem, cita o aumento do tempo de prensagem quando os teores de umidade são muito altos, tempo este necessário para a retirada da umidade excedente no painel. Para cada material existe um teor de umidade ótimo que concilia boa transferência de calor sem influenciar negativamente a cura da resina pelo excesso de umidade.

Em alguns casos a aspersão de água nas faces do colchão pode ser utilizada para melhorar a qualidade da superfície, aumentar a resistência àflexão e aumentar a transmissão de calor para o centro. A possibilidade de acelerar a fase de cura da resina é limitada justamente pela velocidade com que o calor chega nas camadas internas (Kollmann et al., 1975 e Maloney, 1989).

Chow \& Zhao (1992), afirmam que o teor de umidade do colchão afetou significativamente o módulo de ruptura, a adesão interna, a expansão linear, a absorção de água e o inchamento em espessura; sendo que o painel proveniente de um colchão com $12 \%$ de umidade apresentou melhores propriedades que aqueles com 6 e $8 \%$ de umidade. Maloney (1989) afirma que um maior teor de umidade nas faces do colchão em relação ao seu miolo, promoverá um maior contraste no perfil de densidade.

Segundo Lee \& Maloney (1996) o teor de umidade ideal do colchão para uma mistura de coníferas é ao redor de 13\%, maior que 8 a $11 \%$ atualmente comuns na produção de painéis MDF. Segundo os mesmo autores, bolhas de vapor só se formam quando o teor de umidade do colchão estiver acima de $15,4 \%$. 


\subsubsection{Influência da prensagem}

A prensagem é uma das fases mais importantes da fabricação de painéis a base de madeira, pois determina a espessura e a densidade final do painel e, ainda, transfere calor responsável pela cura da resina proporcionando a consolidação do painel.

A resistência à tração paralela ao plano, módulo de ruptura na flexão estática, absorção de água e inchamento em espessura foram significativamente afetados pela pressão de prensagem, temperatura de prensagem e interação entre ambos (Siagian, 1983).

Chow \& Zhao (1992) afirmam que a temperatura de prensagem afetou significativamente o módulo de ruptura na flexão estática, a adesão interna, a expansão linear, a absorção de água e o inchamento em espessura.

Segundo Maloney (1989) uma maior temperatura de prensagem aumenta a densidade do centro do painel enquanto diminui a densidade das faces, formando um perfil de densidade mais homogêneo. Este fato é devido àuma transferência de calor mais rápida para o centro do painel.

Myers (1983) afirma que ciclos de tratamentos de calor e prensagem mais longos tem grande influência na redução das mudanças dimensionais e de massa, porém de maneira mais acentuada em algumas espécies do que em outras.

Huang et al. (1976) encontraram relação entre o módulo de ruptura na flexão e tempo de prensagem para aglomerado, da mesma forma quando analisaram a adesão interna. 
A prensagem é um dos parâmetros que influenciam na rugosidade final da superfície de painéis MDF (Hiziroglu, 1996).

\subsubsection{Influência do alinhamento das fibras}

Analisando a resistência de aglomerados e painéis MDF, Niemz et al. (1996), determinaram que um pequeno alinhamento das partículas ou das fibras tem um claro efeito na resistência a ruptura e no módulo de elasticidade na flexão de ambos os materiais.

Maloney (1989) e Suchsland \& Woodson (1987), comentam e ilustram na forma de gráficos que a melhoria das propriedades na direção do alinhamento das fibras é seguida por proporcional redução destas propriedades no sentido oposto.

Kawai \& Sasaki (1989) não encontraram efeito significativo do alinhamento de fibras na adesão interna e no inchamento em espessura.

Para Suchsland et al. (1978), um aumento no número de fibras posicionadas verticalmente ao plano do painel resultaria em aumento da adesão interna, redução no inchamento em espessura e aumento na expansão linear.

Suchsland \& McMillin (1983) estimaram que o ângulo vertical das fibras de painéis MDF está entre $10^{\circ}$ e $20^{\circ}$, assumindo que a média é $15^{\circ}$. Esse alinhamento tem influência sobre a adesão interna.

\subsubsection{Influência da densidade do painel}

A densidade é um fator que afeta fortemente as propriedades dos painéis. A densificação dos painéis é um método fácil de melhorar as suas propriedades e em alguns casos, um volume adicional de resina não é necessário, tendo em vista 
o uso mais eficiente desta, como resultado do incremento na densidade do painel. Deve-se lembrar que o aumento da densidade promove um maior contato entre as fibras, significando menor perda de resina em espaços vazios (Maloney, 1989).

Segundo Kelly (1977) o fator que realmente influencia as propriedades mecânicas em aglomerados, é a taxa de compactação da matéria-prima, ou seja, a relação entre densidade do painel e densidade da madeira. Quanto maior a compactação maior o contato entre partículas e entre partículas e adesivo. Dessa forma podemos ter painéis com a mesma densidade final, mas com taxas de compactação diferentes, em função da densidade da madeira utilizada.

Segundo Kollmann et al. (1975), a densidade influência, de forma parabólica e hiperbólica, não linearmente, muitas propriedades das chapas de fibras.

Suzuki \& Kato (1989) afirmam que o módulo de elasticidade e de ruptura na flexão estática aumentam com o aumento da densidade do painel. Segundo Suchsland et al. (1978) muitas propriedades mecânicas são positivamente influenciadas pelo aumento da densidade do painel. Alta resistência àruptura na flexão estática foi encontrada com aumento da densidade (Niemz et al., 1997).

Segundo Niemz \& Steinmetzler (1996) a pressão de inchamento aumenta com o incremento da densidade. Segundo Suchsland et al. (1986) a absorção de água é controlada primariamente pela densidade ou porosidade. O inchamento em espessura não é afetado pela densidade. Para Maloney (1989) um aumento na densidade reduz a estabilidade dimensional, como na madeira.

As propriedades mecânicas são linearmente relacionadas com a densidade do painel, mas a estabilidade dimensional e a absorção de água não seguem esta tendência (Chow, 1976 e Nelson, 1973). 
Ao contrário das chapas duras, painéis MDF não mostram uma relação clara entre densidade do painel ou densidade máxima e rugosidade da superfície, provavelmente devido ao fato da maior heterogeneidade no tamanho das fibras (Hiziroglu, 1996).

Molina et al. (1998) utilizaram a densificação como forma de compensar o uso de matéria-prima de baixa qualidade, em painéis MDF colados com resina diisocianato.

\subsubsection{Influência do perfil de densidade do painel}

O perfil de densidade dos painéis MDF, com faces mais densas que o centro, forma-se durante a prensagem. Os pratos aquecidos da prensa, transmitem calor para o colchão de fibra e a umidade do colchão transforma-se em vapor, que plasticiza a lignina da madeira e facilita a sua compressão. Este processo ocorre inicialmente nas faces, que são aquecidas primeiro. O centro do painel, nos primeiros instantes da prensagem, está mais frio e resiste à compressão. Quando o centro do painel atinge a temperatura que permitiria uma maior compactação, o painel já atingiu a espessura desejada e, assim, não é tão compactado (Maloney, 1989).

Maloney (1989), Suchsland \& Woodson (1987) e Winistorfer et al. (1993), explicando a formação do perfil de densidade, citam como fatores mais importantes o tempo de fechamento da prensa que quanto maior, menor é o contraste de densidade, a umidade nas faces e no centro, faces mais úmidas que no centro aumentam o contraste no perfil de densidade e a pressão atingida, que quanto maior, menor o contraste.

Para Laufenberg (1986), os principais fatores que influenciam o perfil de densidade são a espécie utilizada, o tamanho das partículas e sua distribuição, o 
teor de umidade e sua distribuição, a temperatura de prensagem e o tempo de fechamento da prensa.

Segundo Suchsland \& Woodson (1987), o perfil de densidade é mais importante em painéis de maior espessura que em painéis finos. Contraste acentuado neste perfil, resulta em maior módulo de elasticidade na flexão, menor adesão interna, trabalhabilidade e resistência ao arrancamento lateral de parafusos.

A relação entre o perfil de densidade e as propriedades físico-mecânicas dos painéis MDF, bem como com a qualidade da superfície usinada, foi estudada por Jenson \& Emler (1996). Estes autores encontraram uma forte correlação entre o perfil de densidade e a qualidade da superfície e, dessa forma, espera-se uma menor qualidade superficial, com mais rugosidade, quando as camadas internas dos painéis MDF são expostas.

Para Kollmann et al. (1975), maior densidade nas faces de painéis aglomerados proporcionam alta resistência à flexão, melhor superfície para laminação, melhor resistência à absorção e inchamento e maior resistência à ignição e propagação de chamas.

Existem correlações significativas entre o módulo de cisalhamento interlaminar, resistência ao cisalhamento e adesão interna com o perfil de densidade. Entretanto, a definição precisa do local de ruptura não foi possível ser efetuada a partir do perfil de densidade (Schulte \& Fruhwald, 1996).

Boheme (1992) também encontrou influência do perfil de densidade nas propriedades dos painéis MDF. Segundo este último autor, o perfil de densidade é influenciado basicamente pela pressão aplicada e pelo teor de umidade e de resina no colchão de fibras. 
A característica do perfil de densidade influencia também a emissão de formaldeído. Marutzky et al. (1992), constataram que a emissão de formaldeído é extremamente influenciada pela densidade da camada superficial. Painéis com alta densidade superficial emitiram a metade do formaldeído dos painéis com menor densidade superficial.

O módulo de ruptura e o módulo de elasticidade na flexão foram preditos, a partir do perfil de densidade estabelecido por radiografia de raios- $X$, sendo $24 \mathrm{e}$ $23 \%$ maiores em painéis com gradiente de densidade, que em painéis com densidade uniforme (Woodson, 1977). Nearn \& Basse (1968) utilizaram metodologia de raios-X para determinar o perfil de densidade em chapas de fibra.

Huang et. al. (1976), utilizaram metodologia de raios-X e microdensitômetro para avaliar o perfil de densidade em aglomerados e encontraram que a resistência à flexão depende primariamente da resistência nas faces e que a adesão interna depende da densidade na camada central. Suchsland et al. (1978), também encontraram forte correlação $(r=0,96)$ entre módulo de elasticidade e densidades nas faces, mas não encontraram nenhuma correlação entre módulo de elasticidade ou adesão interna e densidade média do painel. Nenhuma correlação foi encontrada entre adesão interna e densidade no centro do painel.

Segundo Winistorfer et al. (1986), a avaliação do perfil de densidade, com um densitômetro direto de raios gama, pode ser utilizado como o método padrão com a vantagem de ser uma técnica rápida, não destrutiva, precisa e acurada, eliminando todos os passos associados a processamento de filmes e calibração. 
Winistorfer et al. (1994) usaram análise de regressão não-paramétrica, com curvas spline cúbicas, permitindo assim comparações estatisticamente embasadas entre perfis de densidade.

\subsubsection{Influência do teor de umidade do painel}

Um incremento no conteúdo de umidade determina uma redução na resistência à ruptura dos painéis MDF (Niemz et al., 1997). Chow \& Redmond (1981), indicam que uma alta umidade relativa e conseqüente alto teor de umidade de equilíbrio, resultam em redução da densidade o que diminui o módulo de elasticidade e o módulo de ruptura na flexão.

Niemz \& Steinmetzler (1996), determinaram um incremento linear na pressão de inchamento de painéis MDF, partindo de um conteúdo de umidade de $10 \%$ e finalizando com um conteúdo de umidade de $45 \%$.

Para Watkinson \& Gosliga (1990), em painéis, todas as propriedades mecânicas variam significativamente com a variação do teor de umidade.

\subsubsection{Influência de tratamento preservativo e outros aditivos}

Segundo Hashim et al. (1994), painéis podem ser tratados contra fogo e biodeterioração, pela aplicação de produtos químicos na matéria-prima; junto com a resina, ou aplicados depois de o painel estar completamente fabricado, usualmente por processos de impregnação. Este mesmo autor, utilizando vaporização de ácido bórico, com dois níveis de retenção, observou redução significativa na resistência ao impacto, na adesão interna e na durabilidade da colagem em painéis MDF, utilizando-se longos tempos de aplicação. 
Maloney (1989), comenta sobre a aplicação de 0,5 a 1,0\% de parafina com o objetivo de reduzir a absorção de água líquida pelo produto final, citando que também podem ser adicionados produtos retardantes ao fogo e preservativos.

Modificações na madeira, como a acetilação, podem ser benéficas em algumas propriedades e prejudiciais em outras, sendo influenciadas também pelo tipo de resina. Segundo Rowell (1995) a acetilação promoveu uma redução significativa nas propriedades mecânicas e na retratibilidade, em painéis de partículas tipo flakes colados com resina fenólica. A mesma redução nas propriedades mecânicas não foi observada em painéis colados com resina isocianato.

\subsection{Metodologias utilizadas em análises de fibras}

Butterfield et al. (1992) e Niemz et al. (1997), utilizaram microscopia eletrônica de varredura para avaliar o tipo e a superfície de fratura em corpos-deprova de adesão interna e flexão estática. Kim \& Park (1996) observaram micromorfologicamente a superfície de ruptura resultante do teste de adesão interna analisando a distribuição da resina e a superfície das fibras. Park et al. (1998) caracterizaram fibras de eucalipto, populus e cicuta pelo comprimento das fibras e sua distribuição, morfologia, densidade a granel e acidez. Nelson (1973) procedeu a medição de 100 fibras, desprezando células de parênquima.

Labosky Jr. et al. (1993) empregaram processo Bauer McNett, que utiliza de uma série de peneiras de diferentes malhas, para classificar as fibras por comprimento, adotando este método por considera-lo um método bem estabelecido e que revela mais informações sobre as fibras. Estes autores também avaliaram o pH das fibras misturadas com água deionizada, pela sua relação com extrativos e influência na redução do gel time. 
Myers \& Crist (1986) classificaram as fibras utilizando o método Bauer McNett, análise química e microscopia eletrônica de varredura com magnificações de 250, 1000 e 2000 vezes. Myers (1983) utilizou quatro critérios de caracterização de fibras: taxa de drenagem; método Bauer McNett, medida do comprimento de um número representativo de fibras, que permite avaliar as alterações causadas pelo desfibramento e análise morfológica usando microscopia eletrônica de varredura. Este autor procedeu a medição microscópica de 200 a 400 fibras individuais para determinação do comprimento médio e examinou amostras da polpa em microscópio eletrônico de varredura usando aumentos de 200 , 1000 e 2000 vezes, que ilustraram as modificações medidas em outros métodos. Singh \& McDonald (1998) caracterizaram fibras de Pinus radiata e Hevea brasiliensis por microscopia eletrônica de transmissão. 


\section{MATERIAL E MÉTODOS}

\subsection{Delineamento experimental}

Com o objetivo de avaliar os efeitos da densidade do painel, do teor de resina e da sua interação, estes fatores foram combinados em diferentes níveis e aplicados em painéis MDF experimentais, formando um arranjo fatorial dos tratamentos. Os tratamentos compreenderam um delineamento experimental inteiramente casualizado, com painéis experimentais quadrados de $43 \mathrm{~cm}$ de aresta e $16 \mathrm{~mm}$ de espessura.

Os fatores foram o teor de resina em 5 níveis $(6 ; 8 ; 10 ; 12$ e $14 \%$ ) e a densidade dos painéis, também em 5 níveis (600;650; 700; 750 e $800 \mathrm{~kg} / \mathrm{m}^{3}$ ), que combinados resultaram em 25 tratamentos (Tabela 2), que com 2 repetições, totalizaram 50 painéis MDF produzidos.

As variáveis dependentes analisadas foram o módulo de elasticidade e de ruptura na flexão estática, a adesão interna, também chamada de tração perpendicular ao plano do painel ou ligação interna, o inchamento em espessura e a absorção de água após imersão em água por 24h. Ainda foram realizadas análises do perfil de densidade dos painéis. 
TABELA 2. Tratamentos para fabricação de painéis MDF.

\begin{tabular}{ccc}
\hline TRATAMENTO & \multicolumn{2}{c}{ FATORES } \\
& Teor de resina $(\%)$ & Densidade do painel $\left(\mathrm{kg} / \mathrm{m}^{3}\right)$ \\
\hline 01 & & 600 \\
02 & 6 & 650 \\
03 & & 700 \\
04 & & 750 \\
05 & & 800 \\
\hline 06 & \multirow{2}{*}{8} & 600 \\
07 & & 650 \\
08 & & 700 \\
09 & & 750 \\
10 & 10 & 800 \\
\hline 11 & & 600 \\
12 & & 650 \\
13 & & 700 \\
14 & & 750 \\
15 & & 800 \\
\hline 16 & 12 & 600 \\
17 & & 650 \\
18 & & 700 \\
19 & & 750 \\
20 & & 800 \\
\hline 21 & & 600 \\
22 & & 650 \\
23 & & 700 \\
24 & & 750 \\
25 & & 800 \\
\hline
\end{tabular}




\subsection{Insumos}

\subsubsection{Fibras $^{1}$ utilizadas}

Foram utilizadas fibras, provenientes de uma mistura, sem controle da proporção, de cavacos de madeira de Pinus oocarpa SHIEDE e Pinus caribaea MORELET var hondurensis BARR ET GOLF. As árvores que deram origem a estes cavacos provinham de um reflorestamento com mais de 20 anos na região de Agudos (SP).

Para a caracterização das fibras inteiras, foi retirada uma amostra dos cavacos antes da passagem pelo desfibrador. Esta amostra foi dividida em cinco sub-amostras, e de cada, foram selecionados dois cavacos aleatoriamente. Estes cavacos foram picados, o material foi submetido à maceração, utilizando-se solução de peróxido de hidrogênio, mantido por cerca de $72 \mathrm{~h}$ em estufa a $60^{\circ} \mathrm{C}$.

Com o macerado foram montadas três lâminas semipermanentes de cada sub-amostra, totalizando 15 lâminas. O comprimento de 20 das fibras inteiras de cada lâmina foi avaliado, resultando num total de 300 observações. $O$ método de medição foi o mesmo utilizado para fibras obtidas termomecânicamente, citado anteriormente.

A largura e espessura da parede das fibras inteiras não foram medidas pois o processo de maceração provoca um inchamento exagerado da parede celular inviabilizando qualquer comparação.

\footnotetext{
${ }^{1}$ Por ser mais usual, o termo traqueídes foi substituído por fibras.
} 
Os cavacos foram desfibrados, após tratamento com vapor saturado à pressão entre 0,6 e 0,8 MPa, em um desfibrador industrial Andritz Sprout Bauer, modelo 54/58-1CP. As fibras para produção dos painéis experimentais foram secas em estufa de laboratório com ventilação forçada, como mostra a Figura 2, até atingirem 0 teor de umidade de $3 \%$ (base úmida), controlado gravimetricamente.

Para a caracterização das fibras obtidas termomecânicamente, foi retirada uma amostra aleatória, e desta, foram retiradas cinco sub-amostras e de cada uma montou-se três lâminas, perfazendo um total de 15 lâminas.

Para as medições foram montadas lâminas de forma semipermanente, com glicerina e coloridas com safranina. De cada lâmina foram medidos o comprimento de 50 fibras e a largura e espessura da parede de 20 fibras, perfazendo um total de 750 e 300 medições, respectivamente. As medições de comprimento foram feitas utilizando-se um projetor de fibras Bausch \& Lomb, obtidas em centímetros e transformadas para milímetros, empregando-se um fator de correção. Para a determinação da largura e espessura da parede das fibras, utilizou-se um microscópio óptico cuja ocular é dotada de escala. 


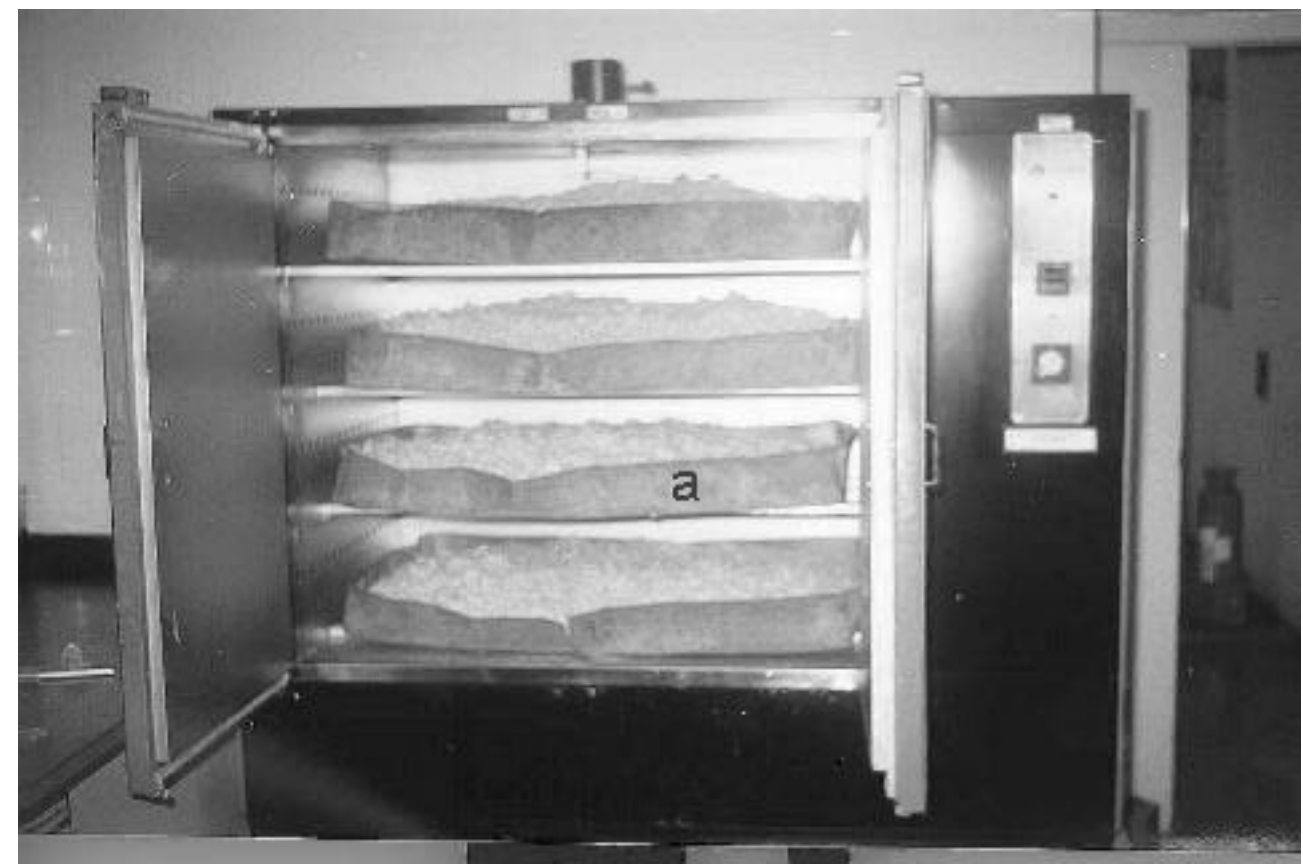

FIGURA 2. Estufa utilizada para secagem artificial das fibras dispostas em bandejas de tela metálica (a).

\subsubsection{Resina uréia-formaldeído}

A resina utilizada foi a uréia-formaldeído reforçada com melamina, fabricada pela Duratex S.A., cujas características são apresentadas na Tabela 3. Esta resina é considerada Classe $A$ devido a sua baixa emissão de formaldeído e a ausência de extensor. A quantidade de resina variou conforme os tratamentos aplicados em cada painel.

TABELA 3. Características da resina UF utilizada.

\begin{tabular}{ccc}
\hline Variável & Condições Experimentais & Valor Médio \\
\hline Teor de Sólidos & 4 horas a $105^{\circ} \mathrm{C}$ & $66 \%$ \\
Viscosidade Brookfield & $25^{\circ} \mathrm{C}$ & $150 \mathrm{cP}$ \\
$\mathrm{pH}$ & $25^{\circ} \mathrm{C}$ & 8,8 \\
Gel-time & $98^{\circ} \mathrm{C}$ & $130 \mathrm{~s}$ \\
Massa Específica & $20^{\circ} \mathrm{C}$ & $1,29 \mathrm{~g} / \mathrm{cm}^{3}$ \\
\hline
\end{tabular}




\subsubsection{Emulsão de parafina}

Visando reduzir a higroscopicidade final dos painéis utilizou-se emulsão de parafina, na proporção de 1\% de sólidos da emulsão em relação ao peso das fibras anidras. A emulsão de parafina comercial empregada continha $70 \%$ de teor de sólidos.

\subsubsection{Catalisador}

Como catalisador da cura da resina foi utilizado sulfato de amônia comercial, com teor de sólidos de $20 \%$, na dosagem de 2,5\% de sólidos de catalisador, em relação ao teor de sólidos da resina.

\subsection{Preparo da cola}

O preparo da cola constituiu-se nas operações de mistura da resina, do catalisador, da emulsão de parafina e da água, em proporções variáveis segundo o teor de resina requerido.

Para exemplo de cálculo apresenta-se a dosagem para uma massa de $2500 \mathrm{~g}$ de fibras com teor de umidade de 3\% (base úmida), visando o preparo de fibras encoladas com $10 \%$ de teor de resina (sólidos da resina em relação às fibras anidras).

\subsubsection{Dosagem da resina}

Na dosagem de resina levou-se em consideração o seu teor de sólidos, em relação àmassa anidra de fibras.

Considerando, como exemplo, a dosagem para obtenção de fibras encoladas com teor de resina de $10 \%$, temos a equação 1 : 


$$
\begin{aligned}
& R S=M F *(1-u) * T R * \frac{1}{T S R} \\
& R S=2500 *(1-0.03) * 0.1 * \frac{1}{0.66} \\
& R S=367.42 g
\end{aligned}
$$

onde: $\mathrm{RS}=$ massa de resina a ser adicionada às fibras $(\mathrm{g})$

$$
\begin{aligned}
& \text { MF = massa de fibras úmidas }(\mathrm{g}) \\
& \mathrm{u}=\text { teor de umidade das fibras (base úmida) (decimal) } \\
& \mathrm{TR}=\text { teor de resina desejado (decimal) } \\
& \mathrm{TSR}=\text { teor de sólidos da resina (decimal) }
\end{aligned}
$$

\subsubsection{Dosagem de emulsão de parafina}

A dosagem empregada de parafina foi de 1\% (sólidos de parafina em relação às fibras anidras), constante para todos os tratamentos e pode ser calculada conforme a equação 2 :

$$
\begin{aligned}
& P F=M F *(1-u)^{*} T P^{*} \frac{1}{T S P} \\
& P F=2500 *(1-0.03)^{*} 0.01^{*} \frac{1}{0.7} \\
& P F=34.64 g
\end{aligned}
$$

onde: $\mathrm{PF}=$ massa de emulsão de parafina a ser adicionada às fibras $(\mathrm{g})$

$\mathrm{MF}=$ massa de fibras úmidas $(\mathrm{g})$

$\mathrm{u}=$ teor de umidade das fibras (base úmida) (decimal)

TP $=$ teor de parafina desejado (decimal)

TSP = teor de sólidos da emulsão de parafina (decimal)

\subsubsection{Dosagem de catalisador}

$\mathrm{Na}$ dosagem do catalisador levou-se em consideração o seu teor de sólidos, em relação ao teor de sólidos da resina. 
Seguindo o exemplo, a dosagem de catalisador para a massa de resina determinada no item 3.3.1. é apresentada na equação 3:

$$
\begin{aligned}
& C T=R S * T S R * T C * \frac{1}{T S C} \\
& C T=367.42 * 0.66 * 0.025 * \frac{1}{0.20} \\
& C T=30.31 \mathrm{~g}
\end{aligned}
$$

onde: $\mathrm{CT}=$ massa de catalisador àser adicionada àresina $(\mathrm{g})$

$\mathrm{RS}=$ massa de resina àser adicionada ̀̀ fibras $(\mathrm{g})$

TSR = teor de sólidos da resina (decimal)

$\mathrm{TC}=$ teor de catalisador desejado (decimal)

TSC = teor de sólidos do catalisador (decimal)

\subsubsection{Dosagem de água}

Para atingir o teor de umidade desejado para o colchão de fibras (10\% base úmida) é necessária a adição de uma certa quantidade de água. Essa quantidade de água é diretamente proporcional ao teor de sólidos dos outros componentes da cola. A dosagem d'água pode ser calculada através da equação 4:

$$
\begin{aligned}
& \mathrm{uc}=\frac{\mathrm{MF}^{*} \mathrm{u}+\mathrm{RS}^{*}(1-\mathrm{TSR})+\mathrm{PF}^{*}(1-\mathrm{TSP})+\mathrm{CT}^{*}(1-\mathrm{TSC})+\mathrm{MH}_{2} \mathrm{O}}{\mathrm{MF}+\mathrm{RS}+\mathrm{PF}+\mathrm{CT}+\mathrm{MH}_{2} \mathrm{O}} \\
& 0.1=\frac{2500{ }^{*} 0.03+367.42{ }^{*}(1-0.66)+34.64{ }^{*}(1-0.7)+30.31{ }^{*}(1-0.2)+\mathrm{MH}_{2} \mathrm{O}}{2500+367.42+34.64+30.31+\mathrm{MH}_{2} \mathrm{O}} \\
& \mathrm{MH}_{2} \mathrm{O}=65.19 \mathrm{~g}
\end{aligned}
$$

onde: $u c=$ teor de umidade desejado para colchão (base úmida) (decimal) $\mathrm{MF}=$ massa de fibras úmidas $(\mathrm{g})$

$\mathrm{u}=$ teor de umidade das fibras (base úmida) (decimal)

$\mathrm{RS}=$ massa de resina àser adicionada ̀̀ fibras $(\mathrm{g})$

TSR = teor de sólidos da resina (decimal)

PF = massa de emulsão de parafina a ser adicionada às fibras $(\mathrm{g})$ 
TSP = teor de sólidos da emulsão de parafina (decimal)

$\mathrm{CT}=$ massa de catalisador àser adicionada àresina $(\mathrm{g})$

TSC = teor de sólidos do catalisador (decimal)

$\mathrm{MH}_{2} \mathrm{O}=$ massa de água a ser adicionada $(\mathrm{g})$

\subsubsection{Solução a ser pulverizada sobre as fibras}

A massa de cada componente da cola, utilizada como exemplo prático, para a preparação de solução com resina e aditivos a ser pulverizada em $2500 \mathrm{~g}$ de fibras com teor de umidade de 3\%, para atingir um teor de resina de $10 \%$ e teor de umidade do colchão de 10\% (base úmida), é apresentado na Tabela 4.

TABELA 4. Exemplo de solução a ser pulverizada nas fibras.

\begin{tabular}{cccc}
\hline Material & Teor de Sólidos & Teor Desejado & Massa $(\mathrm{g})$ \\
Resina & 0.66 & $10 \%$ & 367.42 \\
Emulsão de Parafina & 0.70 & $1 \%$ & 34.64 \\
Catalisador & 0.20 & $2.5 \%$ & 30.31 \\
Água & 1.00 & - & 65.19 \\
Total & & & 497.56 \\
\hline
\end{tabular}

\subsection{Preparação dos painéis experimentais}

\subsubsection{Encolagem}

Lotes de fibras, com massa de $2500 \mathrm{~g}$ e com teor de umidade de $3 \%$ (base úmida), foram depositadas em uma encoladeira de laboratório. A encoladeira é dotada de um tambor de $800 \mathrm{~mm} \times 715 \mathrm{~mm}$ (comprimento $X$ diâmetro), com abertura na região central, dividido em 2 compartimentos de $380 \mathrm{~mm}$, equipados com 4 pás para homogeneização do material, acionadas por um motor com rotação de cerca de 115rpm, conforme a Figura 3 (Benaduce, 1998). 


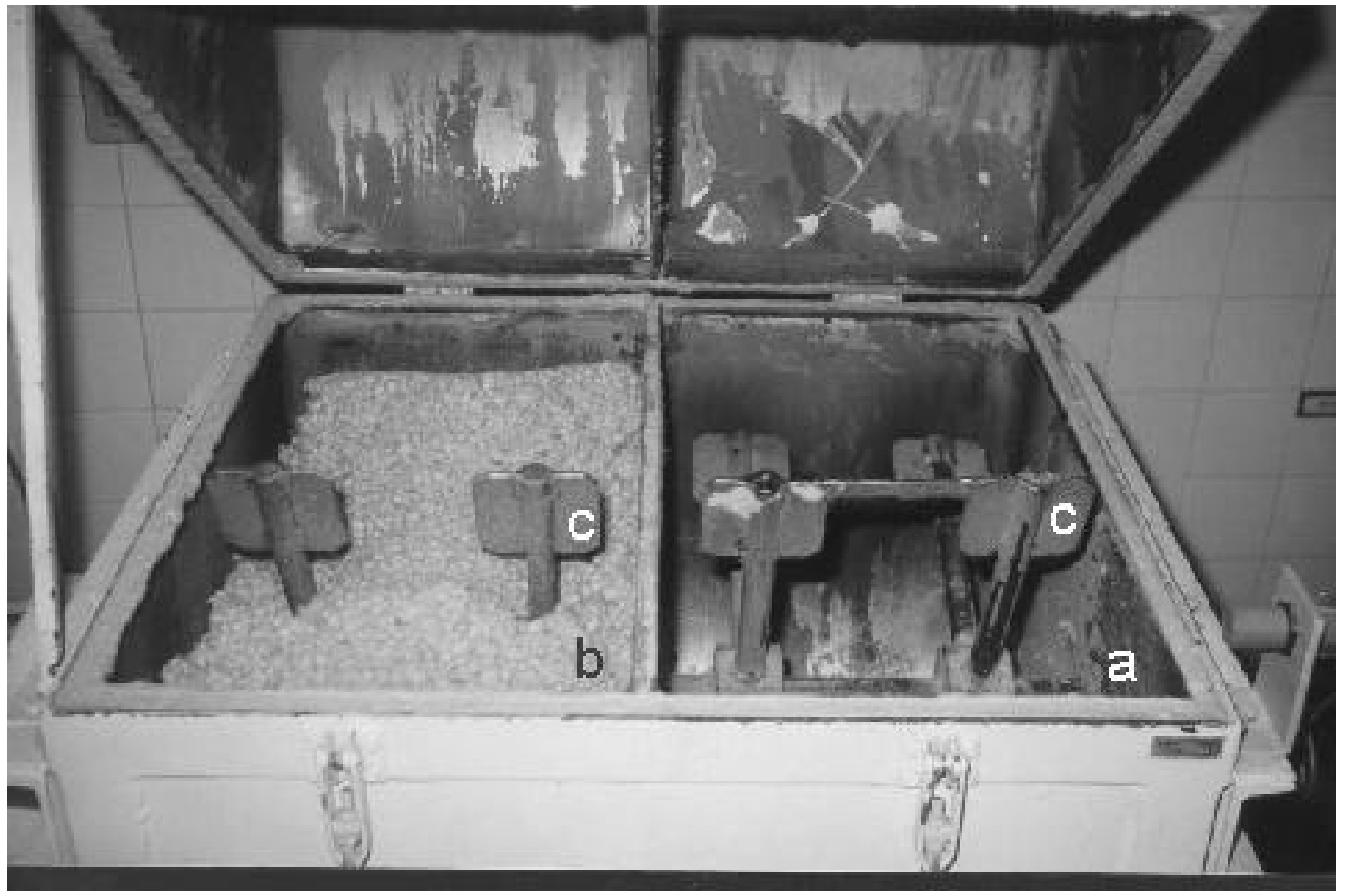

FIGURA 3. Encoladeira de laboratório aberta, mostrando o compartimento para encolagem (a) e o compartimento para desagregação de grumos (b). Ambos os compartimentos, dotados de pás para movimentação do material (c).

As fibras foram depositadas no compartimento da direita, destinado à encolagem. Após o seu fechamento e com o movimento rotativo das pás, iniciouse a pulverização da cola pronta, com uma pistola de pulverização à ar comprimido. Após o término da pulverização, as fibras encoladas foram transferidas para o compartimento da esquerda, dotado de uma peneira com malha de $12,7 \mathrm{~mm}$ na sua parte inferior. O movimento rotativo das pás contra a peneira possibilitou a desagregação dos grumos de fibras com resina.

Foram coletadas as fibras encoladas que passaram pela peneira e pesadas até que a massa permitisse atingir a densidade desejada em função do tratamento. 


\subsubsection{Formação do colchão de fibras}

O colchão de fibras foi formado em uma formadora de laboratório, que compreende uma caixa sem fundo com as dimensões da base de $43 \times 43 \mathrm{~cm}$, com tampa introduzível. A formadora do colchão foi apoiada sobre uma chapa de alumínio e as fibras distribuídas uniforme e manualmente no seu interior (Figura 4). Após a deposição das fibras, o colchão foi compactado aplicando-se uma carga de aproximadamente $700 \mathrm{~N}$ sobre a tampa da formadora.

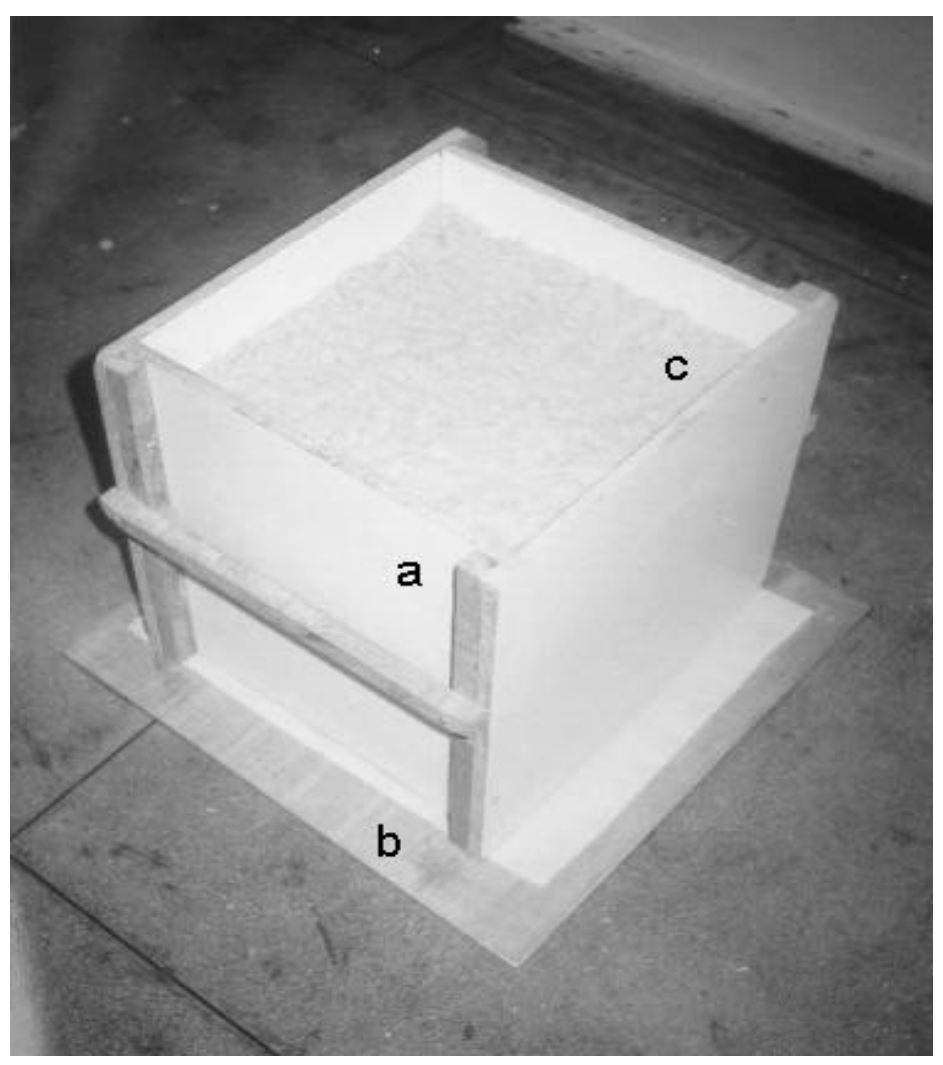

FIGURA 4. Formadora laboratorial do colchão de fibras (a), sobre chapa metálica (b), preenchida com fibras encoladas (c).

\subsubsection{Ciclo de pré-prensagem}

Foi realizada uma pré-prensagem, sem transferência de calor, para reduzir o volume do colchão de fibras durante a prensagem. $O$ ciclo foi de $5 \mathrm{~s}$, para atingir a 
pressão de 1,14 MPa, mantida por $14 \mathrm{~s} \mathrm{e,} \mathrm{por} \mathrm{fim,} \mathrm{o} \mathrm{alívio} \mathrm{total} \mathrm{da} \mathrm{pressão} \mathrm{em} 5 \mathrm{~s}$ (Figura 5).

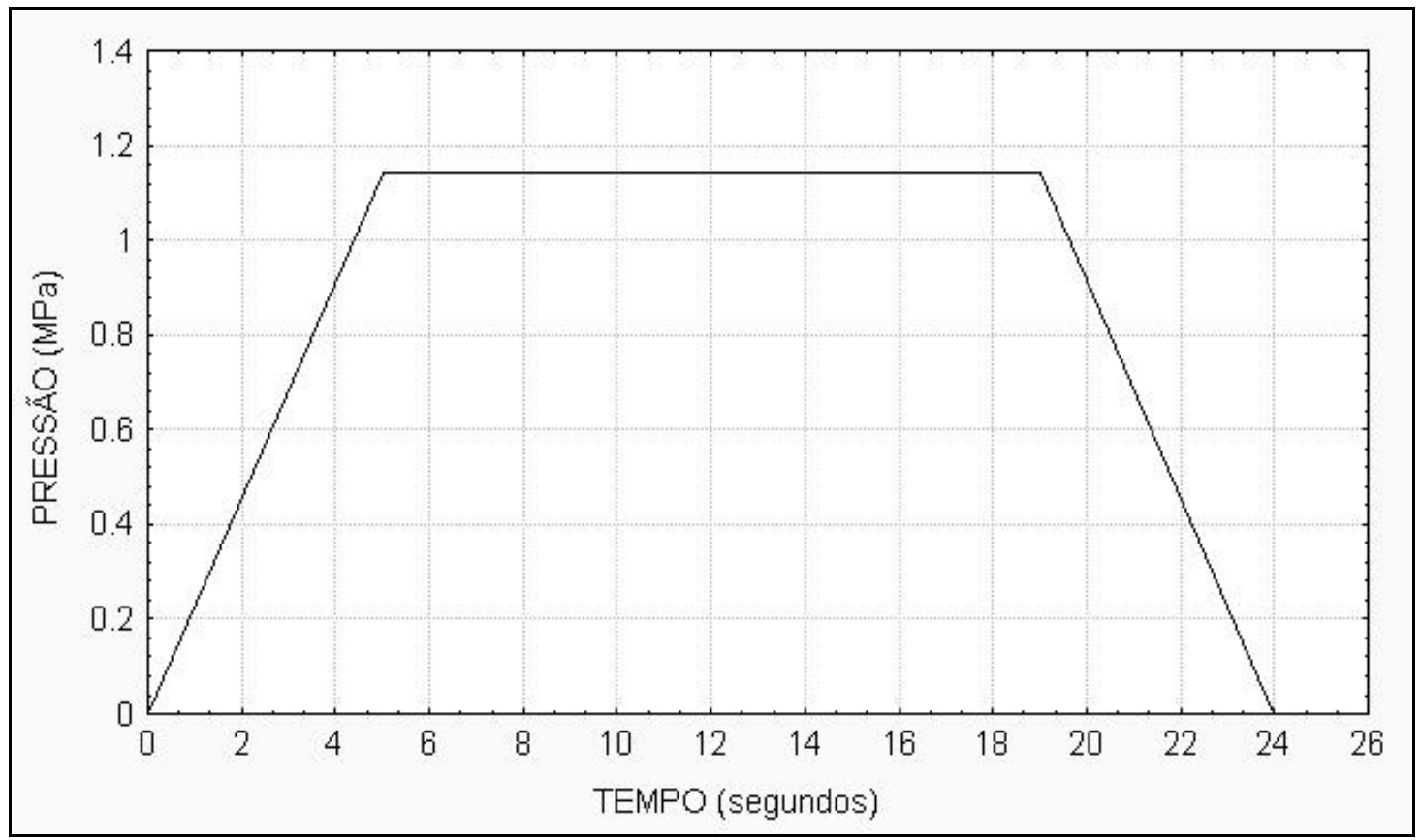

FIGURA 5. Ciclo de pré-prensagem utilizado no colchão de fibras.

O colchão de fibras, entre as chapas metálicas, isoladas termicamente, dos pratos superior e inferior da prensa, por placas de aglomerado é mostrado na Figura 6. 


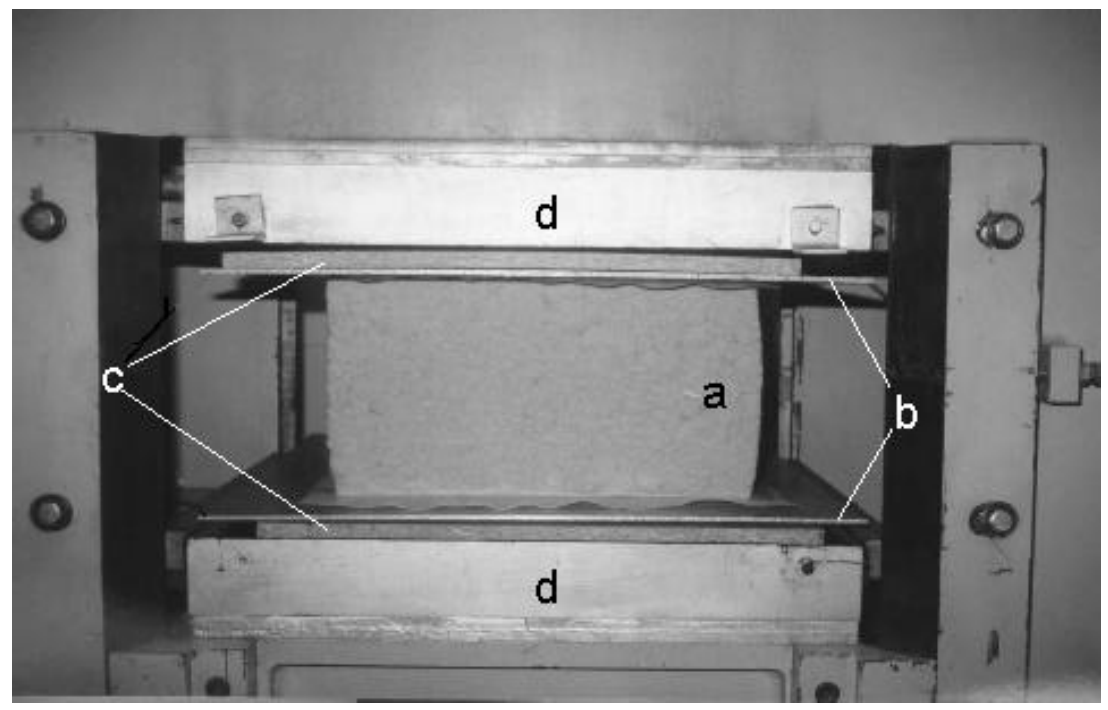

FIGURA 6. Aspecto da pré-prensagem: colchão de fibras (a), chapas metálicas (b), pratos da prensa (d) e chapas de aglomerado (c).

\subsubsection{Ciclo de prensagem}

Foi utilizada uma prensa hidráulica de laboratório, marca Sirma, dotada de aquecimento elétrico e independente dos pratos e com ciclo de prensagem controlado por CNC, possibilitando a repetição do ciclo e manutenção da temperatura dos pratos em $195^{\circ} \mathrm{C}$.

O ciclo de prensagem do colchão de fibras, necessário para a cura da resina e consolidação do painel foi o mesmo para todos os tratamentos. Foram estabelecidas 9 fases: (i) $5 \mathrm{~s}$ para atingir 2,96 MPa de pressão, (ii) manutenção por $20 \mathrm{~s}$, (iii) redução para $1,10 \mathrm{MPa}$ em $5 \mathrm{~s}$, (iv) manutenção por $5 \mathrm{~s}$, (v) queda de pressão para $0,44 \mathrm{MPa}$ em $70 \mathrm{~s}$, (vi) manutenção por $5 \mathrm{~s}$, (vii) leve aumento para 0,65 MPa em $5 \mathrm{~s}$, (viii) redução na pressão para 0,29 MPa em $10 \mathrm{~s}$ e (ix) alívio total da pressão em 117 s (Figura 7). 


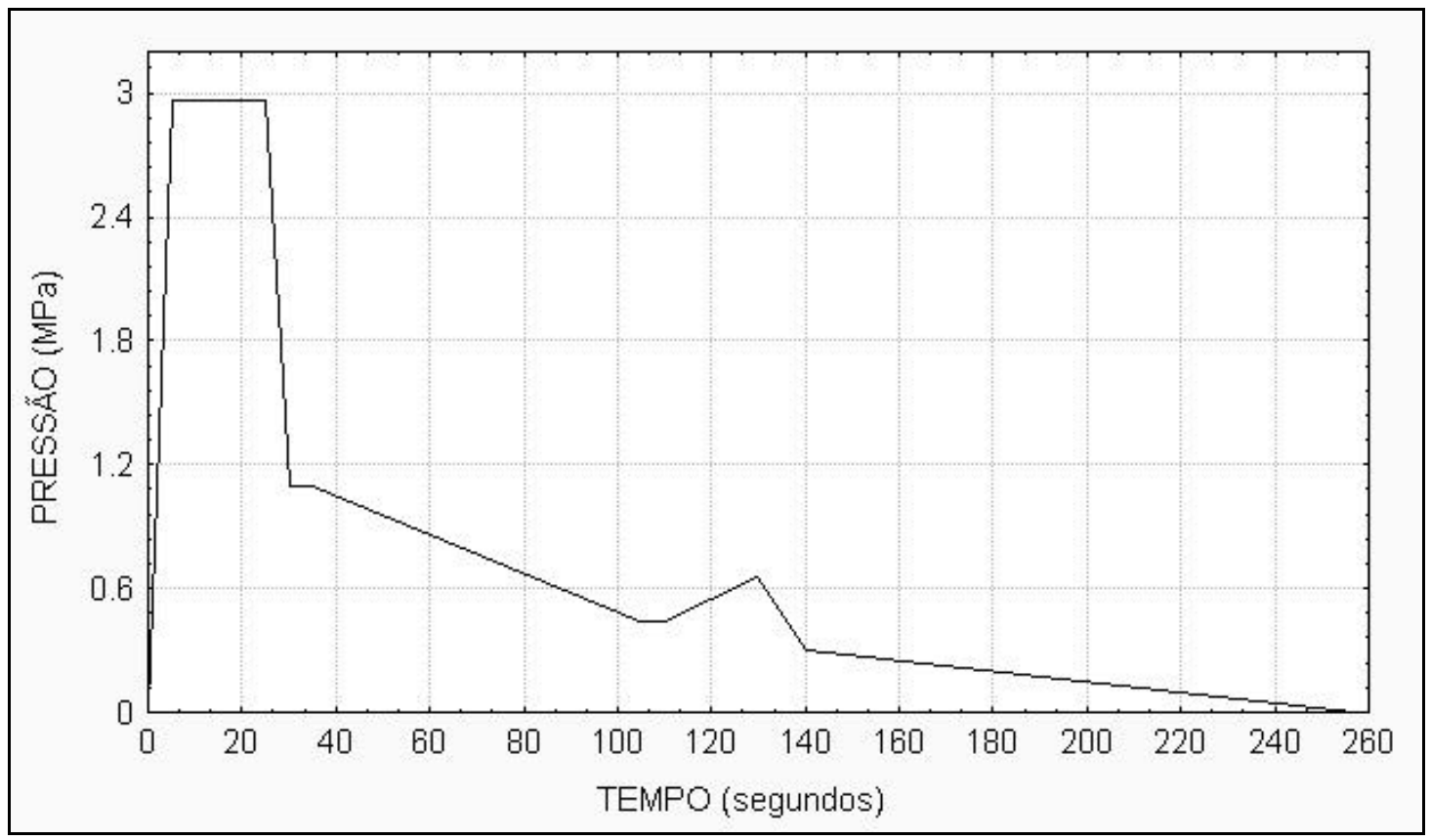

FIGURA 7. Ciclo de prensagem utilizado na confecção dos painéis MDF.

A espessura mínima e a densidade dos painéis foram asseguradas por 2 bitoladores de $16 \mathrm{~mm}$ de espessura (Figura 8a).

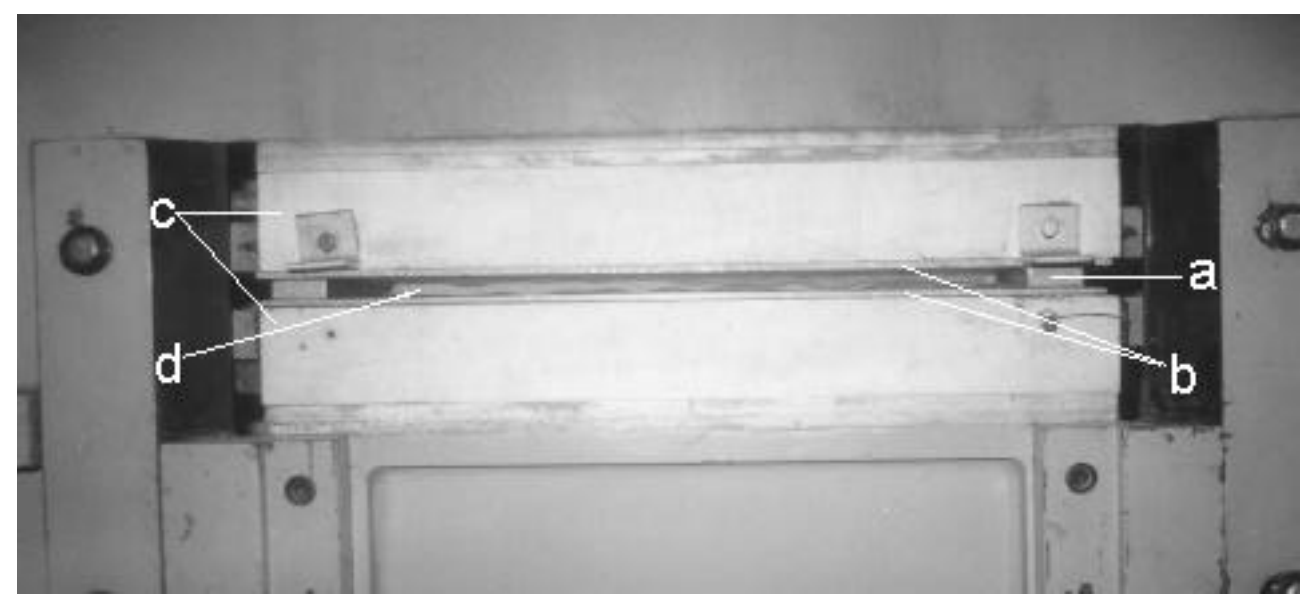

FIGURA 8. Estrutura utilizada para prensagem dos painéis MDF: bitoladores (a), chapas metálicas (b), pratos da prensa (c) e painel prensado (d). 


\subsubsection{Retirada e condicionamento dos corpos-de-prova}

Dos painéis MDF, resfriados à temperatura ambiente, foram retirados corpos-de-prova para os diferentes ensaios, conforme mostra a Figura 9.

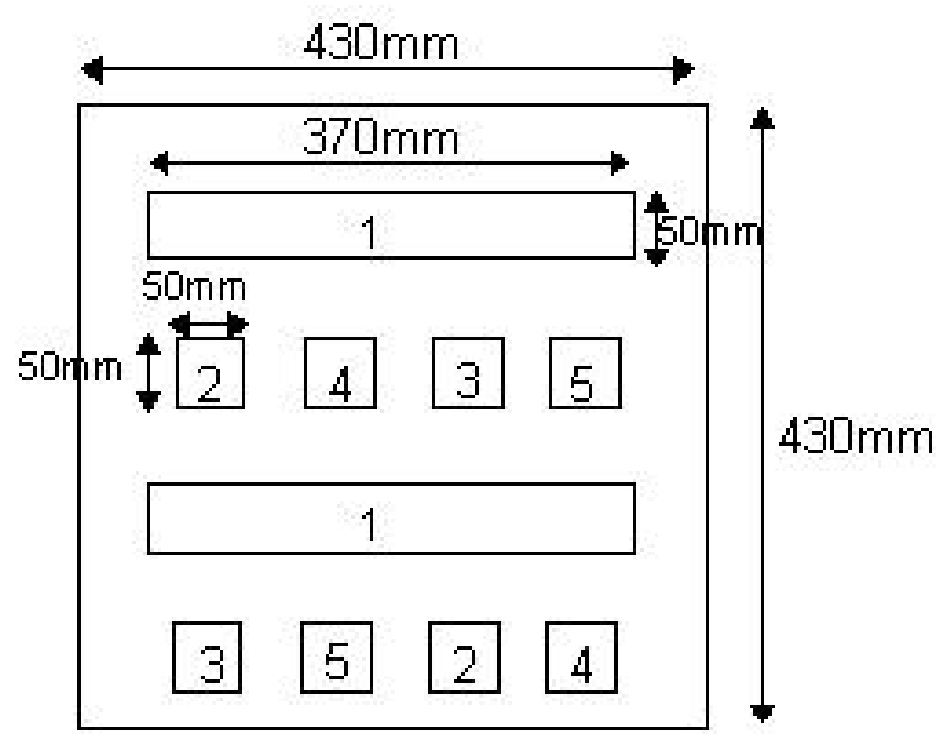

FIGURA 9. Forma de retirada dos corpos-de-prova: 1 flexão estática, 2 adesão interna, 3 inchamento em espessura e absorção de água, 4 densidade e 5 perfil de densidade.

Os corpos-de-prova obtidos dos painéis MDF, foram condicionados em câmara climatizada a temperatura de $20^{\circ} \mathrm{C}$ e umidade relativa de $65 \%$ até atingirem peso constante e posteriormente destinados a realização dos ensaios previstos.

\subsubsection{Ensaio de inchamento em espessura e absorção de água}

Os ensaios de inchamento em espessura e absorção de água após imersão em água destilada por $24 \mathrm{~h}$, foram realizados conforme a norma EN 317-1993. Os corpos-de-prova utilizados tinham as dimensões de $50 \pm 1 \mathrm{~mm}$ de aresta (Figura 10). 


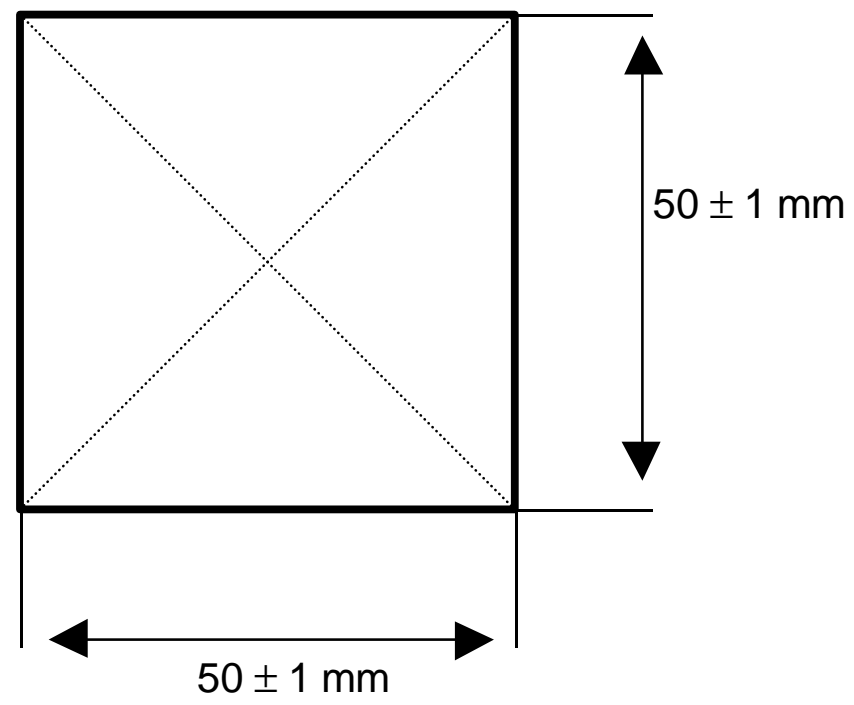

FIGURA 10. Dimensões do corpo-de-prova para os ensaios de inchamento em espessura e absorção de água.

Para o ensaios de inchamento em espessura, foi medida a espessura dos corpos-de-prova na interseção das diagonais antes e após sua imersão em água limpa, com pH $7 \pm 1$ e temperatura de $20 \pm 1{ }^{\circ} \mathrm{C}$. Os corpos-de-prova ficaram cobertos por $25 \pm 5 \mathrm{~mm}$ de água durante $24 \mathrm{~h}$. O inchamento em espessura, dado em percentagem, foi calculado através da equação 5 .

$$
\mathrm{G}_{\mathrm{t}}=\frac{\mathrm{t}_{2}-\mathrm{t}_{1}}{\mathrm{t}_{1}} * 100
$$

Onde: $\mathrm{G}_{\mathrm{t}}$ : inchamento (\%);

$\mathrm{t}_{1}$ : espessura inicial $(\mathrm{mm})$;

$\mathrm{t}_{2}$ : espessura final $(\mathrm{mm})$.

Para o ensaio de absorção de água, foi medida a massa dos mesmos corpos-de-prova, antes e após imersão em água. A absorção de água foi determinada através da equação 6 . 


$$
A_{m}=\frac{m_{2}-m_{1}}{m_{1}} * 100
$$

Onde: $A_{m}$ : absorção (\%);

$\mathrm{m}_{1}$ : massa inicial $(\mathrm{g})$;

$\mathrm{m}_{2}$ : massa final $(\mathrm{g})$.

\subsubsection{Ensaio para determinação da densidade}

A determinação da densidade dos painéis foi realizada conforme a norma EN 323-1993, com corpos-de-prova quadrados, de $50 \pm 1 \mathrm{~mm}$ de aresta (Figura 11). Os corpos-de-prova foram condicionados até atingirem peso constante, em câmara climatizada à $20^{\circ} \mathrm{C}$ e $65 \%$ de umidade relativa. Posteriormente, determinou-se sua espessura no ponto de interseção das diagonais (precisão de $0,05 \mathrm{~mm}$ ) e massa, juntamente com 2 medidas paralelas às bordas, ortogonais, que passem por seu centro, (precisão de 0,1 mm).

A densidade foi determinada segundo a equação 7 .

$$
\rho=\frac{m}{b_{1}{ }^{*} b_{2}{ }^{*} t} * 10^{6}
$$

Onde: $\rho=$ densidade $\left(\mathrm{kg} / \mathrm{m}^{3}\right)$;

$\mathrm{m}=$ massa $(\mathrm{g})$;

b1 e b2= medidas ortogonais dos lados $(\mathrm{mm})$;

$\mathrm{t}=$ espessura $(\mathrm{mm})$. 


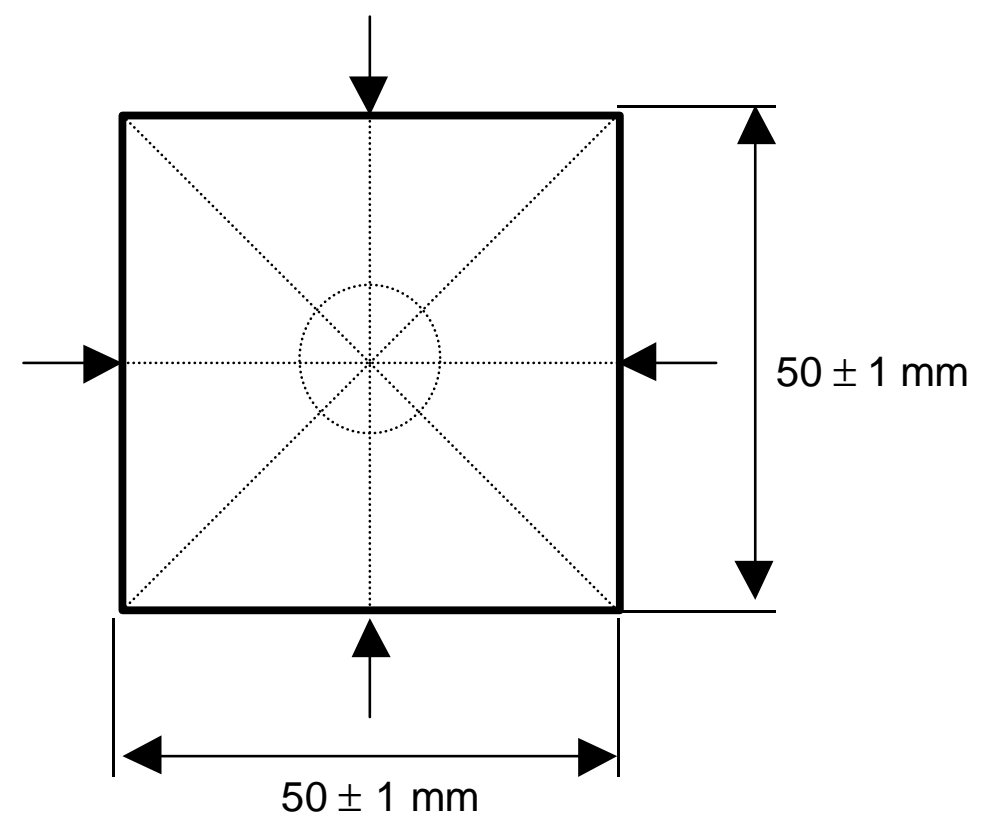

FIGURA 11. Dimensões do corpo-de-prova para o ensaio de densidade.

\subsubsection{Ensaios para determinação do módulo de ruptura e de elasticidade}

Os ensaios de módulo de ruptura e de elasticidade na flexão estática seguiram a norma EN 310-1993. Esta norma prescreve corpos-de-prova com comprimento 20 vezes a sua espessura nominal adicionado de $50 \mathrm{~mm}$ sendo, neste caso, $370 \mathrm{~mm}$ de comprimento e $50 \pm 1 \mathrm{~mm}$ de largura.

Mede-se a largura na metade do comprimento e a espessura na interseção das diagonais. O corpo-de-prova é apoiado em suportes com distância entre si de 20x a espessura nominal, neste caso de $320 \mathrm{~mm}$. O incremento de carga utilizado foi ajustado para atingir a carga máxima em $60 \pm 30 \mathrm{~s}$, aplicado no centro do corpo-de-prova (Figura 12).

O módulo de elasticidade (MOE) foi calculado, utilizando-se a região linear da curva de leituras de carga $X$ deformação, através da equação 8. 


$$
\operatorname{MOE}=\frac{\mathrm{l}_{1}^{3 *}\left(\mathrm{~F}_{2}-\mathrm{F}_{1}\right)}{4 * \mathrm{~b}^{*} \mathrm{t}^{3 *}\left(\mathrm{a}_{2}-\mathrm{a}_{1}\right)}
$$

Onde: MOE: módulo de elasticidade $(\mathrm{Pa})$

a1 e a2: deflexão na metade do vão (m);

11: distância entre os suportes $(\mathrm{m})$;

b: largura do corpo-de-prova (m);

t: espessura do corpo-de-prova $(m)$;

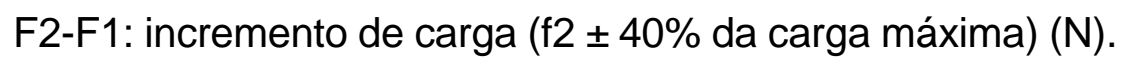

Para o cálculo do módulo de ruptura (MOR), utilizou-se do mesmo teste de flexão usado para o cálculo do MOE porém, para este ensaio, é considerada a carga máxima. O módulo de ruptura foi calculado a partir da equação 9.

$$
\operatorname{MOR}=\frac{3{ }^{*} F_{\max }{ }^{*} I_{1}}{2^{*} b^{*} t^{2}}
$$

Onde: MOR: módulo de ruptura $(\mathrm{Pa})$;

11: distância entre os suportes $(\mathrm{m})$;

b: largura do corpo-de-prova (m);

t: espessura do corpo-de-prova $(m)$;

$\mathrm{F}_{\text {max }}$ : carga na ruptura $(\mathrm{N})$.

Os ensaios de módulo de elasticidade e de ruptura foram realizados em uma máquina universal de ensaios eletromecânica, marca EMIC, dotada de sistema computadorizado para controle das variáveis do ensaio e coleta dos dados de carga e deslocamento. 


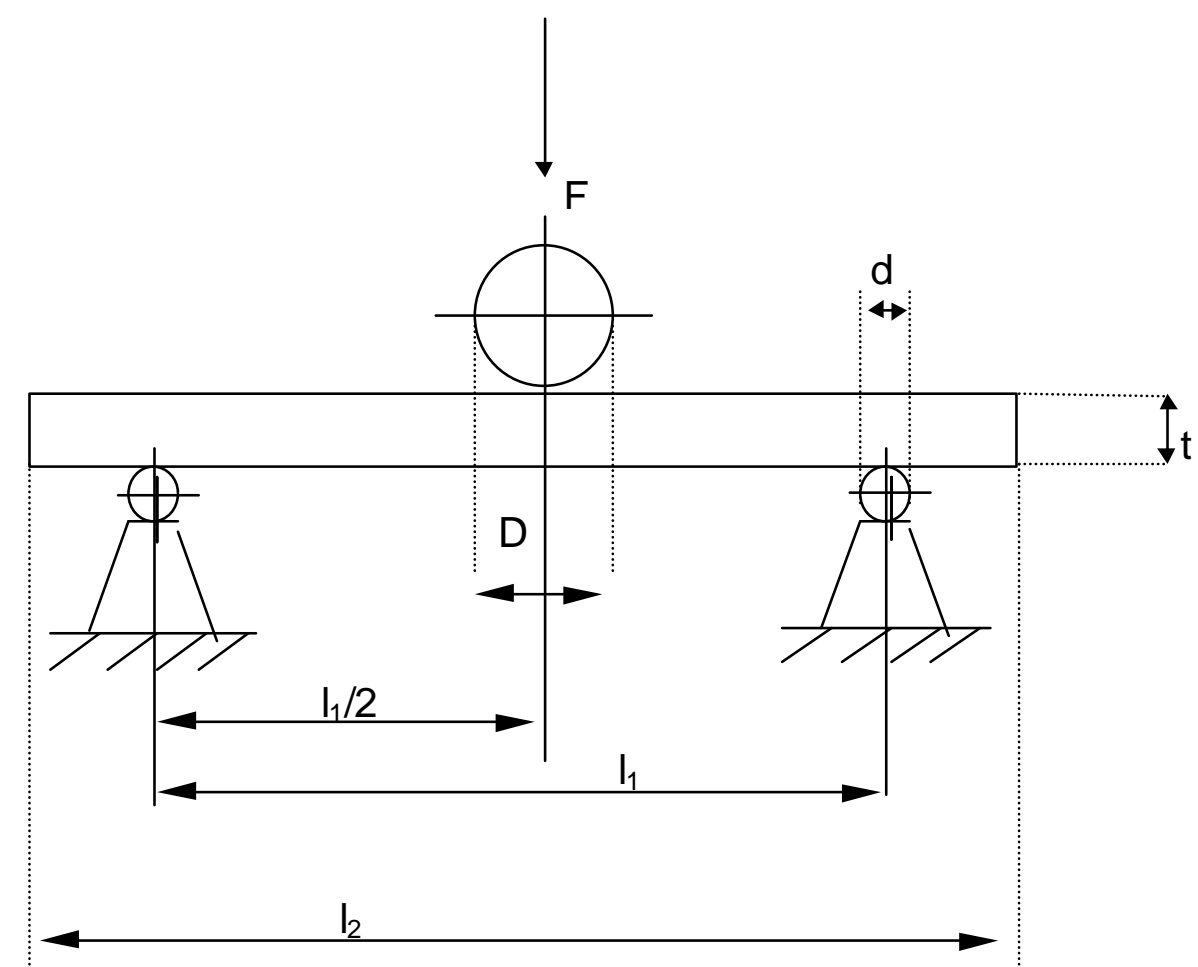

FIGURA 12. Representação gráfica do ensaio de flexão estática, sendo t espessura do corpo-de-prova, $\mathbf{I}_{2}=$ comprimento do corpo-deprova, $\mathbf{l}_{\mathbf{1}}=$ distância entre os apoios, $\mathbf{D}=$ diâmetro do cutelo, $\mathbf{d}=$ diâmetro do suporte, $\mathbf{F}=$ força aplicada.

\subsubsection{Ensaio para determinação da adesão interna}

O ensaio de adesão interna ou de tração perpendicular ao plano do painel foi realizado segundo a norma EN 319-1993, que prescreve o uso de corpos-deprova quadrados, com $50 \pm 1 \mathrm{~mm}$ de aresta. Nas 2 faces do corpo-de-prova são colados suportes de metal, tracionados posteriormente em direções opostas, de forma que o mesmo se rompa (Figura 13).

A adesão interna foi calculada segundo a equação 10. 


$$
\mathrm{Al}=\frac{\mathrm{F}_{\max }}{\mathrm{a}^{*} \mathrm{~b}}
$$

Onde: $\mathrm{Al}$ : adesão interna $(\mathrm{Pa})$;

$\mathrm{F}_{\max }$ : carga máxima $(\mathrm{N})$;

a: comprimento do corpo-de-prova $(\mathrm{m})$;

b: largura do corpo-de-prova $(m)$.

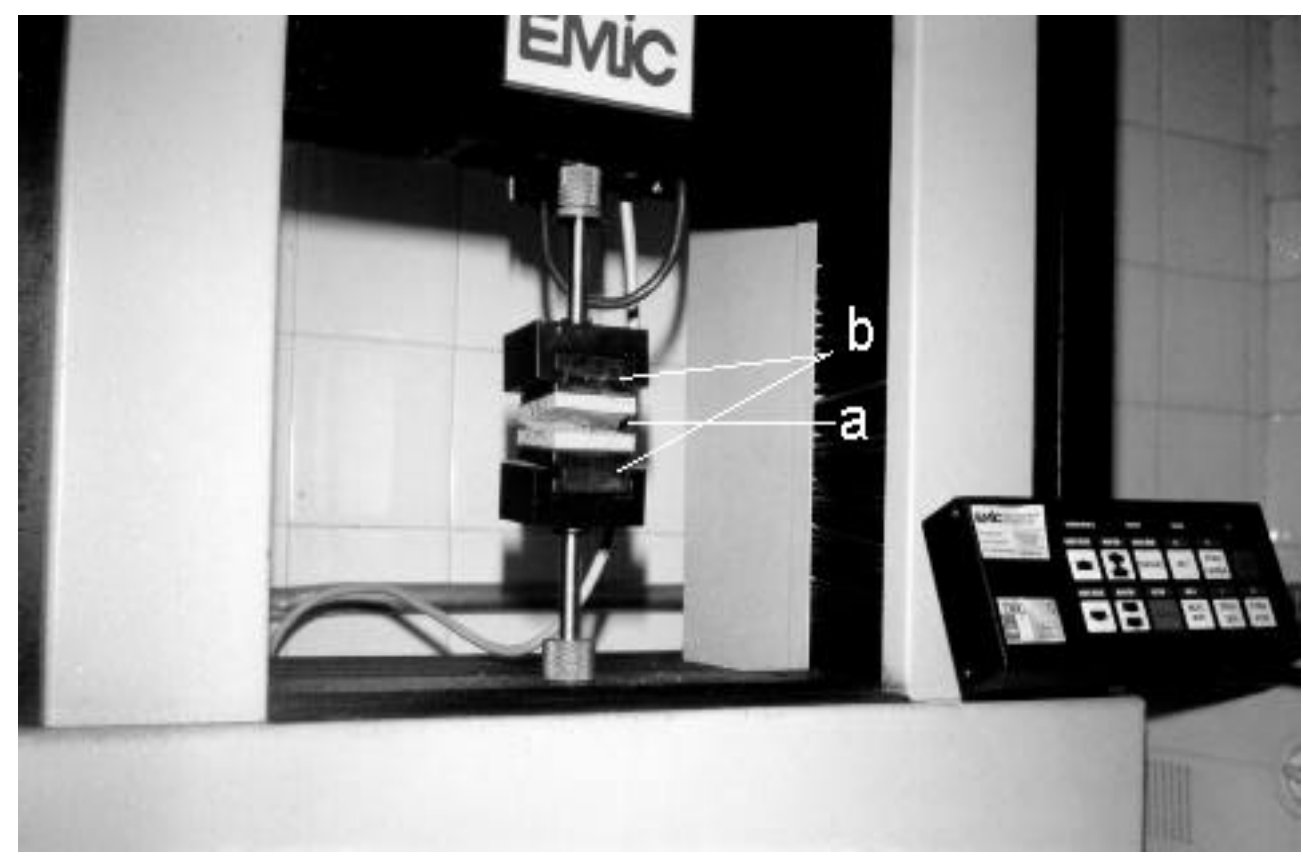

FIGURA 13. Ensaio de adesão interna: corpo-de-prova (a) e suportes de metal (b).

A mesma máquina universal de ensaios utilizada para os ensaios de flexão foi utilizada para os ensaios de adesão interna.

\subsubsection{Determinação do perfil de densidade}

O perfil de densidade na espessura dos corpos-de-prova dos painéis experimentais foi obtido a partir de corpos-de-prova quadrados, com $50 \pm 1 \mathrm{~mm}$ de aresta. 
Foi utilizado um densitômetro, marca Carl Schenk, cujo princípio é a atenuação de radiação gama. Este equipamento é dotado de um sistema denominado DENSEROB EWS, que converte os valores de radiação gama em densidade a cada ponto e informa os valores de densidade máxima, mínima, média, da camada externa e da camada interna. O equipamento permite a análise de lotes de 10 corpos-de-prova de cada vez.

O intervalo entre duas medidas de densidade ao longo do perfil foi de $0,1 \mathrm{~mm}$ e a duração da leitura de $1 \mathrm{~s}$. Os primeiros $3 \mathrm{~mm}$ de espessura em cada face do painel foram considerados como sendo as camadas externas.

\subsection{Análise estatística}

Para descrever as dimensões das fibras foram apresentados histogramas de freqüência, analisando a dispersão dos dados. Foram comparados o comprimento das fibras antes e após o desfibramento.

Após a apresentação dos dados obtidos nos ensaios de módulo de elasticidade e de ruptura, inchamento em espessura, absorção de água e adesão interna; foram determinadas as correlações entre estas variáveis e os fatores teor de resina em percentagem e absoluto, e densidade. Também foram calculadas as correlações entre variáveis dependentes.

Foram determinadas as correlações entre as variáveis analisadas e os dados de densidade média, máxima, mínima, da camada externa e interna, obtidos através da análise do perfil de densidade. Também foram calculadas as correlações entre as densidades ao longo do perfil.

Todas as correlações foram determinadas através do coeficiente de correlação de Pearson (r). 
Em seguida, através de uma ANOVA para um conjunto de dados desbalanceados, foram analisadas, para as 5 variáveis consideradas, as interações entre densidade e teor de resina.

Antes das análises de regressão, foi verificada a normalidade dos dados. Nenhuma variável necessitou de transformação para satisfazer esta exigência.

As análises de regressão foram desenvolvidas para as variáveis dependentes em função da densidade e do teor de resina relativo. O objetivo desta análise foi propor modelos que permitissem a simulação de diferentes densidades e teores de resina em percentagem.

Como o teor de resina é expresso usualmente em relação a massa de fibras, uma redução no teor de resina em percentagem não significa necessariamente uma redução no teor de resina absoluto. Dessa forma, também foram realizadas análises de regressão em função da densidade e do teor absoluto de resina, expresso em $\mathrm{kg} / \mathrm{m}^{3}$.

O procedimento utilizado para estas análises de regressão foi o Stepwise. A vantagem deste procedimento é incluir no modelo apenas as variáveis puras e/ou transformadas que são significativas para o aumento da sua precisão.

Este procedimento inicia com a construção de uma tabela com os coeficientes de correlação linear de Pearson das variáveis independentes e dependentes. A variável independente de maior correlação com a variável dependente é a primeira a entrar no modelo. Em seguida é realizado o teste $\mathrm{F}$ para comprovar a significância desta variável, sendo que permanecem no modelo variáveis com $\alpha \leq 15 \%$. 
Após a entrada da primeira variável, a tabela de correlações é recalculada tendo como base a variável escolhida. A segunda variável, de maior correlação com a variável dependente na nova tabela de correlações é selecionada.

Agora são realizados 2 testes $F$, um para comprovar ou rejeitar a significância da nova variável e outro para reavaliar a significância da primeira variável em conjunto com a segunda, ambos os testes efetuados com probabilidade de erro $\alpha=15 \%$.

A matriz de correlações é recalculada e selecionada e testada outra variável, e assim por diante até que a variável independente de maior correlação com a variável dependente não seja aceita pelo teste $F$ para ser incluída no modelo, àuma probabilidade de erro. Schneider (1997) e Draper \& Smith (1966) apresentam maiores detalhes e exemplos práticos.

Os modelos obtidos foram avaliados através da análise do coeficiente de determinação $\left(r^{2}\right)$, do valor do teste $F$, do erro padrão da estimativa (Syx) e da distribuição gráfica dos resíduos.

Sendo os dois fatores analisados, densidade e teor de resina, quantitativos, os modelos obtidos geravam superfícies de resposta. Para facilitar a visualização, essas superfícies foram projetadas num plano e traçadas isolinhas, como exemplificado na Figura 14.

Os modelos obtidos são válidos apenas para a faixa onde foram obtidos valores experimentais, não sendo recomendáveis extrapolações. 


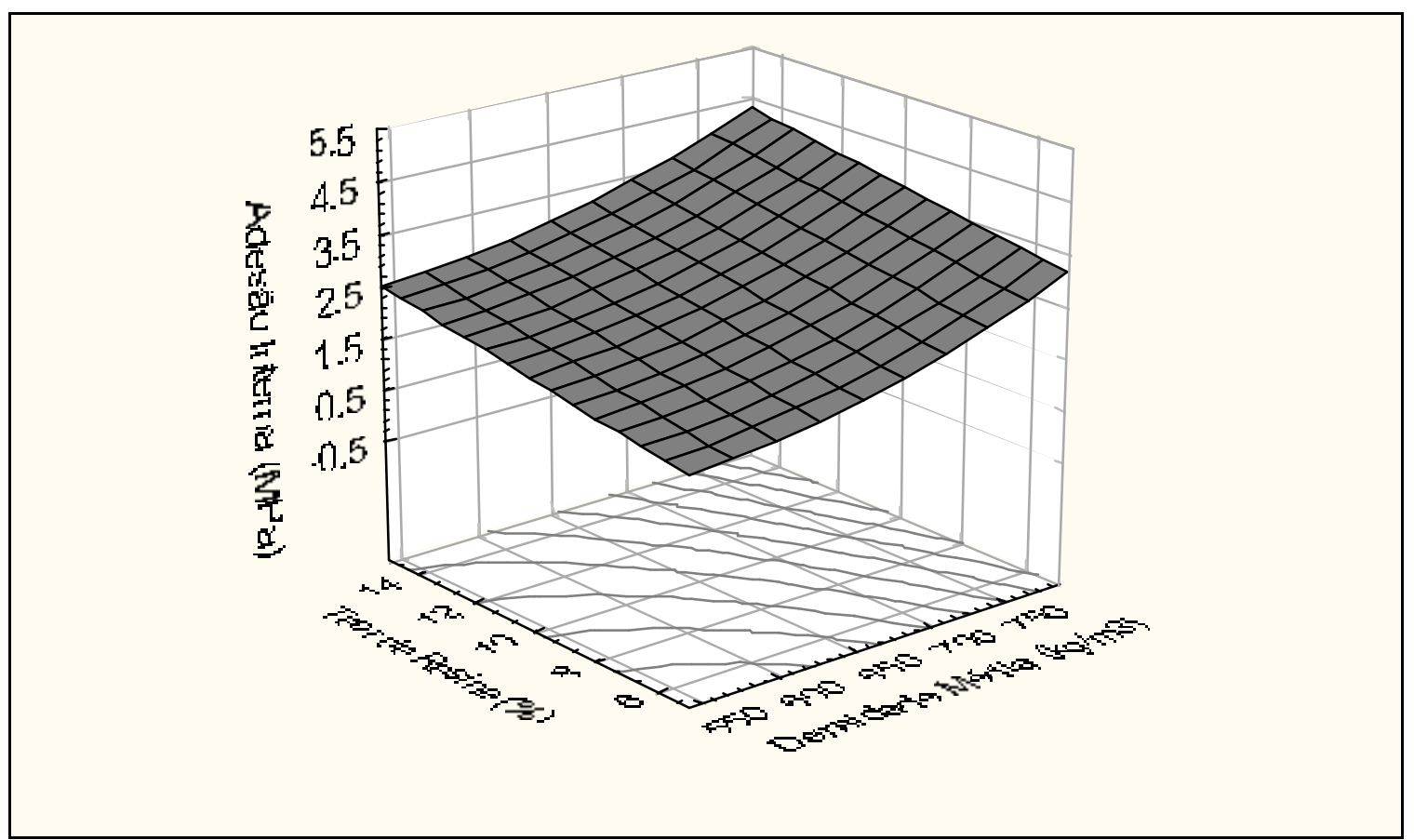

FIGURA 14. Exemplo de uma superfície de resposta obtida e sua projeção no plano, na forma de isolinhas. 


\section{RESULTADOS E DISCUSSÃo}

\subsection{Dimensões das fibras}

\subsubsection{Comprimento das fibras}

Os resultados das medições de 300 fibras inteiras, provenientes da maceração de cavacos e 750 fibras coletadas após o desfibramento termomecânico, distribuídos em classes de comprimento são apresentados na Tabela 5 e Figura 15.

TABELA 5. Distribuição das freqüências absoluta e relativa do comprimento das fibras inteiras e desfibradas termomecanicamente.

\begin{tabular}{crrrr}
\hline Classes de & \multicolumn{2}{c}{ Freq. Inteiras } & \multicolumn{2}{c}{ Freq. Desfibradas } \\
Comprimento $(\mathrm{mm})$ & Absoluta & Relativa & Absoluta & Relativa \\
$0.0-1.0$ & - & - & 80 & 10,7 \\
$1.0-2.0$ & - & - & 157 & 20,9 \\
$2.0-3.0$ & 4 & 1,3 & 224 & 29,9 \\
$3.0-4.0$ & 54 & 18,0 & 141 & 18,8 \\
$4.0-5.0$ & 120 & 40,0 & 97 & 12,9 \\
$5.0-6.0$ & 91 & 30,3 & 40 & 5,3 \\
$6.0-7.0$ & 30 & 10,0 & 8 & 1,1 \\
$7.0-8.0$ & 1 & 0,3 & 3 & 0,4 \\
Total & 300 & 100 & 750 & 100 \\
\hline
\end{tabular}


Quando analisa-se o comprimento das fibras observa-se que, para as inteiras, a maior freqüência encontra-se na classe de 4 a $5 \mathrm{~mm}$, com $40 \%$ das fibras, enquanto que nas desfibradas está na classe de 2 a 3mm, com 29,9\% das fibras. A redução no comprimento médio das fibras indica que ocorreu a sua quebra durante o processo de desfibramento termomecânico.

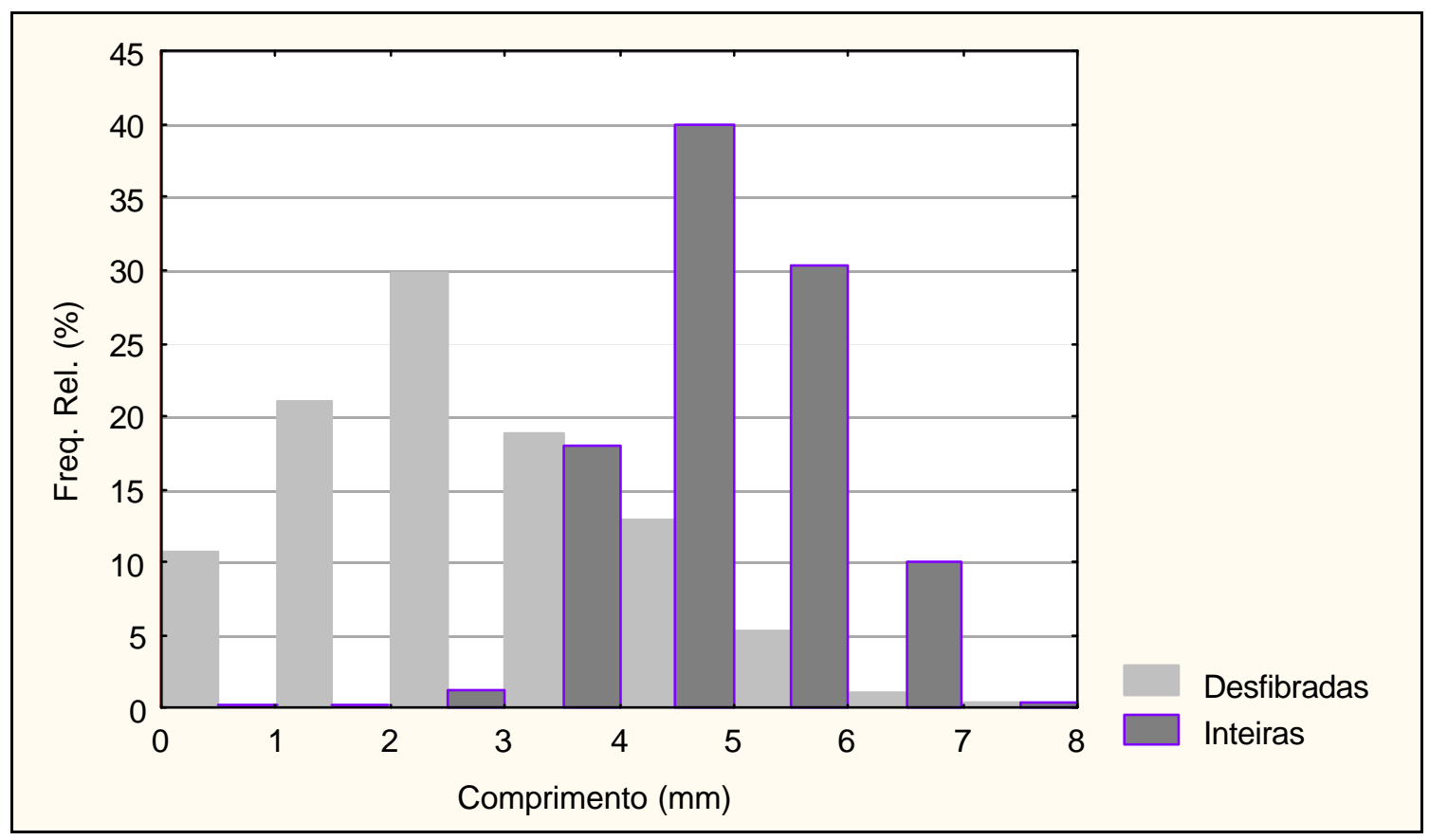

FIGURA 15. Distribuição da freqüência relativa (\%) do comprimento das fibras inteiras e desfibradas termomecanicamente.

A estatística básica do comprimento das fibras inteiras e desfibradas (Tabela 6), indica uma redução no comprimento médio e aumento da variabilidade com o desfibramento. O aumento da fração de "finos" é positivo na fabricação de painéis MDF, auxiliando na elevação dos valores do módulo de ruptura e de elasticidade, ao permitir uma maior acomodação das fibras por ocasião da formação do colchão (Myers, 1983), embora contribua de forma negativa com o aumento da movimentação linear e do consumo de resina (Park et al., 1998). 
TABELA 6. Estatísticas básicas do comprimento das fibras obtidas termomecânicamente e inteiras.

\begin{tabular}{ccc}
\hline Estatística & Fibras Inteiras & Fibras Desfibradas \\
\hline Número de Medidas & 300 & 750 \\
\hline Média $(\mathrm{mm})$ & 4,81 & 2,74 \\
\hline Mínimo $(\mathrm{mm})$ & 2,71 & 0,15 \\
\hline Máximo $(\mathrm{mm})$ & 7,01 & 7,10 \\
\hline Coef. Variação $(\%)$ & 18,9 & 51,1 \\
\hline
\end{tabular}

O coeficiente de variação demonstra que a quebra das fibras aumentou a variabilidade do seu comprimento. Pode-se observar, através da distribuição de freqüência (Tabela 5), que algumas fibras $(0,4 \%)$ se apresentaram com comprimento semelhante ao das fibras inteiras, mesmo após o desfibramento termomecânico.

Os valores de comprimento das fibras inteiras obtidos neste trabalho são coerentes com os observados por Klock (1989) para as mesmas espécies, com material coletado na mesma região.

\subsubsection{Largura e espessura da parede das fibras}

A distribuição da freqüência da largura das fibras obtidas termomecanicamente é apresentada na Tabela 7 e Figura 16.

TABELA 7. Distribuição de freqüência absoluta e relativa da largura das fibras desfibradas termomecanicamente.

\begin{tabular}{ccc}
\hline Classes de Largura & \multicolumn{2}{c}{ Freqüência } \\
$(\mu \mathrm{m})$ & Absoluta & Relativa \\
\hline $20-30$ & 20 & 6,7 \\
\hline $30-40$ & 60 & 20,0 \\
\hline $40-50$ & 115 & 38,3 \\
\hline $50-60$ & 74 & 24,7 \\
\hline $60-70$ & 27 & 9,0 \\
\hline $70-80$ & 4 & 1,3 \\
\hline
\end{tabular}


Observa-se uma maior freqüência de fibras com largura de 40 a $50 \mu \mathrm{m}$, em percentual de $38,3 \%$.

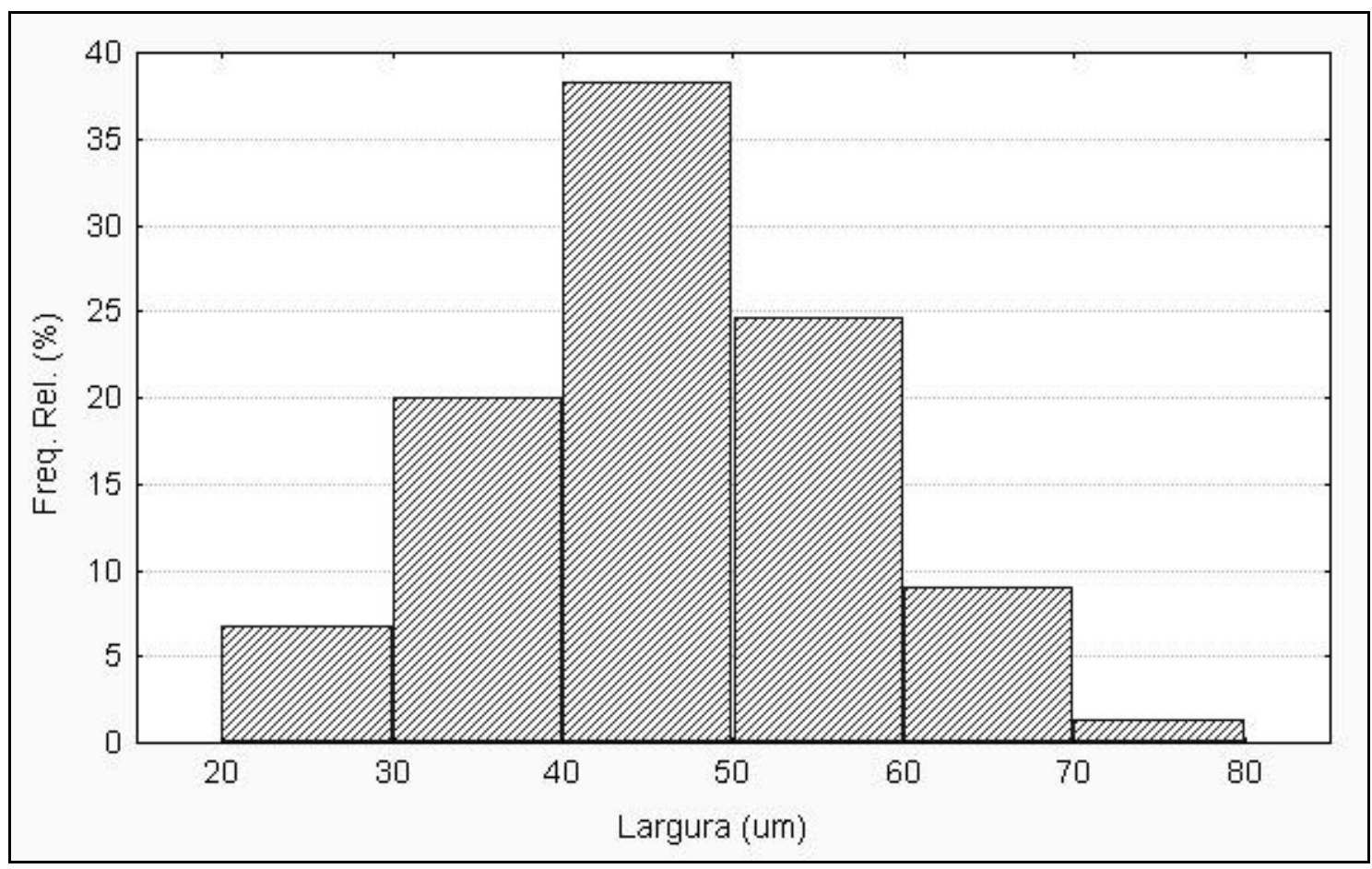

FIGURA 16. Distribuição da freqüência da largura das fibras obtidas termomecânicamente.

A distribuição da freqüência da espessura da parede das fibras é apresentada na Tabela 8 e Figura 17.

TABELA 8. Distribuição da freqüência absoluta e relativa da espessura da parede das fibras desfibradas termomecânicamente.

\begin{tabular}{ccc}
\hline Classes de Espessura $(\mu \mathrm{m})$ & \multicolumn{2}{c}{ Freqüência } \\
& Absoluta & Relativa \\
\hline $2-4$ & 5 & 1,7 \\
\hline $4-6$ & 18 & 6,0 \\
\hline $6-8$ & 76 & 25,3 \\
\hline $8-10$ & 59 & 19,7 \\
\hline $10-12$ & 62 & 20,7 \\
\hline $12-14$ & 32 & 10,7 \\
\hline $14-16$ & 36 & 12,0 \\
\hline $16-18$ & 9 & 3,0 \\
\hline $18-20$ & 3 & 1,0 \\
\hline & &
\end{tabular}


Com base na Tabela 8 e Figura 17, pode-se afirmar que a distribuição da freqüência da espessura da parede das fibras tem seu máximo de 6 a $8 \mu \mathrm{m}$, com ampla dispersão. Esta deve-se à características da madeira das espécies, em função dos lenhos inicial e tardio dos anéis de crescimento.

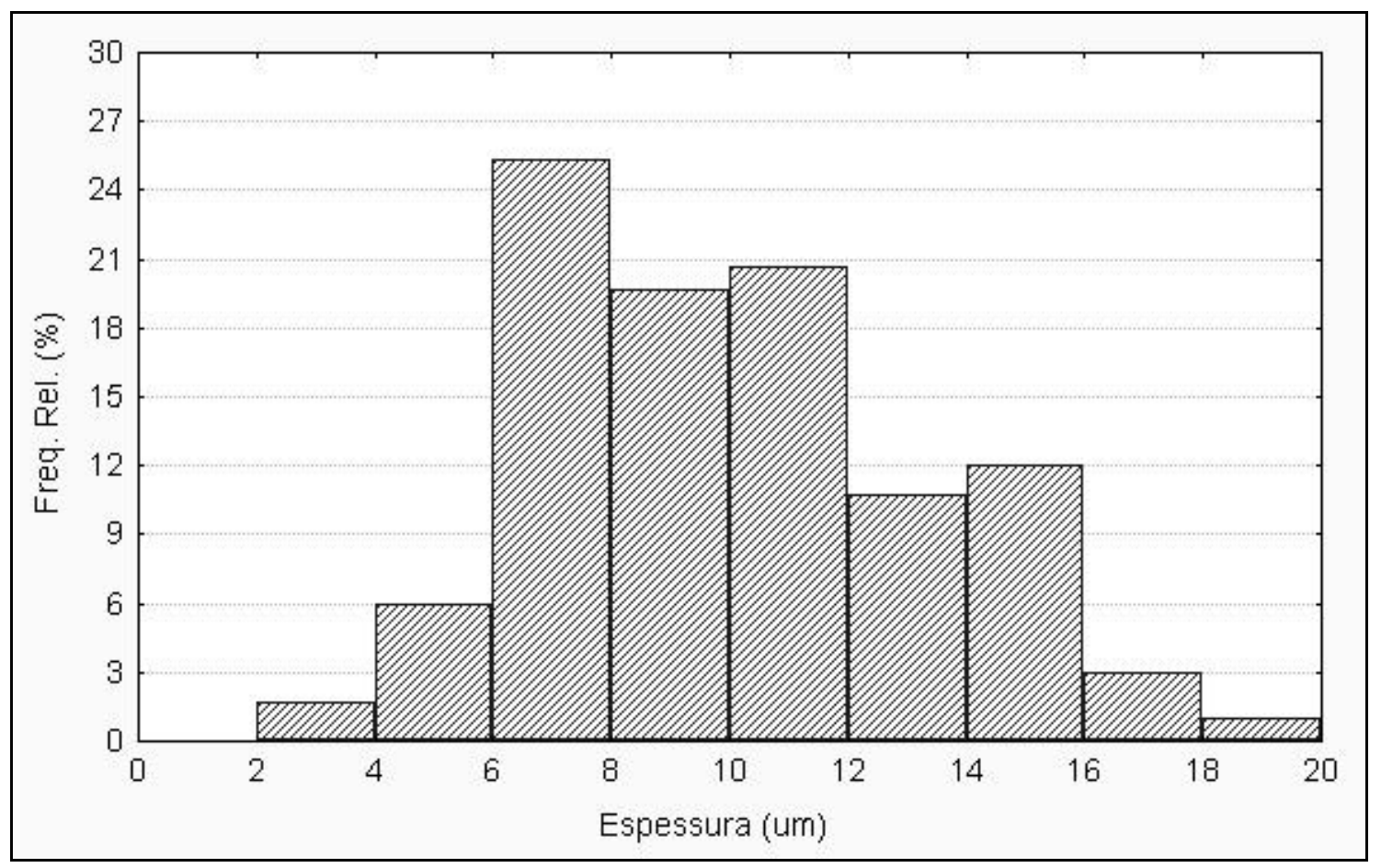

FIGURA 17. Distribuição de freqüência para espessura de parede das fibras.

A estatística básica da largura e da espessura da parede das fibras obtidas termomecânicamente é apresentada na Tabela 9.

TABELA 9. Estatística da espessura da parede e largura das fibras.

\begin{tabular}{ccc}
\hline Estatísticas & Largura & Espessura da Parede \\
Número de Medidas & 300 & 300 \\
Média $(\mu \mathrm{m})$ & 4,56 & 1,00 \\
Mínimo $(\mu \mathrm{m})$ & 2,19 & 0,31 \\
Máximo $(\mu \mathrm{m})$ & 7,97 & 1,95 \\
Coef. Variação $(\%)$ & 22,8 & 32,0 \\
\hline
\end{tabular}


A Figura 18 apresenta o aspecto geral das fibras após desfibramento termomecânico.

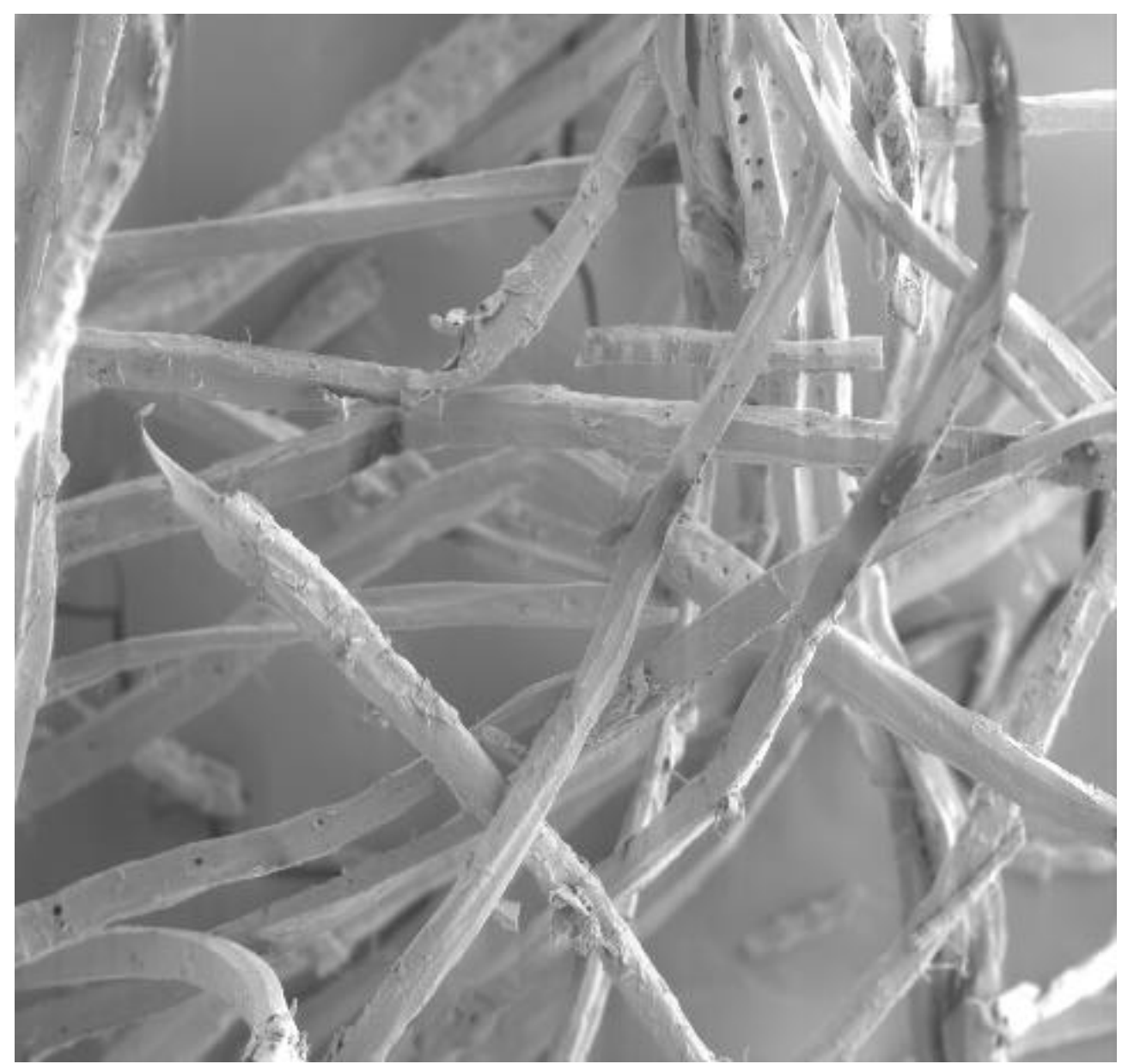

FIGURA 18. Aspecto das fibras obtidas termomecânicamente.

\subsubsection{Resultados dos ensaios físicos e mecânicos}

Os resultados, médios de duas amostras por painel, dos ensaios de adesão interna, módulo de elasticidade e de ruptura na flexão estática, inchamento em espessura e absorção de água após imersão por 24 h em água, são apresentados, ordenados por teor de resina e por densidade, na Tabela 10. 
TABELA 10. Resultados médios por painel para os ensaios de adesão interna (Al), módulo de elasticidade (MOE), módulo de ruptura (MOR), inchamento em espessura e absorção de água.

\begin{tabular}{|c|c|c|c|c|c|c|}
\hline $\begin{array}{l}\text { Resina } \\
(\%)\end{array}$ & $\begin{array}{c}\text { Densidade } \\
\left(\mathrm{kg} / \mathrm{m}^{3}\right)\end{array}$ & $\mathrm{Al}(\mathrm{MPa})$ & $\begin{array}{l}\text { MOE } \\
(\mathrm{GPa})\end{array}$ & $\begin{array}{l}\text { MOR } \\
(\mathrm{MPa})\end{array}$ & $\begin{array}{c}\text { Inchamento } \\
(\%)\end{array}$ & $\begin{array}{c}\text { Absorção } \\
(\%)\end{array}$ \\
\hline 6 & 547,2 & 0,09 & 1,77 & 10,69 & 31,63 & 61,63 \\
\hline 6 & 569,9 & 0,10 & 1,62 & 11,28 & 30,57 & 67,34 \\
\hline 6 & 573,0 & 0,12 & 1,33 & 10,66 & 23,42 & 56,09 \\
\hline 6 & 588,9 & 0,10 & 1,35 & 8,72 & 31,94 & 74,15 \\
\hline 6 & 611,5 & 0,15 & 1,56 & 13,10 & 29,15 & 58,69 \\
\hline 6 & 646,9 & 0,09 & 1,99 & 13,07 & 25,16 & 57,88 \\
\hline 6 & 657,0 & 0,11 & 1,74 & 11,01 & 19,10 & 41,51 \\
\hline 6 & 664,2 & 0,11 & 2,03 & 11,81 & 25,95 & 59,83 \\
\hline 6 & 673,7 & 0,17 & 1,85 & 14,52 & 20,63 & 46,58 \\
\hline 6 & 720,7 & 0,17 & 2,37 & 16,67 & 14,31 & 32,21 \\
\hline 8 & 605,9 & 0,15 & 1,99 & 14,63 & 12,10 & 29,41 \\
\hline 8 & 618,2 & 0,19 & 2,47 & 19,98 & 11,52 & 31,07 \\
\hline 8 & 630,2 & 0,20 & 2,12 & 15,59 & 13,35 & 31,60 \\
\hline 8 & 648,1 & 0,17 & 2,16 & 14,88 & 13,14 & 29,24 \\
\hline 8 & 659,6 & 0,22 & 2,59 & 19,63 & 11,80 & 26,89 \\
\hline 8 & 667,1 & 0,14 & 2,29 & 13,12 & 18,16 & 36,21 \\
\hline 8 & 669,4 & 0,18 & 2,31 & 15,24 & 13,20 & 33,22 \\
\hline 8 & 686,7 & 0,17 & 2,57 & 16,97 & 13,07 & 28,24 \\
\hline 8 & 692,8 & 0,29 & 2,58 & 21,41 & 12,48 & 25,64 \\
\hline 8 & 728,9 & 0,30 & 3,02 & 23,38 & 9,83 & 22,26 \\
\hline 10 & 577,6 & 0,22 & 2,00 & 18,49 & 12,92 & 35,32 \\
\hline 10 & 591,9 & 0,25 & 2,12 & 16,21 & 10,89 & 27,10 \\
\hline 10 & 632,5 & 0,25 & 2,77 & 24,59 & 10,41 & 27,70 \\
\hline 10 & 635,2 & 0,32 & 2,06 & 23,56 & 18,83 & 39,46 \\
\hline 10 & 662,6 & 0,21 & 2,51 & 20,62 & 17,26 & 28,51 \\
\hline 10 & 671,9 & 0,21 & 2,80 & 22,93 & 11,62 & 26,28 \\
\hline 10 & 692,7 & 0,17 & 2,49 & 18,66 & 11,97 & 25,03 \\
\hline 10 & 693,2 & 0,21 & 2,72 & 20,73 & 10,89 & 25,59 \\
\hline 10 & 713,7 & 0,30 & 3,17 & 27,48 & 9,55 & 23,73 \\
\hline 10 & 750,3 & 0,29 & 3,02 & 28,36 & 7,95 & 19,98 \\
\hline 12 & 584,5 & 0,50 & 2,74 & 25,92 & 12,38 & 27,71 \\
\hline 12 & 597,4 & 0,23 & 2,09 & 15,95 & 13,40 & 34,39 \\
\hline 12 & 645,3 & 0,38 & 2,80 & 24,93 & 8,06 & 19,82 \\
\hline 12 & 647,4 & 0,17 & 2,25 & 15,73 & 16,84 & 43,46 \\
\hline 12 & 661,0 & 0,19 & 2,30 & 16,06 & 16,88 & 39,95 \\
\hline 12 & 669,4 & 0,42 & 3,23 & 29,80 & 9,09 & 24,82 \\
\hline 12 & 676,9 & 0,19 & 2,11 & 15,64 & 18,84 & 45,08 \\
\hline 12 & 747,5 & 0,55 & 3,57 & 31,95 & 8,31 & 16,97 \\
\hline 12 & 762,8 & 0,47 & 3,65 & 33,60 & 10,16 & 16,40 \\
\hline 12 & 774,1 & 0,51 & 3,42 & 28,24 & 7,35 & 19,86 \\
\hline
\end{tabular}


TABELA 10. Resultados médios por painel para os ensaios de adesão interna (Al), módulo de elasticidade (MOE), módulo de ruptura (MOR), inchamento em espessura e absorção de água (continuação).

\begin{tabular}{ccccccc}
\hline $\begin{array}{c}\text { Resina } \\
(\%)\end{array}$ & $\begin{array}{c}\text { Densidade } \\
\left(\mathrm{kg} / \mathrm{m}^{3}\right)\end{array}$ & $\mathrm{Al}(\mathrm{MPa})$ & $\begin{array}{c}\mathrm{MOE} \\
(\mathrm{GPa})\end{array}$ & $\begin{array}{c}\mathrm{MOR} \\
(\mathrm{MPa})\end{array}$ & $\begin{array}{c}\text { Inchamento } \\
(\%)\end{array}$ & $\begin{array}{c}\text { Absorção } \\
(\%)\end{array}$ \\
\hline & & & & & & \\
14 & 586,3 & 0,32 & 2,67 & 23,73 & 9,35 & 26,71 \\
14 & 607,5 & 0,33 & 2,50 & 19,54 & 10,28 & 28,56 \\
14 & 617,2 & 0,20 & 2,31 & 17,39 & 11,95 & 28,52 \\
14 & 638,6 & 0,28 & 2,32 & 19,19 & 9,09 & 28,97 \\
14 & 638,7 & 0,36 & 2,79 & 20,41 & 9,33 & 28,91 \\
14 & 664,6 & 0,31 & 3,08 & 28,33 & 9,69 & 21,21 \\
14 & 676,8 & 0,31 & 2,76 & 23,58 & 10,65 & 24,46 \\
14 & 688,8 & 0,71 & 3,47 & 33,48 & 7,42 & 20,04 \\
14 & 713,2 & 0,60 & 3,56 & 32,48 & 7,50 & 17,87 \\
14 & 739,5 & 0,46 & 3,88 & 31,96 & 7,52 & 18,59 \\
\hline
\end{tabular}

Os ensaios de densidade de duas amostras em cada painel revelaram que a variação média intrapainel para esta propriedade é de 5,2\%.

Por outro lado a variação entre a densidade dos painéis obtidos e a prevista nos tratamentos foi maior, obtendo-se painéis com menor densidade que o planejado e assim algumas faixas não foram representadas, como a de $800 \mathrm{~kg} / \mathrm{m}^{3}$. Painéis produzidos por Pugel et al. (1990a) e Shupe et al. (1999) também apresentaram a mesma tendência de densidade menor que a estipulada.

Um dos fatores que contribuíram para este fato foi o espalhamento das fibras durante a prensagem, determinando que a mesma massa de fibras se dispersasse por uma área maior que a planejada para o painel $(43 \times 43 \mathrm{~cm})$, sendo o mesmo fato descrito por Pugel et al. (1990a). Outro fator determinante desse desvio em relação ao planejado foi o inchamento do painel de alguns décimos de milímetros após o alívio da pressão, em parte resultado de um baixo teor de resina. Uma possível alternativa seria elevar o teor de umidade do colchão, o que torna as fibras mais plásticas durante a prensagem e reduz a tensão residual . 
Apesar desse fato, a variação de densidade dentro de cada nível de resina foi suficientemente ampla, permitindo a utilização destes painéis na análise. Os pontos obtidos experimentalmente estão apresentados, na forma de losângulos, nas Figuras 24 a 33.

As variáveis analisadas foram correlacionadas com os fatores teor relativo e absoluto de resina e densidade, através do coeficiente de correlação de Pearson, gerando a Tabela 11.

TABELA 11. Coeficientes de correlação de Pearson (\%) entre as variáveis analisadas e teor relativo e absoluto de resina e densidade média.

\begin{tabular}{cccccc}
\hline & $\begin{array}{c}\text { Adesão } \\
\text { Interna }\end{array}$ & MOR & MOE & Inchamento & Absorção \\
\hline Densidade Média & 46,1 & 60,6 & 72,3 & $-50,0$ & $-57,2$ \\
\hline Teor de Resina $(\%)$ & 70,1 & 67,9 & 65,3 & $-69,7$ & $-64,6$ \\
\hline Teor de Resina $\left(\mathrm{kg} / \mathrm{m}^{3}\right)$ & 77,2 & 78,6 & 79,1 & $-74,5$ & $-72,1$ \\
\hline
\end{tabular}

Todos os coeficientes foram significativos a $1 \%$.

Observa-se que as variáveis analisadas apresentaram maior correlação com o teor de resina em comparação com a densidade, com exceção para a correlação entre módulo de elasticidade e teor relativo de resina. Destaca-se ainda que o teor de resina expresso em $\mathrm{kg} / \mathrm{m}^{3}$ apresenta maior correlação com as variáveis que o mesmo fator expresso em percentagem. Isso demonstra que um mesmo teor de resina, em percentagem, para painéis de diferentes densidades tem efeitos diversos e que o recobrimento das fibras não é constante, para este mesmo teor.

O fato do teor de resina ter alta correlação com a adesão interna já é consenso na literatura, como apresentado por Maloney (1989) e Labosky Jr. et al. (1993). A análise da disposição das fibras no painel pode explicar esta maior correlação. A quase totalidade das fibras está disposta no eixos $X$ e $Y$ (Figura 
19). Dessa forma, o que vai determinar a resistência é a ligação paralela entre fibras ou área superficial específica, promovida pela resina. Pode-se esperar que parte da correlação com a densidade deve-se ao aumento da eficiência da resina com o aumento da densidade, ou seja, um benefício indireto determinado pela interação (Tabela 12).

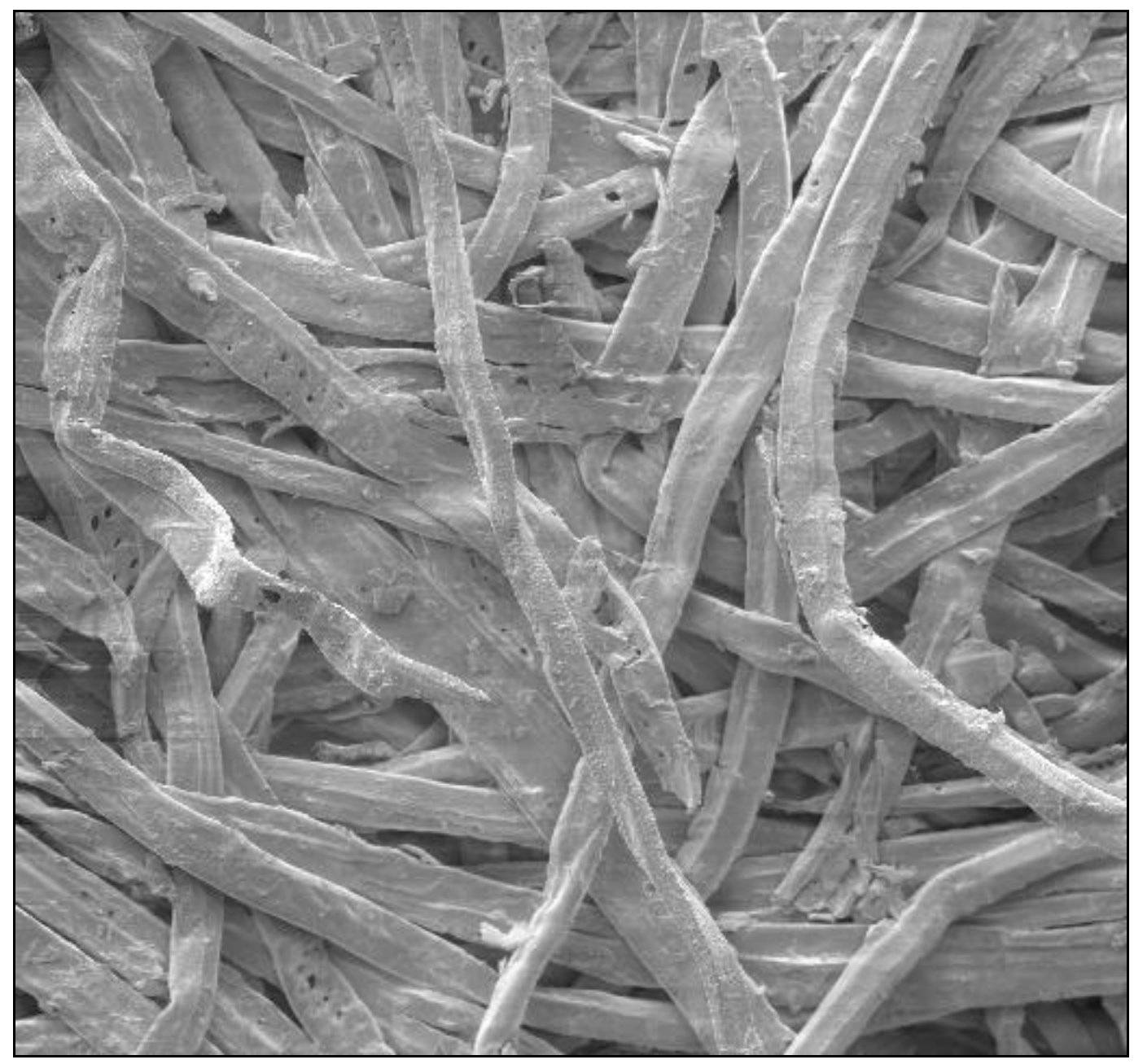

FIGURA 19. Disposição das fibras na camada interna de um painel MDF.

A influência positiva do aumento do teor de resina sobre o módulo de ruptura e de elasticidade também foi encontrada por Labosky Jr. et al. (1993), Maloney (1989), Benaduce (1998) e Suzuki \& Kato (1989). 
A abordagem da influência da densidade sobre o inchamento em espessura varia de autor para autor. Maloney (1989) afirma que o aumento da densidade ocasiona aumento do inchamento em espessura; Kelly (1977) afirma que a densificação pode restringir a entrada de umidade no painel e consequentemente o inchamento, Suchsland et al. (1986), Chow (1976) e Nelson (1973) afirmam que o inchamento não varia com a densidade.

Segundo Kelly (1977) e Carll (1996), o inchamento em espessura não é apenas devido à retratibilidade do material dado em função da densidade, mas tem também um componente proveniente do alívio da tensão residual de compressão existente no painel.

A densidade média apresenta um efeito conflitante, por um lado, o aumento de massa origina uma maior pressão para o inchamento quando umedecida, por outro lado, uma maior densidade origina maior eficiência da resina, restringindo $o$ inchamento.

A análise da interação entre a densidade e o teor relativo e absoluto de resina, para as 5 variáveis analisadas é apresentada na Tabela 12.

TABELA 12. Interação entre os fatores densidade e teor de resina, expressa através do valor do teste $F$.

\begin{tabular}{cccccc}
\hline & $\begin{array}{c}\text { Adesão } \\
\text { Interna }\end{array}$ & MOE & MOR & Inchamento & Absorção \\
\hline $\begin{array}{c}\text { Densidade X Teor } \\
\text { relativo de resina }\end{array}$ & $4,46^{*}$ & $1,87^{\text {ns }}$ & $2,65^{\text {ns }}$ & $10,18^{* *}$ & $6,48^{*}$ \\
$\begin{array}{c}\text { Densidade X Teor } \\
\text { absoluto de resina }\end{array}$ & $4,25^{*}$ & $1,34^{\text {ns }}$ & $2,20^{\text {ns }}$ & $10,72^{* *}$ & $6,79^{*}$ \\
\hline "* significativo a 1\%, ${ }^{*}=$ significativo a $5 \%,{ }^{\text {ns }}=$ não significativo &
\end{tabular}


Ao contrário do esperado, a interação entre os fatores densidade e teor de resina não foi significativa sobre todas as variáveis. Nas variáveis relacionadas a flexão estática a interação não foi significativa. A variável inchamento apresentou interação com a maior significância. Acreditava-se que uma maior densidade promoveria maior contato entre fibras e assim maior eficiência no uso da resina, caracterizando uma interação e que tal fato seria significativo para todas as variáveis, o que como visto não confirmou-se para módulo de ruptura e de elasticidade

A análise de correlação das variáveis dependentes entre si é apresentada na Tabela 13.

TABELA 13. Coeficientes de correlação de Pearson (\%) entre variáveis dependentes.

\begin{tabular}{cccccc}
\hline & Adesão Interna & MOR & MOE & Inchamento Absorção \\
\hline Adesão Interna & 100,0 & & & & \\
\hline MOR & 89,6 & 100,0 & & & \\
\hline MOE & 83,1 & 94,0 & 100,0 & & \\
\hline Inchamento & $-66,8$ & $-75,7$ & $-78,8$ & 100,0 & \\
\hline Absorção & $-67,9$ & $-79,6$ & $-83,0$ & 96,7 & 100,0 \\
\hline
\end{tabular}

As maiores correlações foram encontradas entre variáveis dependentes obtidas de um mesmo corpo-de-prova, ou seja, inchamento em espessura e absorção de água e módulo de ruptura e de elasticidade. Os módulos de elasticidade e de ruptura estão fortemente relacionados por apresentarem um comportamento semelhante no que se refere à exigência mecânica do corpo-deprova. A absorção de água determina o inchamento do corpo-de-prova, o que explica a correlação entre estas duas variáveis. 
As variáveis inchamento em espessura e absorção de água apresentaram relação inversa com as outras variáveis.

\subsubsection{Resultados da análise do perfil de densidade}

A partir da análise do perfil de densidade de duas amostras extraídas de cada painel experimental, foram obtidos os valores médios, por painel, da densidade média, máxima, mínima, da camada externa e da camada interna, apresentados na Tabela 14 e Figura 20.

TABELA 14. Densidade $\left(\mathrm{kg} / \mathrm{m}^{3}\right)$ média (MÉDIA), da camada externa (CE), da camada interna $(\mathrm{Cl})$, máxima (MÁX) e mínima (MÍN) por painel.

\begin{tabular}{ccccc}
\hline MÉDIA & CE & Cl & MAX & MIN \\
\hline 547,2 & 604,3 & 500,7 & 716,1 & 455,9 \\
569,9 & 590,9 & 521,0 & 737,1 & 464,4 \\
573,0 & 593,1 & 526,4 & 722,3 & 470,0 \\
577,6 & 647,3 & 532,9 & 739,3 & 492,6 \\
584,5 & 659,3 & 533,3 & 783,1 & 489,4 \\
586,3 & 649,0 & 533,2 & 774,8 & 487,3 \\
588,9 & 607,2 & 551,3 & 709,5 & 492,9 \\
591,9 & 650,1 & 549,2 & 759,1 & 501,5 \\
597,4 & 666,7 & 550,1 & 779,8 & 509,0 \\
605,9 & 686,6 & 553,1 & 806,6 & 508,4 \\
607,5 & 703,6 & 555,3 & 830,6 & 515,5 \\
611,5 & 614,9 & 562,8 & 798,9 & 493,6 \\
617,2 & 708,1 & 568,8 & 836,3 & 512,7 \\
618,2 & 693,5 & 566,9 & 805,2 & 527,0 \\
630,2 & 718,2 & 578,8 & 835,9 & 533,2 \\
632,5 & 723,8 & 577,6 & 862,9 & 530,6 \\
635,2 & 659,9 & 576,9 & 822,7 & 515,4 \\
638,6 & 763,0 & 584,8 & 874,4 & 517,4 \\
638,7 & 698,3 & 594,4 & 804,7 & 558,5 \\
645,3 & 741,9 & 588,6 & 87,5 & 549,1 \\
646,9 & 743,6 & 590,1 & 878,2 & 531,6 \\
647,4 & 723,9 & 592,7 & 837,7 & 533,9 \\
648,1 & 728,4 & 597,1 & 901,3 & 542,0 \\
657,0 & 729,2 & 599,3 & 857,4 & 539,4 \\
659,6 & 753,1 & 601,4 & 899,3 & 550,1 \\
661,0 & 734,3 & 604,3 & 852,3 & 550,7 \\
662,6 & 742,5 & 609,6 & 871,4 & 564,6 \\
664,2 & 731,7 & 609,3 & 860,4 & 561,5 \\
664,6 & 749,8 & 603,7 & 884,5 & 555,6 \\
667,1 & 768,0 & 603,9 & 899,8 & 541,2 \\
669,4 & 750,7 & 621,3 & 854,2 & 571,8 \\
669,4 & 766,3 & 611,3 & 910,0 & 570,0 \\
\hline
\end{tabular}


TABELA 14. Densidade $\left(\mathrm{kg} / \mathrm{m}^{3}\right.$ ) média (MÉDIA), da camada externa (CE), da camada interna $(\mathrm{Cl})$, máxima (MÁX) e mínima (MÍN) por painel (continuação).

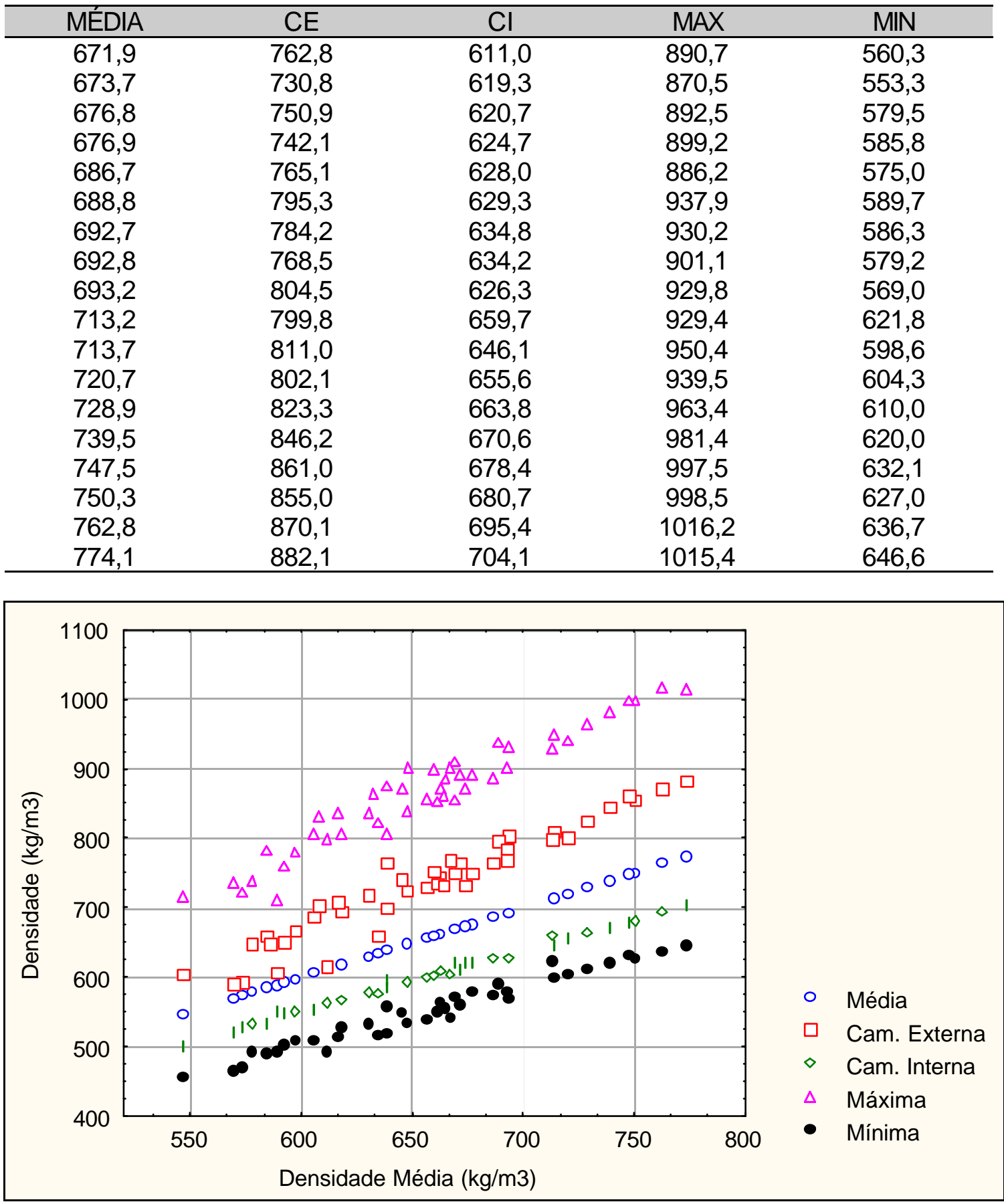

FIGURA 20. Relação entre densidades de referência ao longo do perfil e densidade média. 
As figuras 21, 22 e 23 apresentam, um perfil de densidade ilustrativo, obtido por radiação gama, uma fotomicrografia da camada externa e uma fotomicrografia da camada interna de um painel MDF experimental, respectivamente.

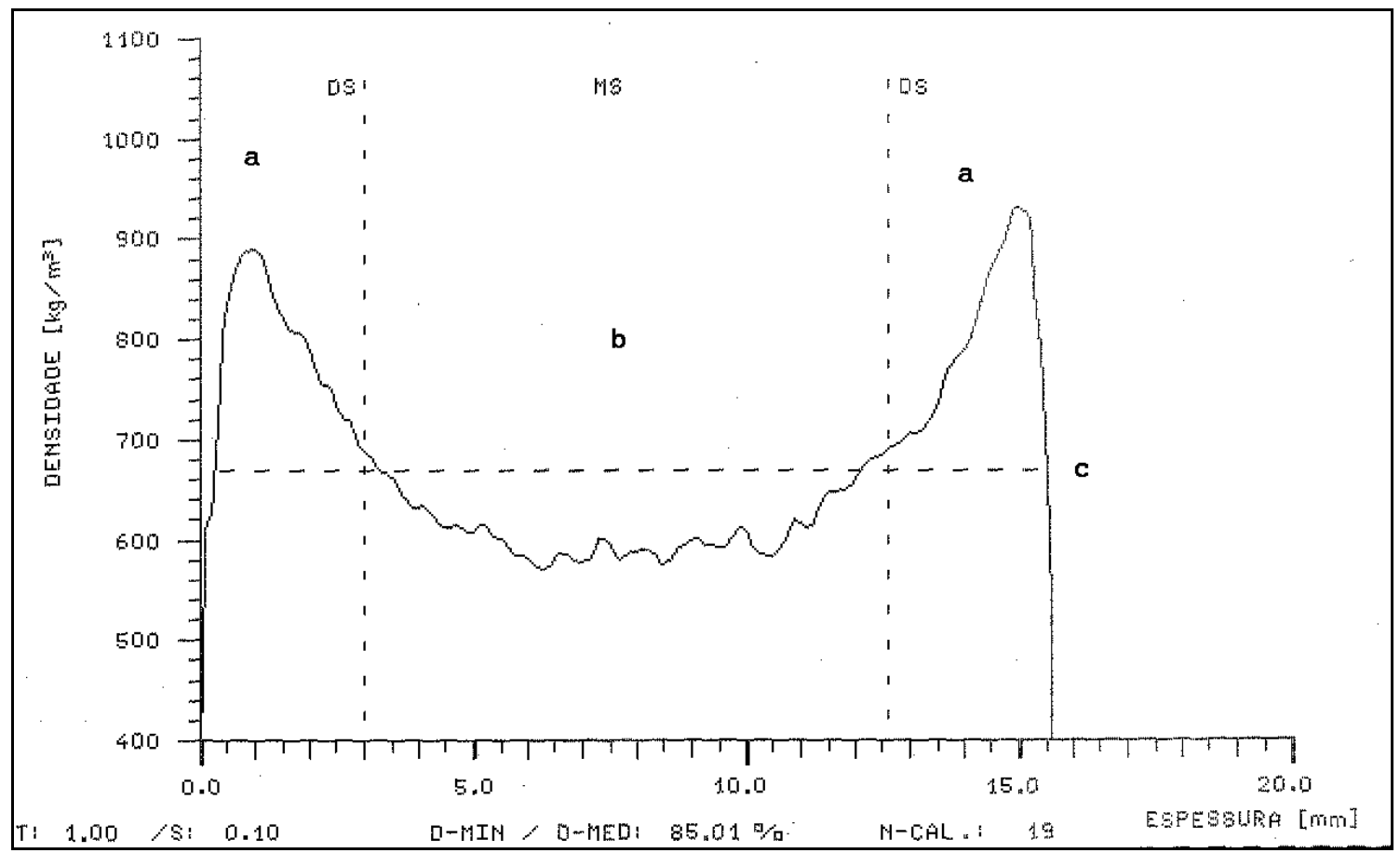

FIGURA 21. Exemplo de perfil de densidade do painel: camada externa (a), camada interna (b) e densidade média (c). 


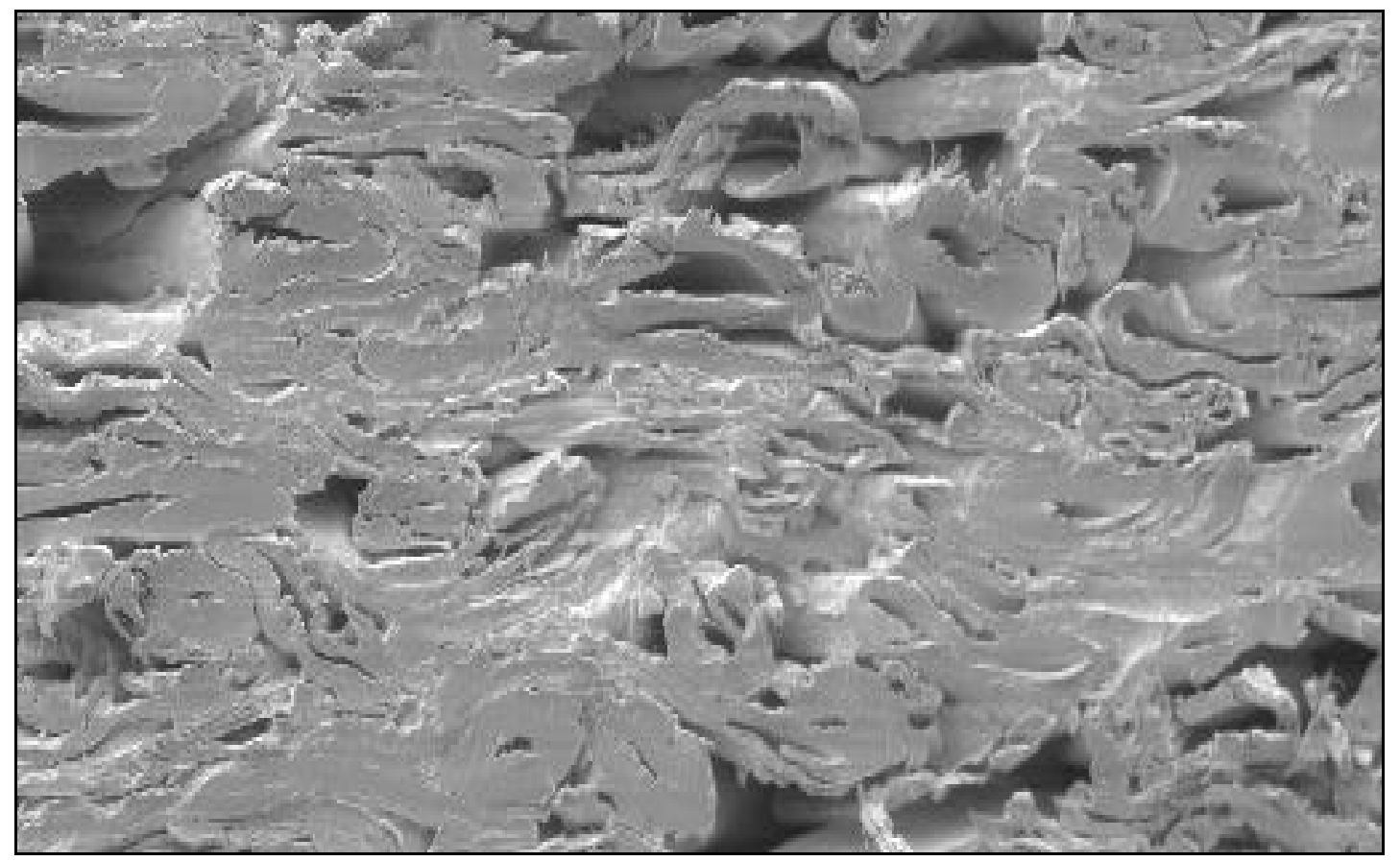

FIGURA 22. Camada externa de um painel MDF experimental, demonstrando a compactação das fibras, que ocasiona maior densidade do painel

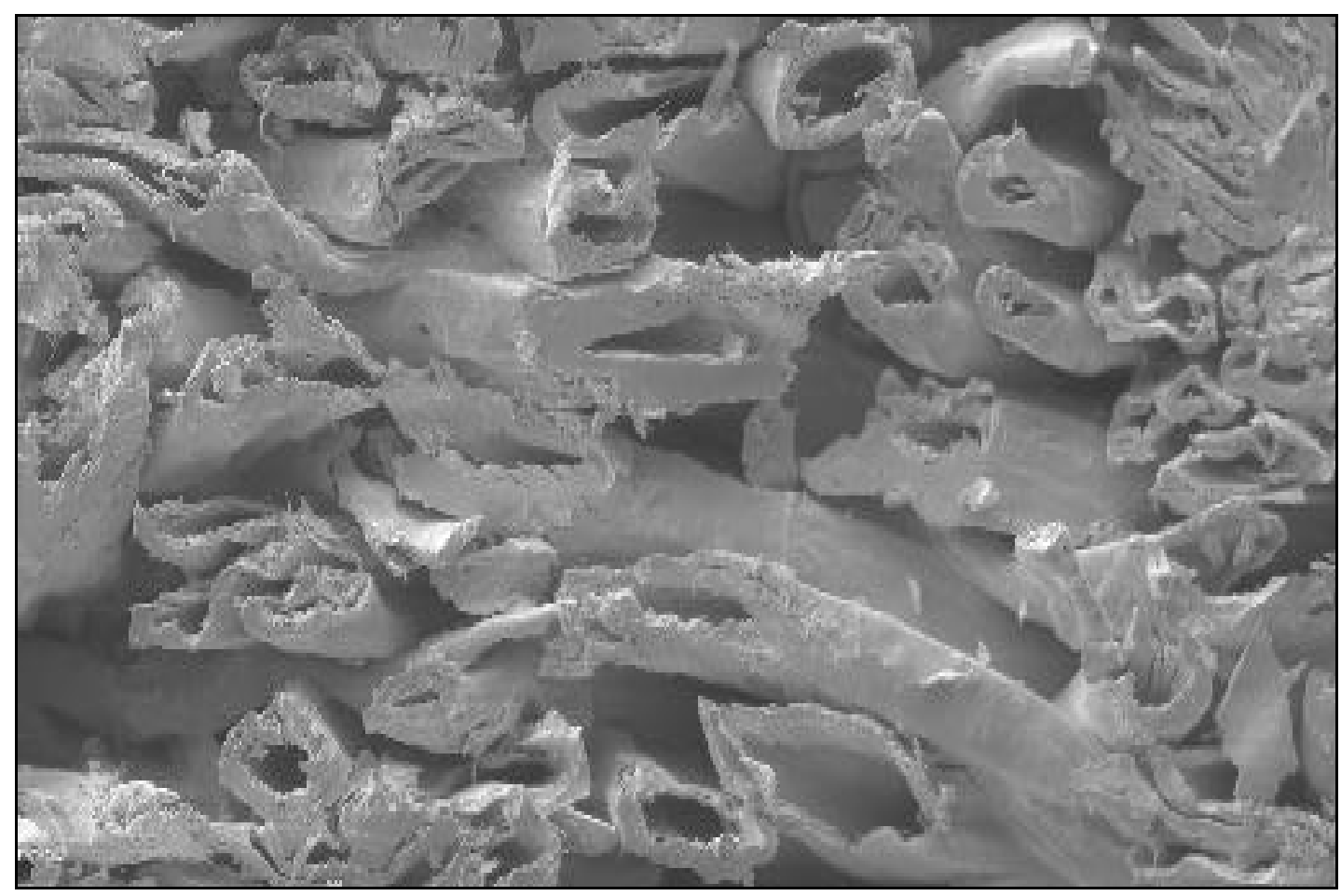

FIGURA 23. Camada interna de um painel MDF experimental, demonstrando a presença de espaços vazios, que ocasiona menor densidade do painel. 
Os valores de densidade ao longo do perfil (Tabela 14) foram correlacionados, através do coeficiente de correlação de Pearson, com as variáveis analisadas, gerando a Tabela 15.

TABELA 15. Coeficientes de correlação de Pearson (\%) entre as variáveis analisadas e a densidade ao longo do perfil.

\begin{tabular}{cccccc}
\hline & $\begin{array}{c}\text { Adesão } \\
\text { Interna }\end{array}$ & MOR & MOE & Inchamento & Absorção \\
\hline Densidade Média & 46,1 & 60,6 & 72,3 & $-50,0$ & $-57,2$ \\
\hline Dens. Camada Externa & 50,1 & 65,2 & 79,1 & $-63,1$ & $-68,7$ \\
\hline Dens. Camada Interna & 45,8 & 58,8 & 70,9 & $-49,1$ & $-55,9$ \\
\hline Densidade Máxima & 49,2 & 65,1 & 76,4 & $-57,1$ & $-64,9$ \\
\hline Densidade Mínima & 52,3 & 64,5 & 76,8 & $-56,1$ & $-62,1$ \\
\hline
\end{tabular}

A variável adesão interna, ou tração perpendicular ao plano do painel, apresentou correlação com a densidade média, mínima e da camada interna, na faixa de 45,8 a 52,3\% (Tabela 15). Pelos corpos-de-prova romperem na camada interna, esperava-se que a correlação com a densidade mínima e/ou densidade da camada interna se destacasse.

Os módulo de ruptura e de elasticidade apresentaram maior correlação com a densidade da camada externa e máxima. Isto pode ser explicado porque no ensaio de flexão as camadas externas são as mais solicitadas e o ponto de máxima tração localiza-se na face oposta àaplicação da carga e a ruptura ocorre por tração, nesta região. Os painéis MDF comportam-se como vigas em I durante a flexão, graças a maior densidade nas faces. Suzuki \& Kato (1989) e Kollmann et al. (1975) reforçam a existência dessa correlação com a densidade.

A correlação entre os módulos de ruptura e de elasticidade, e a densidade mínima, que está na mesma faixa de correlação com a densidade máxima, pode indicar que houve efeito do esforço de cisalhamento durante o ensaio. 
Atuando como uma barreira à entrada de água e assim impedindo o inchamento em espessura, a densidade da camada externa apresentou a maior correlação com o inchamento em espessura que a densidade média. Nota-se que esta correlação é negativa, um aumento na densidade determina redução no inchamento.

O comportamento da absorção de água, em percentagem da massa inicial, apresentou-se de maneira semelhante ao inchamento em espessura. Dessa forma, as variáveis independentes que apresentaram maior correlação foram densidade da camada externa e máxima. Deduz-se que a camada externa forme uma barreira àentrada de água nos painéis. A correlação com a densidade média pode estar parcialmente relacionada com o aumento da eficiência da resina. Segundo Suchsland et al. (1986) a absorção de água é reduzida com o aumento da densidade. Para Nelson (1976) e Chow (1973) não há influência da densidade sobre a absorção e para Kollmann et al. (1975), em aglomerados, a maior densidade da camada externa reduz a absorção.

A correlação entre as densidades ao longo do perfil é apresentada na Tabela 16.

TABELA 16. Coeficientes de correlação de Pearson (\%) entre as densidades ao longo da espessura: DMED - densidade média, DCE - densidade da camada externa, DCI - densidade da camada interna, DMX densidade máxima e DMIN - densidade mínima.

\begin{tabular}{cccccc}
\hline & DMED & DCE & DCl & DMX & DMIN \\
\hline DMED & 100,0 & & & & \\
\hline DCE & 95,9 & 100,0 & & & \\
\hline DCl & 99,6 & 94,7 & 100,0 & & \\
\hline DMX & 96,4 & 97,6 & 95,0 & 100,0 & \\
\hline DMIN & 97,8 & 94,6 & 98,5 & 93,6 & 100,0 \\
\hline
\end{tabular}


Todas as densidades ao longo do perfil apresentam correlação maior que $90 \%$. Essa correlação permite a adoção da densidade média como fator na análise estatística, apesar de haver maior correlação entre as variáveis consideradas no estudo e a densidade da camada externa. A densidade média tem a vantagem de ser mais facilmente controlável e mensurável.

\subsection{Modelos obtidos em função da densidade média e do teor de resina em percentagem.}

Esta análise tem como objetivo propor modelos que expressem a influência dos fatores teor de resina e densidade, obter dados simulados a partir destes modelos e analisa-los graficamente.

\subsubsection{Adesão interna}

A modelagem dos valores de adesão interna em função do teor de resina e da densidade média resultou no modelo apresentado na eq. 11 .

$$
\mathrm{Al}=\mathrm{b}_{0}+\mathrm{b}_{1}{ }^{*} \text { DENSIDADE }+\mathrm{b}_{2}{ }^{*} \text { DENSIDADE }{ }^{2}+\mathrm{b}_{3}{ }^{*} \text { RESINA }
$$

Sendo $\mathrm{Al}=$ adesão interna $(\mathrm{MPa})$;

$$
\begin{aligned}
& \text { DENSIDADE = densidade média do painel }\left(\mathrm{kg} / \mathrm{m}^{3}\right) \\
& \text { RESINA }=\text { teor de resina }(\%) ; \\
& \mathrm{b}_{0}=+3,453229 \\
& \mathrm{~b}_{1}=-0,011543 \\
& \mathrm{~b}_{2}=+9,38^{*} 10^{-6} \\
& \mathrm{~b}_{3}=+0,031731 \\
& \mathrm{R}^{2}=66,4 \% \\
& \mathrm{~F}=28,04^{* *} \\
& \text { Syx }=0,330
\end{aligned}
$$


Cabe destacar a presença significativa das variáveis teor de resina e densidade média no modelo, reforçando a atuação conjunta e interativa destas duas variáveis.

Na Tabela 17 são apresentados valores obtidos para adesão interna àpartir da equação 11.

TABELA 17. Valores de adesão interna (MPa), obtidos a partir da eq. (11) em função da densidade média e do teor relativo de resina.

\begin{tabular}{c|ccccc}
\hline & \multicolumn{5}{c}{ Teor de Resina (\%) } \\
$\begin{array}{c}\text { Densidade } \\
\left(\mathrm{kg} / \mathrm{m}^{3}\right)\end{array}$ & 6 & 8 & 10 & 12 & 14 \\
\hline 550 & 0,13 & 0,20 & 0,26 & 0,32 & 0,39 \\
600 & 0,09 & 0,16 & 0,22 & 0,29 & 0,35 \\
650 & 0,10 & 0,17 & 0,23 & 0,29 & 0,36 \\
700 & 0,16 & 0,22 & 0,29 & 0,35 & 0,41 \\
750 & 0,26 & 0,33 & 0,39 & 0,45 & 0,52 \\
\hline
\end{tabular}

A partir do modelo apresentado na eq. (11), foi plotada um superfície de resposta, de onde foram tiradas isolinhas, ou seja, linhas onde a variável analisada (adesão interna) tem valor constante. A Figura 24 apresenta as isolinhas para adesão interna (MPa) em função da densidade média do painel e do teor relativo de resina. 


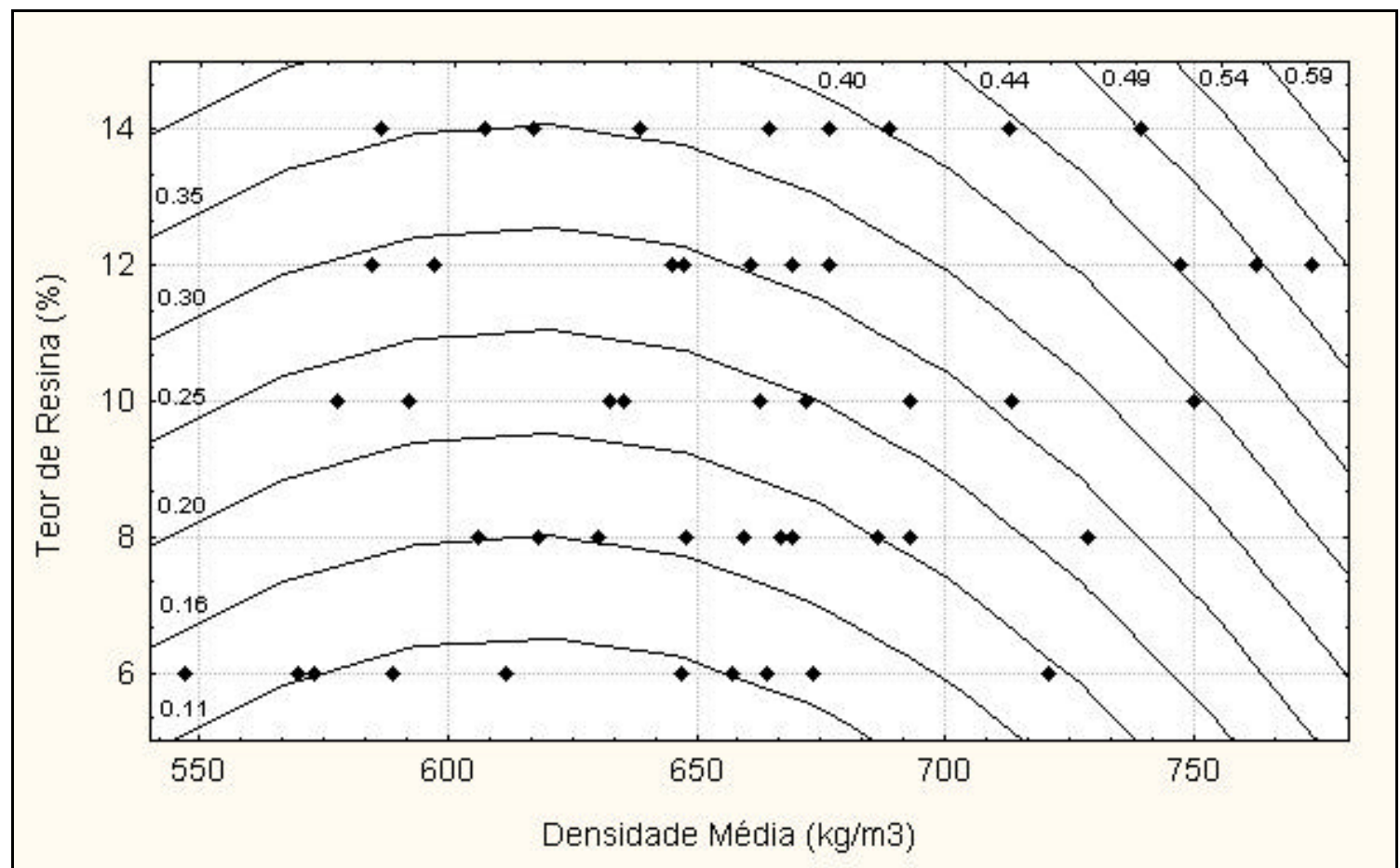

FIGURA 24. Isolinhas de adesão interna ( $\mathrm{MPa})$ em função da densidade média e do teor de resina relativo.

No gráfico da Figura 24, observa-se de maneira mais clara a relação direta entre teor de resina e adesão interna. Da mesma forma com relação àdensidade, em especial acima de $600 \mathrm{~kg} / \mathrm{m}^{3}$. Com base no conceito de isolinhas, pode-se inferir que painéis mais densos, mantendo-se a variável constante, demandam um menor teor de resina.

O aumento da adesão interna com o aumento da densidade não pode ser apenas explicado pela diferente densidade dos painéis, mas também pelo aumento da eficiência da resina, pelo aumento da área de contato entre fibras encoladas. 


\subsubsection{Módulo de ruptura}

O modelo ajustado para módulo de ruptura em função da densidade média e do teor relativo de resina é apresentado na eq. 12.

$$
\text { MOR }=b_{0}+b_{1}{ }^{*} \text { DENSIDADE }+b_{2}{ }^{*} \text { DENSIDADE }{ }^{2}+b_{3}{ }^{*} \text { RESINA }
$$

Sendo $M O R=$ módulo de ruptura $(\mathrm{MPa})$;

DENSIDADE $=$ densidade média do painel $\left(\mathrm{kg} / \mathrm{m}^{3}\right)$;

RESINA = teor de resina (\%);

$$
\begin{aligned}
& \text { b0 }=+116,432383 \\
& \text { b1 }=-0,395845 \\
& \text { b2 }=+3,4533^{*} 10-4 \\
& \text { b3 }=+1,375850 \\
& R^{2}=71,6 \% \\
& F=38,66^{*} \\
& \text { Syx }=0,184
\end{aligned}
$$

Tanto a densidade média como o teor de resina foram incorporados no modelo devido à sua significância, demonstrando que o módulo de ruptura é influenciado positivamente por estas duas variáveis.

Alguns valores obtidos para módulo de ruptura, com base na eq. (12), em função da densidade média e o teor de resina, são apresentados na Tabela 18.

TABELA 18. Módulos de ruptura (MPa), para diferentes densidades médias e teores de resina, a partir da eq. (12).

\begin{tabular}{c|ccccc}
\hline & \multicolumn{5}{|c}{ Teor de Resina (\%) } \\
Densidade $\left(\mathrm{kg} / \mathrm{m}^{3}\right)$ & 6 & 8 & 10 & 12 & 14 \\
\hline 550 & 11,44 & 14,19 & 16,94 & 19,69 & 22,44 \\
600 & 11,50 & 14,25 & 17,00 & 19,75 & 22,51 \\
650 & 13,29 & 16,04 & 18,79 & 21,55 & 24,30 \\
700 & 16,81 & 19,56 & 22,31 & 25,06 & 27,81 \\
750 & 22,05 & 24,80 & 27,56 & 30,31 & 33,06 \\
\hline
\end{tabular}


O modelo apresentado na eq. (12), por contar duas variáveis independentes (fatores), permitiu a construção de uma superfície de resposta. Para facilitar a visualização, esta superfície de resposta foi projetada, na forma de isolinhas, em um plano (Figura 25). Esta figura demonstra a resposta do módulo de ruptura à variação do teor de resina e da densidade média.

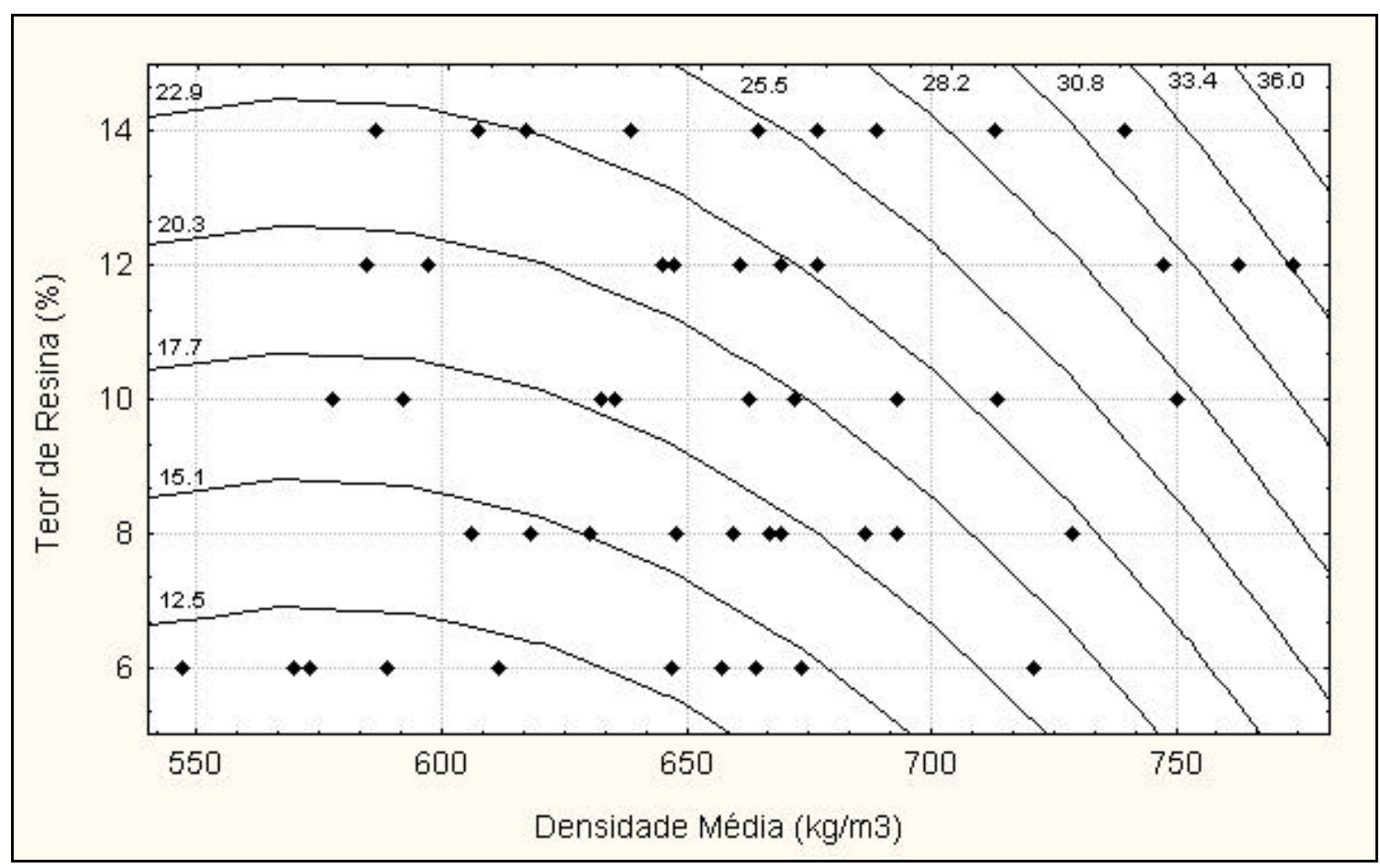

FIGURA 25. Isolinhas de módulo de ruptura (MPa) em função da densidade média e do teor de resina relativo.

As isolinhas são formadas a partir de um conjunto de pontos de módulo de ruptura (MOR) constante, mas de diferentes combinações de teor de resina e densidade média. O comportamento geral é menor necessidade de resina para painéis de maior densidade, mantendo-se constante o MOR. 


\subsubsection{Módulo de Elasticidade}

O modelo ajustado para módulo de elasticidade em função do teor de resina e da densidade média é apresentado na equação 13.

$$
\text { MOE }=b_{0}+b_{1}{ }^{*} \text { DENSIDADE }+b_{2}{ }^{*} \text { DENSIDADE }{ }^{2}+b_{3}{ }^{*} \text { RESINA }
$$

Sendo $\mathrm{MOE}=$ módulo de elasticidade $(\mathrm{GPa})$;

DENSIDADE $=$ densidade média do painel $\left(\mathrm{kg} / \mathrm{m}^{3}\right)$;

RESINA = teor de resina (\%)

$$
\begin{aligned}
& \text { b0 }=+7,035894 \\
& \text { b1 }=-0,024088 \\
& \text { b2 }=+2,343^{*} 10-5 \\
& b 3=+0,111354 \\
& R^{2}=80,3 \% \\
& F=62,46^{* *} \\
& \text { Syx }=0,11
\end{aligned}
$$

O modelo, eq. (13), é semelhante ao obtido para módulo de ruptura, eq. (12), diferindo somente nos coeficientes.

Observa-se, como nas variáveis anteriormente analisadas, a inclusão tanto da densidade média como do teor de resina, indicando atuação significativa destes dois componentes sobre o módulo de elasticidade.

Valores de módulo de elasticidade obtidos em função da densidade e do teor de resina, segundo a eq. (13), são apresentados na Tabela 19. 
TABELA 19. Módulos de elasticidade (MPa), para diferentes densidades médias e teores de resina, a partir da eq. (13).

\begin{tabular}{c|ccccc}
\hline & \multicolumn{5}{|c}{ Teor de Resina (\%) } \\
Densidade $\left(\mathrm{kg} / \mathrm{m}^{3}\right)$ & 6 & 8 & 10 & 12 & 14 \\
\hline 550 & 1,54 & 1,77 & 1,99 & 2,21 & 2,43 \\
600 & 1,69 & 1,91 & 2,13 & 2,35 & 2,58 \\
650 & 1,95 & 2,17 & 2,39 & 2,61 & 2,84 \\
700 & 2,32 & 2,55 & 2,77 & 2,99 & 3,21 \\
750 & 2,82 & 3,04 & 3,26 & 3,49 & 3,71 \\
\hline
\end{tabular}

A determinação de uma superfície de resposta originada a partir do modelo (eq. 13), e sua projeção no plano originou uma série de isolinhas para módulo de elasticidade (GPa) (Figura 26).

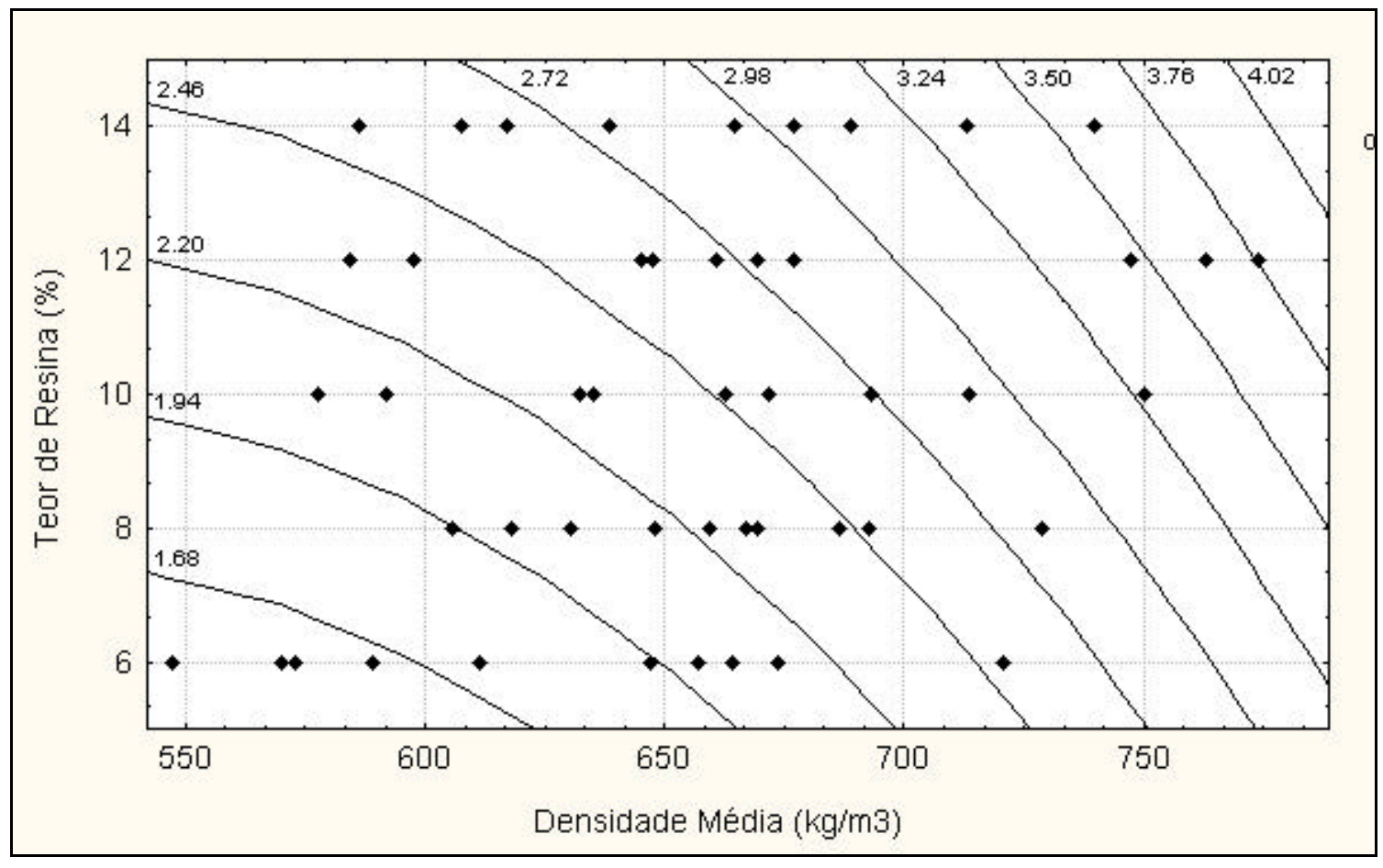

FIGURA 26. Isolinhas de módulo de elasticidade (GPa) em função da densidade média e do teor de resina (\%).

O comportamento observado das isolinhas, de reduzir o teor de resina necessário para manutenção constante do módulo de elasticidade, em painéis de maior densidade, demonstra a possibilidade de adotar-se um teor de resina diferenciado. 


\subsubsection{Inchamento em espessura}

Para observar o efeito conjunto do teor de resina e da densidade média, um modelo foi ajustado utilizando estas 2 variáveis (eq. 14).

$$
\text { INCH }=b_{0}+b_{1}{ }^{*} \text { DENSIDADE }{ }^{-2}+b_{2}{ }^{*} \operatorname{RESINA}+b_{3}{ }^{*} \operatorname{RESINA}^{-1}+b_{4}{ }^{*} \operatorname{RESINA}^{-2} \text { (14) }
$$

Sendo $\mathrm{INCH}=$ inchamento em espessura (\%) após imersão em água;

DENSIDADE $=$ densidade média do painel $\left(\mathrm{kg} / \mathrm{m}^{3}\right)$;

RESINA = teor de resina (\%);

$$
\begin{aligned}
& \text { b0 }=+275,267860 \\
& \text { b1 }=+4961621,375978 \\
& \text { b2 }=-9,407572 \\
& \text { b3 }=-2642,690261 \\
& \text { b4 }=+8419,506187 \\
& R^{2}=78,4 \% \\
& F=40,77^{\star *} \\
& \text { Syx }=0,226
\end{aligned}
$$

Para esta variável, da mesma forma que para as anteriores, o modelo incorpora de maneira significativa, tanto a densidade média como o teor de resina.

A Tabela 20 relaciona alguns valores de inchamento em espessura após imersão em água por 24h, obtidos através da eq. 14. 
TABELA 20. Inchamento em espessura (\%), para diferentes densidades médias e teores de resina, a partir da eq. (14).

\begin{tabular}{c|ccccc}
\hline $\begin{array}{c}\text { Densidade } \\
\left(\mathrm{kg} / \mathrm{m}^{3}\right)\end{array}$ & 6 & 8 & 10 & 12 & 14 \\
\hline 550 & 28,65 & 17,63 & 17,52 & 17,02 & 14,16 \\
600 & 26,03 & 15,01 & 14,90 & 14,40 & 11,54 \\
650 & 23,99 & 12,97 & 12,86 & 12,37 & 9,50 \\
700 & 22,37 & 11,35 & 11,24 & 10,75 & 7,88 \\
750 & 21,07 & 10,05 & 9,94 & 9,44 & 6,58 \\
\hline
\end{tabular}

A projeção no plano da superfície de resposta obtida a partir da eq. (14) é apresentada na Figura 27.

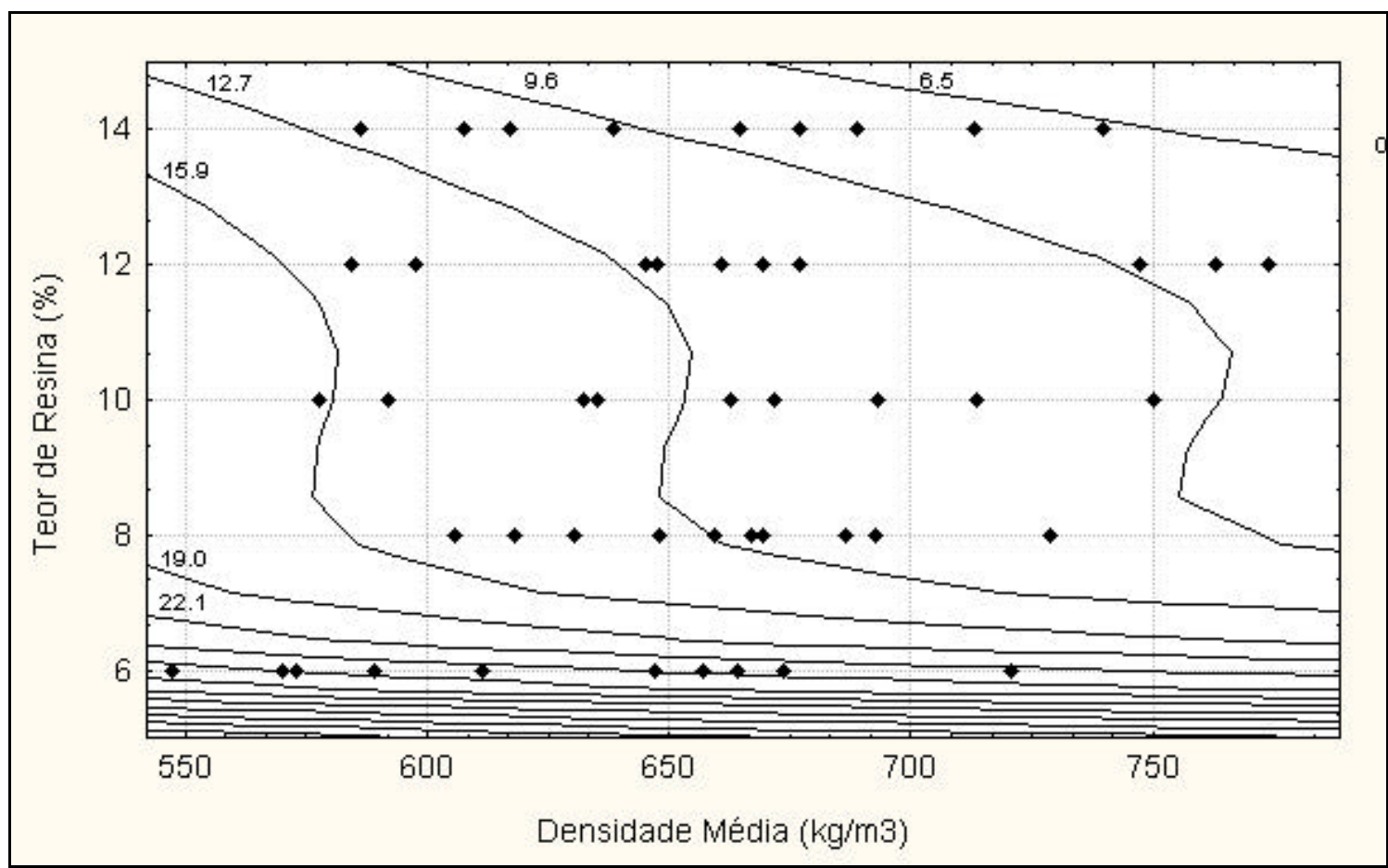

FIGURA 27. Isolinhas de inchamento em espessura (\%) em função da densidade média e do teor relativo de resina.

O primeiro aspecto que chama a atenção é a redução acentuada no inchamento com o aumento do teor de resina de 6 para 8\%, após este valor a redução com o aumento do teor de resina é menor. 
Observa-se também variação em função da densidade, dessa forma, para cada densidade tem-se um teor relativo de resina diferenciado, adotando-se um valor constante de inchamento.

\subsubsection{Absorção de água}

O modelo para absorção de água em função da densidade e do teor de resina é apresentado a seguir (eq. 15).

$$
A B S=b_{0}+b_{1}{ }^{*} \text { DENSIDADE }{ }^{-2}+b_{2}{ }^{*} \text { RESINA }+b_{3}{ }^{*} \text { RESINA }^{-1}+b_{4}{ }^{*} \text { RESINA }^{-2}
$$

Sendo $A B S=$ absorção de água (em \% da massa inicial) após imersão em água por $24 \mathrm{~h}$;

DENSIDADE $=$ densidade média do painel $\left(\mathrm{kg} / \mathrm{m}^{3}\right)$;

RESINA = teor de resina (\%)

$$
\begin{aligned}
& \text { b0 }=+656,3372 \\
& \text { b1 }=-0,097627 \\
& \text { b2 }=-18,8734 \\
& \text { b3 }=-5508,9430 \\
& \text { b4 }=+17703,7739 \\
& R^{2}=80,1 \% \\
& F=45,4 \\
& \text { Syx }=0,195
\end{aligned}
$$

O modelo incorpora de maneira significativa tanto o teor de resina como a densidade para explicar a absorção de água.

A Tabela 19 apresenta valores de absorção de água (\%) em função da densidade e do teor de resina, segundo a eq. (15). 
TABELA 21. Absorção de água (\%), para diferentes densidades médias e teores de resina, a partir da eq. (15).

\begin{tabular}{c|ccccc}
\hline $\begin{array}{c}\text { Densidade } \\
\left(\mathrm{kg} / \mathrm{m}^{3}\right)\end{array}$ & 6 & 8 & 10 & 12 & 14 \\
\hline 550 & 63,02 & 39,66 & 40,05 & 40,03 & 35,24 \\
600 & 58,13 & 34,78 & 35,17 & 35,14 & 30,36 \\
650 & 53,25 & 29,90 & 30,29 & 30,26 & 25,48 \\
700 & 48,37 & 25,01 & 25,41 & 25,38 & 20,60 \\
750 & 43,49 & 20,13 & 20,53 & 20,50 & 15,72 \\
\hline
\end{tabular}

O modelo obtido para absorção de água, eq. (15), foi semelhante ao obtido para o inchamento em espessura. A superfície de resposta e a respectiva projeção no plano, apresentada na Figura 28.

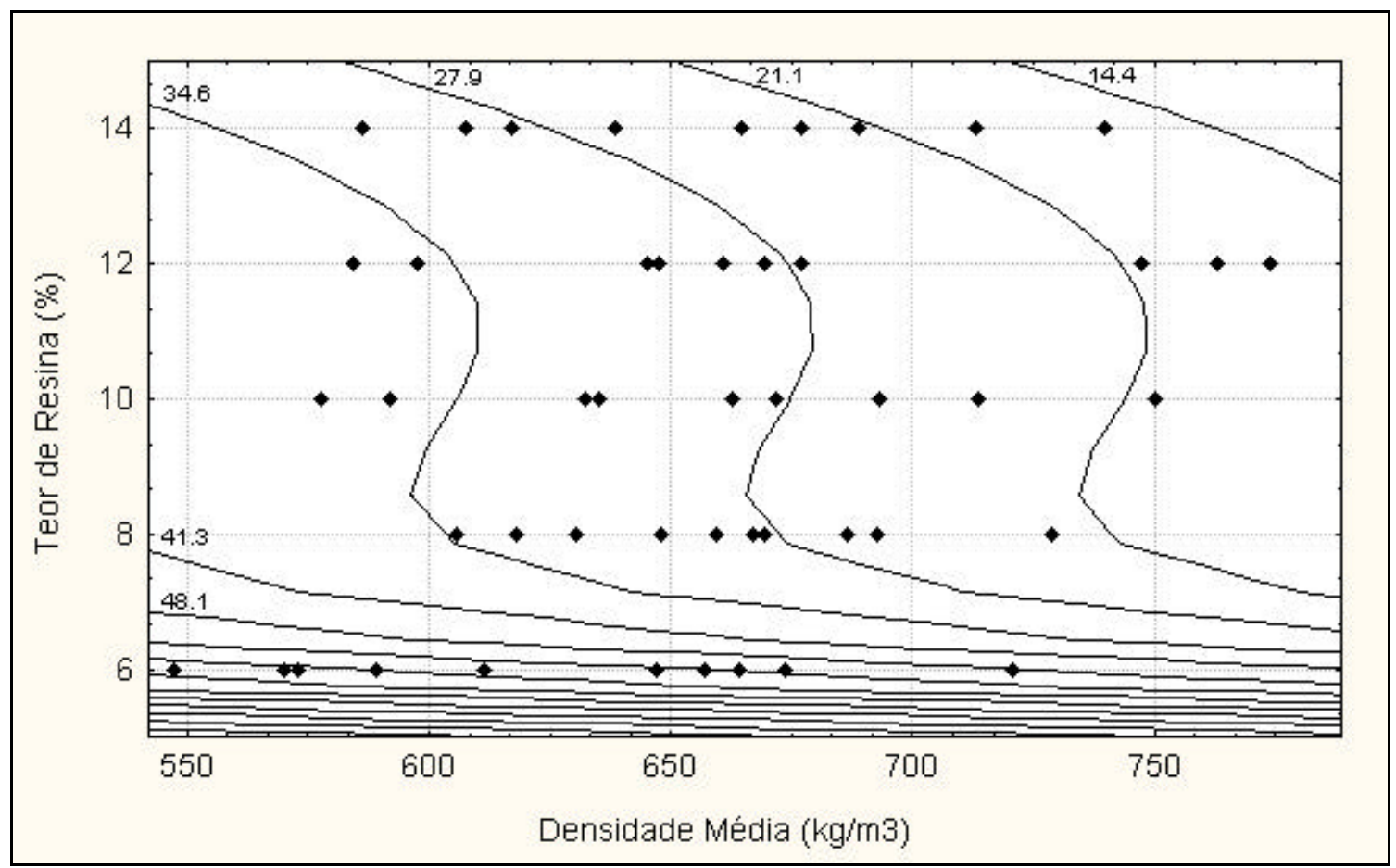

FIGURA 28. Isolinhas de absorção de água (\%) em função da densidade média e do teor relativo de resina. 
Observa-se uma absorção de água bastante elevada em todas as densidades quando os teores de resina estão abaixo de $8 \%$. Ocorre uma rápida redução da absorção de água com o aumento do teor de resina a partir de $8 \%$.

\subsection{Análise em função da densidade e do teor de resina em massa}

A análise do efeito da densidade e do teor de resina em percentagem, demonstrou que o acréscimo de densidade pode ocasionar uma redução percentual de resina sem prejuízo do valor nas propriedades. Deve-se lembrar que a densificação dos painéis MDF é obtida, mantendo-se o volume constante, pelo aumento da massa de fibras e que o teor de resina é expresso como percentagem em relação à massa anidra destas fibras. Desta forma há uma relação direta entre aumento de densidade e aumento da massa de resina, mesmo mantendo-se o teor em percentagem constante.

A análise a seguir busca determinar se o efeito da densidade e da sua interação com a resina permite uma redução do teor de resina em termos absolutos. Também busca determinar se, pela maior correlação, o teor absoluto de resina pode explicar o comportamento das variáveis.

\subsubsection{Adesão interna}

O modelo proposto para adesão interna em função da densidade e do teor absoluto de resina é apresentado na equação 12.

$$
\mathrm{Al}=\mathrm{b}_{0}+\mathrm{b}_{1}{ }^{*} \mathrm{RESINA}{ }^{2}
$$

Sendo $\mathrm{Al}=$ adesão interna $(\mathrm{MPa})$;

RESINA = massa de resina $\left(\mathrm{kg} / \mathrm{m}^{3}\right)$;

$\mathrm{b}_{0}=+0,0693$

$b_{1}=+4,1 * 10^{-5}$ 


$$
\begin{aligned}
& R^{2}=61,3 \% \\
& F=75,95^{* *} \\
& \text { Syx }=0,338
\end{aligned}
$$

O teor de resina absoluto explicou isoladamente o comportamento da adesão interna.

A relação entre adesão interna, teor de resina e densidade pode ser vista na Figura 29.

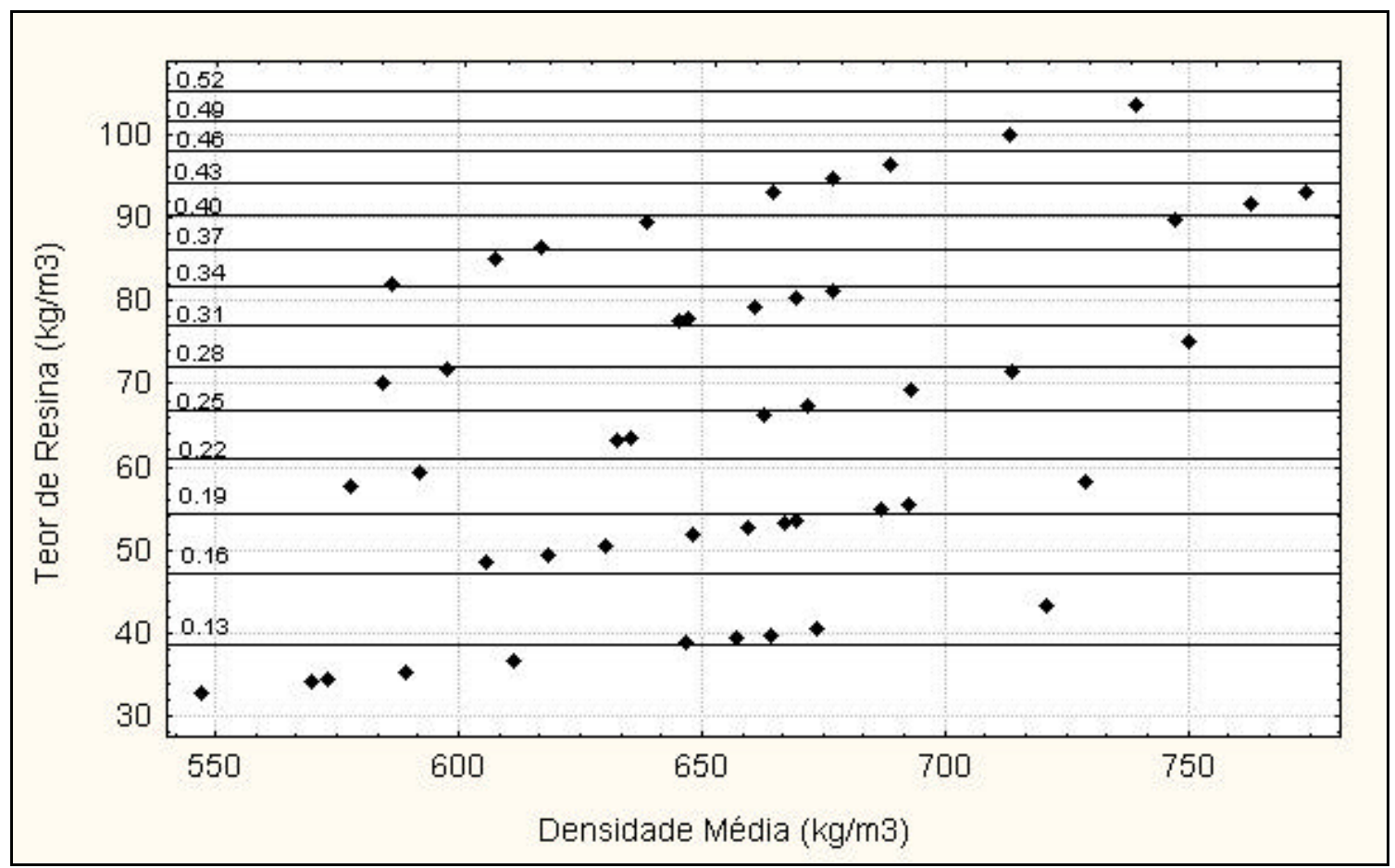

FIGURA 29. Isolinhas de adesão interna (MPa) em função da densidade média e do teor absoluto de resina.

Observa-se que a redução no teor de resina, em termos absolutos, não é possível, mantendo-se a variável constante. 


\subsubsection{Módulo de Ruptura}

O modelo obtido para módulo de ruptura em função da densidade e do teor de resina em $\mathrm{kg} / \mathrm{m}^{3}$ é apresentada na eq. (17).

$$
\begin{aligned}
& \text { MOR }=b_{0}+b_{1}{ }^{*} \text { DENSIDADE }+b_{2}{ }^{*} \text { DENSIDADE }{ }^{2}+b_{3}{ }^{*} \text { RESINA } \\
& \text { Sendo } \text { MOR }=\text { módulo de ruptura }(M P a) ; \\
& \text { DENSIDADE = densidade média do painel }\left(\mathrm{kg} / \mathrm{m}^{3}\right) ; \\
& \text { RESINA = teor de resina }\left(\mathrm{kg} / \mathrm{m}^{3}\right) ; \\
& b_{0}=+110,506784 \\
& b_{1}=-0,357196 \\
& b_{2}=+3,0 * 10^{-4} \\
& b_{3}=+0,212718 \\
& R^{2}=71,8 \% \\
& F=54,56 * \\
& \text { Syx }=0,183
\end{aligned}
$$

O teor de resina não explicou isoladamente a variação no módulo de ruptura, sendo incorporados no modelo coeficientes para a densidade.

Isolinhas para a eq. (17) são apresentadas na Figura 30. 


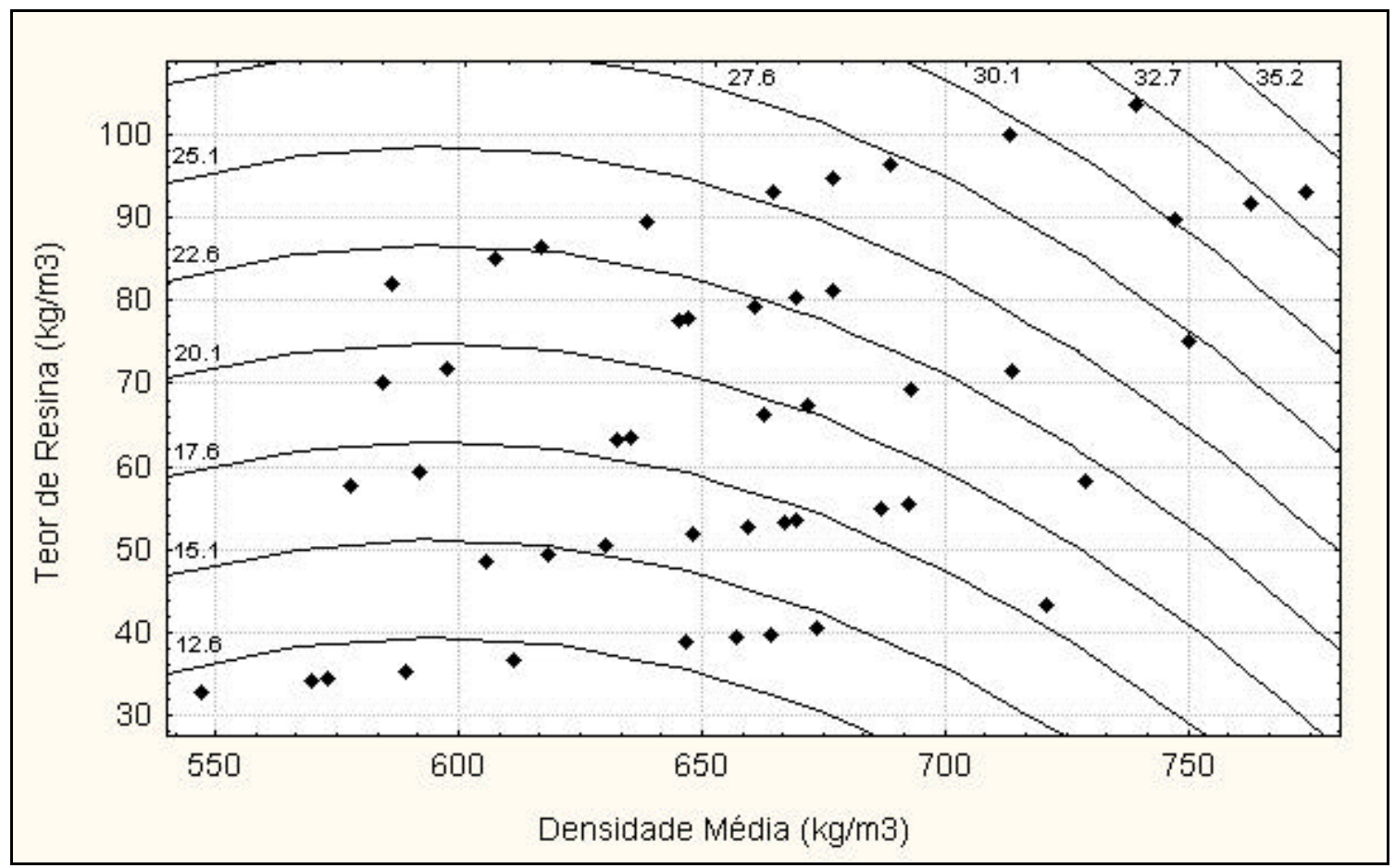

FIGURA 30. Isolinhas de módulo de ruptura (MPa) em função da densidade média e do teor absoluto de resina.

Para módulo de ruptura existe a possibilidade de reduzir o teor de resina em termos absolutos, e compensar essa redução pela densificação, mantendo-se a variável constante.

\subsubsection{Módulo de Elasticidade}

O modelo ajustado de módulo de elasticidade em função da densidade e do teor de resina em kg/m³ é apresentado na equação 18.

$$
\text { MOE }=b_{0}+b_{1}{ }^{*} \text { DENSIDADE }+b_{2}{ }^{*} \text { RESINA }
$$

Sendo $\mathrm{MOE}=$ módulo de elasticidade $(\mathrm{GPa})$;

DENSIDADE = densidade média do painel $\left(\mathrm{kg} / \mathrm{m}^{3}\right)$;

RESINA = teor de resina $\left(\mathrm{kg} / \mathrm{m}^{3}\right)$

$b_{0}=-2,011379$ 


$$
\begin{aligned}
& \mathrm{b}_{1}=+5,1 * 10^{-3} \\
& \mathrm{~b}_{2}=+0,017185 \\
& \mathrm{R}^{2}=79,0 \% \\
& \mathrm{~F}=88,74^{* *} \\
& \text { Syx }=0,113
\end{aligned}
$$

Isolinhas originadas do modelo para módulo de elasticidade ( eq. 18) são apresentadas na Figura 31.

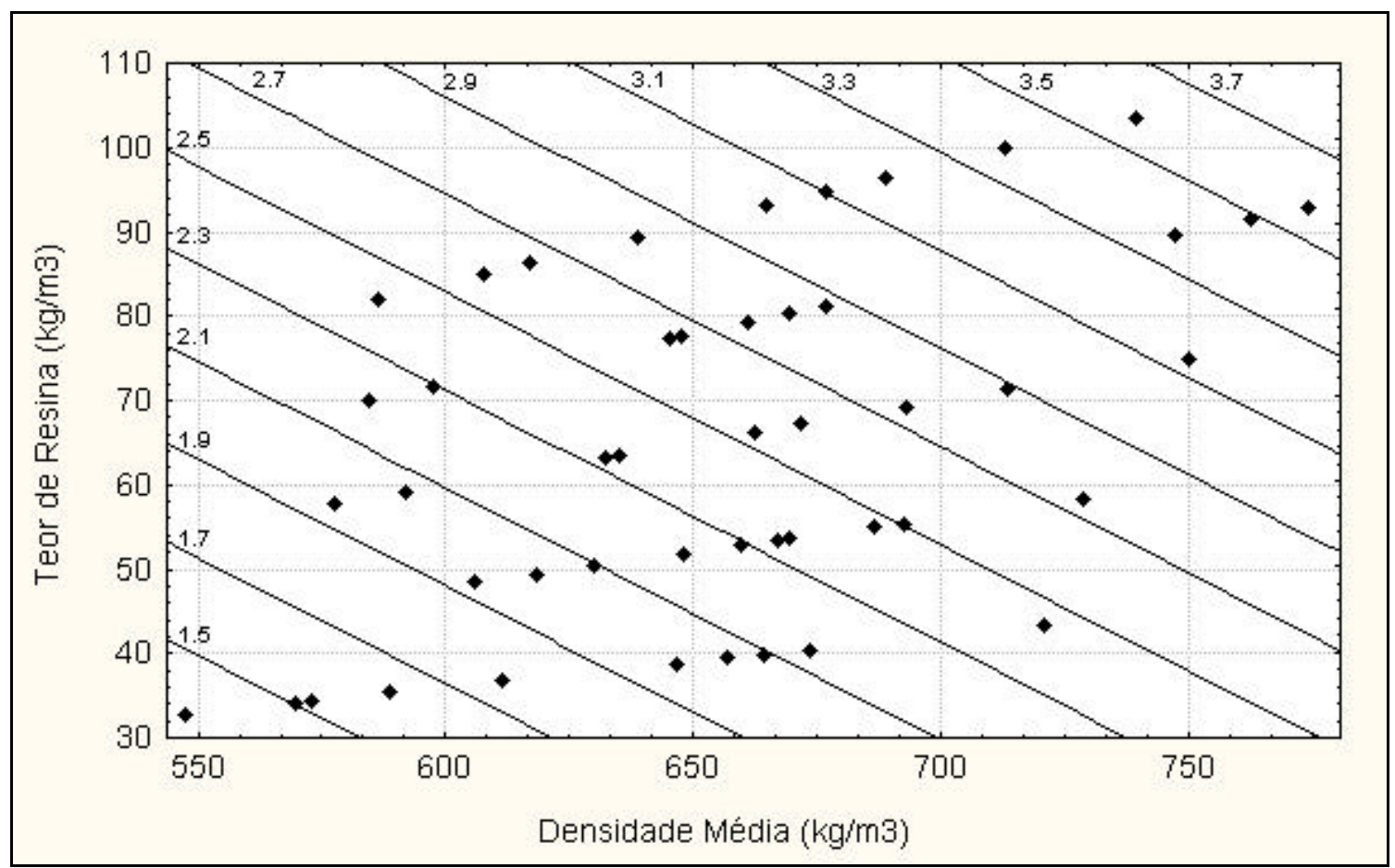

FIGURA 31. Isolinhas de módulo de elasticidade (GPa) em função da densidade média e do teor absoluto de resina.

Para módulo de elasticidade, da mesma forma que para a variável anterior, existe a possibilidade de reduzir o teor de resina em termos absolutos, e compensar essa redução pela densificação, mantendo-se a variável constante. 


\subsubsection{Inchamento em espessura}

Para avaliar a densificação como estratégia para a redução no teor absoluto de resina, procedeu-se a modelagem de inchamento em função da densidade e do teor de resina.

$$
\mathrm{INCH}=\mathrm{b}_{0}+\mathrm{b}_{1}{ }^{*} \mathrm{RESINA}+\mathrm{b}_{2}{ }^{*} \mathrm{RESINA}{ }^{-1}+\mathrm{b}_{3}{ }^{*} \mathrm{RESINA}{ }^{-2}
$$

Sendo $\mathrm{INCH}=$ inchamento em espessura (\%) após imersão em água;

RESINA = teor de resina $\left(\mathrm{kg} / \mathrm{m}^{3}\right)$;

$$
\begin{aligned}
& b_{0}=+133,294441 \\
& b 1=-0,652239 \\
& b 2=-7680,67957 \\
& b 3=+168232,0925 \\
& R^{2}=79,8 \% \\
& F=60,78^{* *} \\
& \text { Syx }=0,216
\end{aligned}
$$

A variação nos valores de inchamento em espessura foi explicada apenas pela variação no teor de resina em $\mathrm{kg} / \mathrm{m}^{3}$, não sendo incorporada a densidade no modelo.

A projeção do modelo para inchamento (eq. 19) sobre um plano gerou as isolinhas apresentadas na Figura 32. 


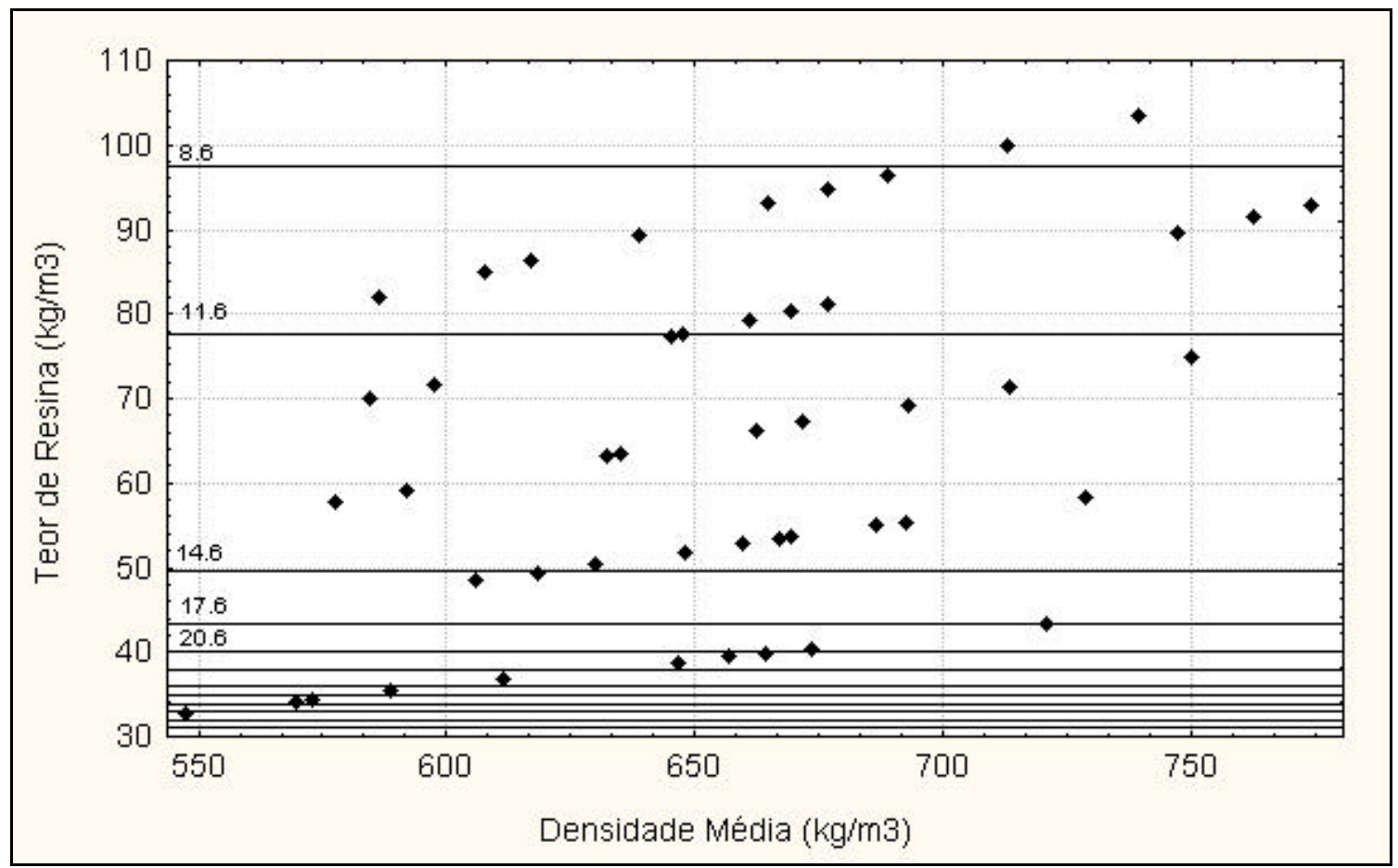

FIGURA 32. Isolinhas de inchamento em espessura (\%) em função da densidade média e do teor absoluto de resina.

Sem aumentar o inchamento em espessura, a redução no teor de resina em termos absolutos, através da densificação, não é possível.

\subsubsection{Absorção de água}

Para avaliar o efeito do aumento da densidade na redução do teor de resina, foi ajustado um modelo para absorção de água em função destas duas variáveis (eq. 20).

$A B S=b_{0}+b_{1}{ }^{*}$ DENSIDADE $+b_{2}{ }^{*}$ DENSIDADE ${ }^{-1}+b_{3}{ }^{*}$ RESINA $+b_{4}{ }^{*} \operatorname{RESINA}^{-1}$ (20)

Sendo $A B S=$ absorção de água (em \% da massa inicial) após imersão em água por $24 \mathrm{~h}$;

DENSIDADE $=$ densidade média do painel $\left(\mathrm{kg} / \mathrm{m}^{3}\right)$;

RESINA = teor de resina $\left(\mathrm{kg} / \mathrm{m}^{3}\right)$ 


$$
\begin{aligned}
& \text { b0 }=+465,439298 \\
& \text { b1 }=-0,441536 \\
& \text { b2 }=-162470,7527 \\
& \text { b3 }=+0,64097 \\
& \text { b4 }=+3820,8389 \\
& R^{2}=78,0 \% \\
& F=39,9 * \\
& \text { Syx }=0,205
\end{aligned}
$$

A projeção da eq. (20) sobre um plano, na forma de isolinhas, é apresentada na Figura 33.

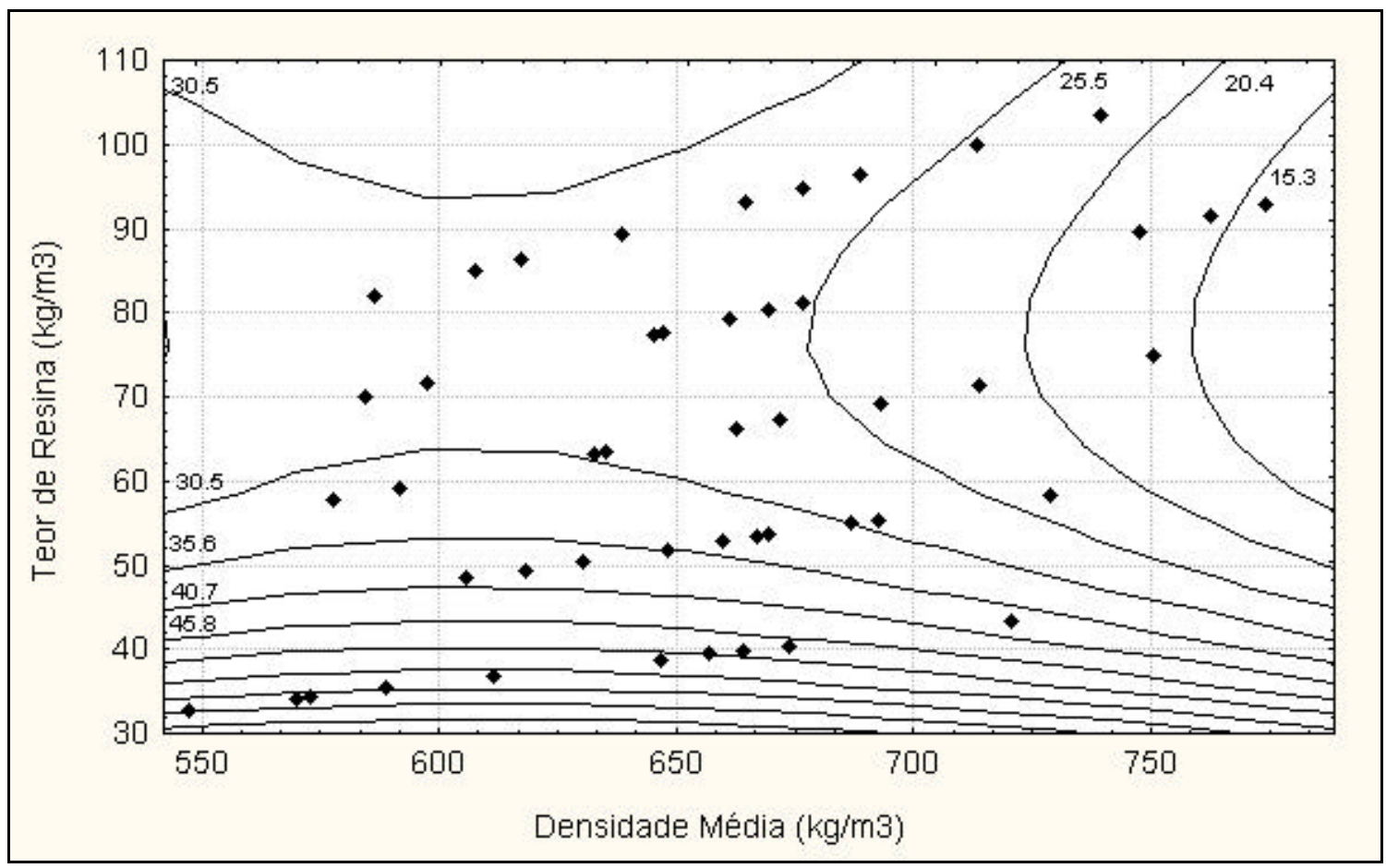

FIGURA 33. Isolinhas de absorção de água (\%) em função da densidade média e do teor absoluto de resina. 
A redução no teor de resina, em $\mathrm{kg} / \mathrm{m}^{3}$, não mostrou-se clara. Pode-se afirmar apenas que abaixo de $60 \mathrm{~kg}$ de resina por $\mathrm{m}^{3}$ de painel, a densificação não permite reduções significativas neste fator.

\subsection{Considerações a respeito do método experimental}

Muitos painéis apresentaram, após a prensagem, espessura maior que a nominal, de $16 \mathrm{~mm}$, com clara influência sobre a densidade. Dessa forma ajustes devem ser feitos ou no ciclo de prensagem ou no teor de umidade do colchão para permitir uma melhor consolidação dos painéis.

Foram medidos dois corpos-de-prova para densidade em cada painel experimental e a média extrapolada para todo o painel. A determinação da densidade em cada corpo-de-prova, seria uma possível forma de melhorar as estimativas e a correlação das variáveis analisadas com esta variável independente.

Com o propósito de garantir maior certeza à correlações entre adesão interna e densidade mínima (que foram menores que o esperado) seria interessante determinar o perfil de densidade no mesmo corpo-de-prova utilizado para adesão interna.

A utilização do mesmo corpo-de-prova para mais testes reduziria a demanda e possibilitaria a retirada de mais corpos-de-prova de um mesmo painel, abrangendo ainda mais a variabilidade dentro do painel.

Como os resultados obtidos neste estudo se referem a painéis experimentais fabricados em laboratório, extrapolações para o processo industrial não devem ser feitas diretamente, podendo-se considerar as tendências observadas. Isso deve-se a diferenças significativas no procedimento de laboratório, como encolagem depois da secagem, processo de formação do colchão manual, prensagem diferente de uma prensa contínua, etc. 


\section{CONCLUSÕES}

Quebras durante o processo de desfibramento aumentaram a variabilidade e reduziram o comprimento médio das fibras.

Todas as variáveis analisadas apresentaram maior correlação com o teor de resina expresso em $\mathrm{kg} / \mathrm{m}^{3}$ em relação ao mesmo fator expresso em percentagem.

A densidade da camada externa apresentou maior correlação com todas as variáveis em relação àdensidade média.

A densidade mínima foi a que apresentou maior correlação com a adesão interna.

As densidades ao longo do perfil apresentaram correlações maiores que $93 \%$.

A interação entre densidade e teor de resina, seja expresso em percentagem ou em valores absolutos, não foi significativa no módulo de elasticidade e de ruptura, foi significativa a 5\% na adesão interna e absorção de água e significativa a $1 \%$ no inchamento em espessura.

Todos os modelos ajustados para as variáveis analisadas incorporaram a densidade quando o teor de resina era expresso em percentagem. 
Considerando um valor constante para as variáveis analisadas, painéis mais densos demandam menor teor de resina em percentagem.

O teor de resina expresso em $\mathrm{kg} / \mathrm{m}^{3}$ explicou isoladamente a variação na adesão interna e no inchamento em espessura. Para as outras variáveis os modelos incorporam a densidade.

A densificação permite redução no teor de resina em termos absolutos apenas para módulo de elasticidade e de ruptura. 


\section{REFERÊNCIAS BIBLIOGRÁFICAS}

AMERICAN SOCIETY FOR TESTING AND MATERIALS. ASTM D1554 Definitions os Terms Relating to Wood-Base Fiber and Particle Panel Material. Philadelphia: 1974.

BAUER, T. J. Use of MDF from a global perspective. In.: MDF industry update with worldwide mill directories, 6.ed., 1995.

BENADUCE, C. Fabricação de Painéis de Média Densidade (MDF) a partir de Fibras de Eucalyptus grandis W. Hill Ex Maiden e Pinus caribaea Morelet var. hondurensis Barret e Golfari. Piracicaba, 1998. Dissertação (M. S.) - Escola Superior de Agricultura "Luiz de Queiroz", Universidade de São Paulo.

BOEHME, C. Significance of the density profile for MDF. Holz als Roh und Werkstoff, v.50, n.1, p.18-24, 1992. /Resumo em CAB Abstracts on CDROM/

BUTTERFIELD, B.; CHAPMAN, K.; CHRISTIE, L.; DICKSON, A. Ultrastructural characteristics of failure surfaces in medium density fiberboard. Forest Products Journal, v.42, n.5, p.55-60, May 1992.

CARLL, C. G. Review of thickness swell in hardboard siding - effect of processing variables. Madison, WI: USDA, Forest Service, Forest Products Laboratory, 1996. 10p. (Gen. Tech. Rep. FPL-GTR-96.) 
CHAPMAN, K. M.; JENKIN, D. J. Hydrogen peroxide as a resin cure accelerator. Journal of Adhesion, v.19, n.2, p.137-151, 1986. /Resumo em CAB Abstracts on CD-ROM/

CHOW, P. Properties of medium-density, dry-formed fiberboard from seven hardwood residues and bark. Forest Products Journal, v.26, n.5, p.48-55, May 1976.

CHOW, P.; REDMOND, M. R. Humidity and temperature effects on MOR and MOE of hard maple-veneered medium density fiberboard. Forest Products Journal, v.31, n.6, p.54-58, Jun. 1981.

CHOW, P.; ZHAO, L. Medium density fiberboard made from phenolic resin and wood residues of mixed species. Forest Products Journal, v.42, n.10, p.6567, Oct. 1992.

DIX, B.; MARUTZKY, R. Use of wood from short-rotation plantations, (1). (II). Holz Zentralblatt, v.123, n.9, p.141-142, 1997. /Resumo em CAB Abstracts on CD-ROM/

DRAPER, N. R.; SMITH, H. Applied Regression Analysis. New York: John Wiley \& Sons, 1966.

DUBE, H.; KEHR, E. Use of waste paper in MDF manufacture - influence of the proportion of waste paper. Holz als Roh und Werkstoff, v.53, n.1, p.20, 1995. /Resumo em CAB Abstracts on CD-ROM/

ERNST, K. MDF development potential. Holz als Roh und Werkstoff, v.55, n.1, p.3-8, 1997. /Resumo em CAB Abstracts on CD-ROM/ 
EUROMDFBOARD. EMB/IS-1:1995 MDF Medium Density Fibreboards: Definitions, Test Methods and Requirements - Industry Standard: Part I: Generalities. Giessen: 1995.

EUROPEAN COMMITTEE FOR STANDARDIZATION. European Standard EN 319 - Particleboards and Fiberboards - Determination of tensile strength perpendicular to the plane of the board. Bruxelas: 1993.

EUROPEAN COMMITTEE FOR STANDARDIZATION. European Standard EN 310 - Wood-based panels - Determination of modulus of elasticity in bending and of bending strength. Bruxelas: 1993.

EUROPEAN COMMITTEE FOR STANDARDIZATION. European Standard EN 317 - Particleboards and Fiberboards - Determination of swelling in thickness after immersion in water. Bruxelas: 1993.

EUROPEAN COMMITTEE FOR STANDARDIZATION. European Standard EN 323 - Wood-based panels - Determination of density. Bruxelas: 1993.

EUROPEAN COMMITTEE FOR STANDARDIZATION. European Standard EN 622-5 - Fiberboards - Specifications - Part 5: Requeriments for dry process boards (MDF). Bruxelas: 1997.

FAO. Fibreboard and particleboard. Rome: FAO, 1958. 73p.

FOREST PRODUCTS LABORATORY. Wood handbook - Wood as an engineering material. Madison, WI: USDA, Forest Service, Forest Products Laboratory, 1999. 463p. (Gen. Tech. Rep. FPL-GTR-113.)

FWI INTERNATIONAL LTD. MDF market outlook. In.: MDF industry update with worldwide mill directories, 6.ed., 1995. 
GONZALEZ MOLINA, J. et al. Tableros MDF com residuos de madera y adhesivos tipo isocianato. In: Seminário Internacional sobre Produtos Sólidos de Madeira de Alta Tecnologia, 1., Belo Horizonte, 1998. Anais. Viçosa: SIF; UFV,DEF, 1998. p.214-232.

GRIGORIOU, A. Comparisons between medium density fibreboard and particleboard. Holz als Roh und Werkstoff, v.41, n.5, p.183-186, 1983. /Resumo em CAB Abstracts on CD-ROM/

GROOM, L. H.; MOTT, L.; SHALER, S. M.; PESACRETA, T. Effect of fiber surface and mechanical properties on the stiffness and strength of mediumdensity fiberboard. In: International Association of Wood Anatomists / International Union of Forestry Research Organizations; 1997 November; Westport, New Zealand. Proceedings. s.I.: s.d. p.375-387.

HASHIM, R.; MURPHY, R. J.; DICKINSON, D. J.; DINWOODIE, J. M. The mechanical properties of boards treated with vapor boron. Forest Products Journal, v.44, n.10, p.73-79, Oct. 1994.

HERMANS, B. M.; SMITH, D. C. Formaldehyde release from urea-formaldehyde bonded wood products. Journal of Adhesion, v.17, n.4, p.297-308, 1985. /Resumo em CAB Abstracts on CD-ROM/

HIZIROGLU, S. Surface roughness analysis of wood composites: a stylus method. Forest Products Journal, v.46, n.7/8, p.67-72, Jul./Aug. 1996.

HUANG, Y.; MORI, M. Density distribution of particleboard throughout the thickness (III) effects of press temperature and pressing time on density distribution of particleboard. Reports of the Kyushu University Forest, n.26, 1976. 
HUANG, Y.; MORI, M.; OA, M. Density distribution of particleboard throughout the thickness ( I ) measurement of the density distribution by soft X-ray and densitometric method. In.: Reports of the Kyushu University Forest, n.26, 1976.

INSTITUTO DE DESENVOLVIMENTO INDUSTRIAL DE MINAS GERAIS -INDI et al. Uso de Florestas Plantadas em Minas Gerais: Estudo de Préviabilidade de uma fábrica de MDF - Sinopse. Belo Horizonte, 1996.

JENSEN, U.; KEHR, E. Dimensional stability of MDF and particleboards. Holz als Roh und Werkstoff, v.53, n.6, p.369-376, 1995. /Resumo em CAB Abstracts on CD-ROM/

JENSON, U.; EMLER, R. The nature of the surface of milled MDF profiles. Holz Zentralblatt, v.122, n.21, p.25,329-330,396,398, 1996. /Resumo em CAB Abstracts on CD-ROM/

KAVVOURAS, P. K. Uptake of formaldehyde by MDF wood-fiber. Holz als Roh und Werkstoff, v.55, n.5, p.323-325, 1997. /Resumo em CAB Abstracts on CD-ROM/

KAWAI, S.; SASAKI, H. Oriented medium-density fiberboard produced with na electrostatic field I. Effects of fibre shape and configuration on fibre alignment and board properties. Journal of the Japan Wood Research Society, v.35, n.3, p.218-226, 1989. /Resumo em CAB Abstracts on CD-ROM/

KELLY, M. W. Critical literature review of relationships between processing parameters and physical properties of particleboard. Madison, WI: USDA, Forest Service, Forest Products Laboratory, 1977. 65p. (Gen. Tech. Rep. FPL-10). 
KIM, J. W.; PARK, S. J. Micromorphological features of MDF fiber surface and adhesives distribution in MDF. Journal of the Korean Wood Science and Technology, v.24, n.2, p.61-70, 1996. /Resumo em CAB Abstracts on CDROM/

KLOCK, U. Qualidade da madeira de Pinus oocarpa SHIEDE e Pinus caribaea MORELET var hondurensis BARR E GOLF. Curitiba, 1989. Dissertação (M. S.) - Universidade Federal do Paraná.

$\mathrm{KOCH}, \mathrm{P}$. Wood versus nonwood materials in U.S. residential construction: some energy-related global implications. Forest Products Journal, v.42, n.5, p.3142, May 1992.

KOLLMANN, F. F. P.; KUENZI, E. W.; STAMM, A. J. Principles of wood science and technology. II, Wood based materials. Berlin: SpringerVerlag, 1975.

LABOSKY Jr., P.; YOBP, R. D.; JANOWIAK, J. J.; BLANKENHORN, P. R. Effect of steam pressure refining and resin levels on the properties of UF-bonded red maple MDF. Forest Products Journal, v.43, n.11/12, p.82-88, Nov./Dec. 1993.

LAUFENBERG, T. L. Using gamma radiation to measure density gradients in reconstituted wood products. Forest Products Journal, v.36, n.2, p.59-62, Feb. 1986.

LEE, HH.; HONG, J. K. Basic properties of medium density fibreboard and ureamelamine copolymer resin content for the furniture industry. (Report 1). Wood Science and Technology Mogjae gonghak, v.12, n.6, p.47-51, 1984. /Resumo em CAB Abstracts on CD-ROM/ 
LEE, HH.; MALONEY, T. M. Effect of final moisture content of mat on the physical and mechanical properties of MDF. In: International Symposium on Particleboard, Thirtyth, Pulman, Washington, 1996. Proceedings. Washington: Washington State University, 1996.

MACEDO, A. R. P.; ROQUE, C. A. L. Painéis de Madeira. BNDES Setorial, n.6, p. 117-132, Set. 1997.

MALONEY, T. M. Modern particleboard \& dry-process fiberboard manufacturing. San Francisco: Miller Freeman, 1989. 672p.

MALONEY, T. M. The family of wood composite materials. Forest Products Journal, v.46, n.2, p.19-26, Feb. 1996.

MARUTZKY, R.; FLENTGE, A.; BOEHME, C. Dependence of formaldehyde emission of MDF on the density profile. Holz als Roh und Werkstoff, v.50, n.6, p.239-240, 1992. /Resumo em CAB Abstracts on CD-ROM/

MOHD-NOR, M. Y. The manufacture of medium density fibreboard from rubberwood of different age groups. Journal of Tropical Forest Products, v.1, n.1, p.78-82, 1995. /Resumo em CAB Abstracts on CD-ROM/

MYERS, G. C. Relationship of fiber preparation and characteristics to performance of medium-density hardboards. Forest Products Journal, v.33, n.10, p.43-51, Oct. 1983.

MYERS, G. C.; CRIST, J. B. Feasibility of manufacturing hardboard from shortrotation intensively cultured Populus. Forest Products Journal, v.36, n.1, p.34-44, Jan. 1986. 
NEARN, W. T.; BASSE, K. X-ray determination and use of surface-to-surface density profile in fiberboard. Forest Products Journal , v.18, n.1, p.73-74, 1968.

NELSON, N. D. Effects of wood and pulp properties on medium-density, dryformed hardboard. Forest Products Journal, v.23, n.9, p.72-80, Sep. 1973.

NEVES, M. R. Tendências do mercado nacional e internacional de produtos de base florestal. In.: SIMPÓSIO FLORESTAL DO RIO GRANDE DO SUL, 5., Caxias do Sul, 1998. Anais. Caxias do Sul: Ageflor/CEPEF/PPGEF/Sindimadeira, 1998. p.81-87.

NIEMZ, P.; DIENER, M.; POHLER, E. Determination of the fracture toughness of MDF board. Holz als Roh und Werkstoff, v.55, n.5, p.327-330, 1997. /Resumo em CAB Abstracts on CD-ROM/

NIEMZ, P.; POBLETE, H. Investigations on the dimensional stability of MDF and particleboards. Holz als Roh und Werkstoff, v.54, n.2, p.141-144, 1996. /Resumo em CAB Abstracts on CD-ROM/

NIEMZ, P.; ROLERI, A.; BARRADIT, E. Investigations on sound propagation velocity in particle boards and MDF and correlation with elastomechanical properties. Holz Zentralblatt, v.122, n.67, p.1088-1091, 1996. /Resumo em CAB Abstracts on CD-ROM/

NIEMZ, P.; STEINMETZLER, J. Investigations on the swelling pressure of MDF with change in moisture content. Holz Zentralblatt, v.122, n.6, p.83, 1996. /Resumo em CAB Abstracts on CD-ROM/

OKAMOTO, H.; SANO, S.; KAWAI, S.; OKAMOTO, T.; SASAKI, H. Production of dimensionally stable medium density fiberboard by use of high-pressure steam 
pressing. Journal of the Japan Wood Research Society, v.40, n.4, p.380389, 1994. /Resumo em CAB Abstracts on CD-ROM/

PARK, B.; RIEDL, B.; KIM, Y. S. Anatomical characteristics of wood fibers for medium density fiberboard (MDF) manufacture. In.: Pacific Regional Wood Anatomy Conference, 4, 1998. IAWA Journal, v.19, n.4, p.472, 1998.

PAWLICKI, J. Use of formaldehyde to improve the properties of fibreboards. Folia Forestalia Polonica, v.16, p.45-52, 1985. /Resumo em CAB Abstracts on CD-ROM/

PIZZI, A. Advanced wood adhesives technology. New York: Marcel Dekker, 1994. 297p.

PUGEL, A. D.; PRICE, E. W.; HSE, C. Y. Composites from southern pine juvenile wood. Part 1. Panel fabrication and inicial properties. Forest Products Journal, v.40, n.1, p.29-33, Jan. 1990.

PUGEL, A. D.; PRICE, E. W.; HSE, C. Y. Composites from southern pine juvenile wood. Part 2. Durability and dimensional stability. Forest Products Journal, v.40, n.3, p.57-61, Mar. 1990.

ROWELL, Roger M. Chemical Modification of Wood for Improved Adhesion in Composites. In: WOOD ADHESIVES 1995, Portland (OR), 1995. Proceedings. Madison (WI): Forest Products Society, 1995. p.56-60.

SCHULTE, M.; FRUHWALD, A. Shear modulus, internal bond and density profile of medium density fibre board (MDF). Holz als Roh und Werkstoff, v.54, n.1, p.49-55, 1996. /Resumo em CAB Abstracts on CD-ROM/ 
SHORT, P. H. Scanning electron microscopy of $-60 /+80$ mesh fiberboard furnish. Wood Science, v.14, n.1, p.32-40, July. 1981.

SHUPE, T. F.; HSE, C. Y.; CHOONG, E. T.; GROOM, L. H. Effect of silvicultural practice and wood type on loblolly pine particleboard and medium density fiberboard properties. Holzforschung, v.53, n.2, p.215-222.

SIAGIAN, R. M. The influence of pressing temperature and pressure on the properties of fibreboard made from industrial wood waste. Laporan, v.167, p.17-26, 1983. /Resumo em CAB Abstracts on CD-ROM/

SINGH, A. P.; McDONALD, A. G. Comparison of radiata pine and rubberwood HTMP fibers by microscopy and MDF panel properties. In.: Pacific Regional Wood Anatomy Conference, 4, 1998. IAWA Journal, v.19, n.4, p.479, 1998.

SOCIETY OF WOOD SCIENCE AND TECHNOLOGY Environmental implications of the use of wood-based products. www1.fpl.fs.fed.us/swst/environ.html (set., 1997).

SPAVEN, G. P. et al. On-line / off-line fiber analysis - it pays. In: International Particleboard / Composite Materials Symposium, Twenty-Seventh, Pulman, Washington, 1993. Proceedings. Washington: Washington State University, 1993.

SUCHSLAND, O.; LYON, D. E.; SHORT, P. E. Selected properties of commercial medium-density fiberboards. Forest Products Journal, v.28, n.9, p.45-48, Sep. 1978.

SUCHSLAND, O.; McMILLIN, C. W. On the measurement of fiber orientation in fiberboard. Forest Products Journal, v.33, n.10, p.39-42, Oct. 1983. 
SUCHSLAND, O.; WOODSON, G. E. Fiberboard manufacturing practices in United States. Washington, DC:USDA, 1986. 263p. (USDA. Agricultural Handbook $n^{\circ} 640$ )

SUCHSLAND, O.; WOODSON, G. E.; McMILLIN, C. W. Pressing of three layer, dry-formed MDF with binderless hardboard faces. Forest Products Journal, v.36, n.1, p.33-36, Jan. 1986.

SUNDIN, B. Issues affecting binders for wood-based panels. In.: MDF industry update with worldwide mill directories, 6.ed., 1995.

SUSUKI, M.; KATO, T. Influence of dependent variables on the properties of medium-density fiberboard. Journal of the Japan Wood Research Society, v.35, n.1, p.8-13, 1989. /Resumo em CAB Abstracts on CD-ROM/

TOMASELLI, I.; DELESPINASSE, B. A indústria de painéis no Brasil: a tendência de mudança no perfil da produção brasileira. Informativo STCP, n.1, 1997.

WALLIN, G. Cornerstones of an MDF plant investment. Sundswall: Sunds Defibrator, s.d. $11 \mathrm{p}$.

WATKINSON, P. J.; van GOSLIGA, N. L. Effect of humidity on physical and mechanical properties of New Zealand wood composites. Forest Products Journal, v.40, n.7/8, p.15-20, Jul./Aug. 1990.

WILSON, J. B.; KRAHMER, R. L. Particleboard: microscopic observations of resin distribution and board fracture. Forest Products Journal, v.26, n.11, p.42-45, Nov. 1976. 
WINISTORFER, P. M. et al. Measuring the density profile during pressing: the method, the equipment, and the results. In: International Particleboard / Composite Materials Symposium, Twenty-Seventh, Pullman, Washington, 1993. Proceedings. Washington: Washington State University, 1993.

WINISTORFER, P. M. et al. Modeling and comparing vertical density profiles. In: International Particleboard / Composite Materials Symposium, Twenty-Eighth, Pullman, Washington, 1994. Proceedings. Washington: Washington State University, 1994.

WINISTORFER, P. M.; DAVIS, W. C.; MOSCHLER Jr., W. W. A direct scanning densitometer to measure density profiles in wood composite products. Forest Products Journal, v.36, n.11/12, p.82-86, Nov./Dec. 1986.

WOODSON, G. E. Density profile and fiber alignment in fiberboard from three southern hardwoods. Forest Products Journal, v.27, n.8, p.29-34, Aug. 1977.

WOODSON, G. E. Properties of medium-density fiberboard related to hardwood specific gravity. In: Tenth Particleboard Symposium, Washington, 1976. Proceedings. Washington: Washington State University, 1976. p.175-192. /Resumo em CAB Abstracts on CD-ROM/

WULF, M.; NETUSCHIL, P.; HORA, G.; SCHMICH, P.; CAMMENGA, H. K. Investigation of the wetting characteristics of medium density fiberboards (MDF) by means of contact angle measurements. Holz als Roh und Werkstoff, v.55, n.5, p.331-335, 1997. /Resumo em CAB Abstracts on CD-ROM/ 
$X U, H$.; SUCHSLAND, O. The expansion potential: a new evaluator of the expansion behavior of wood composites. Forest Products Journal, v.41, n.6, p.39-42, Jun. 1991. 